\title{
Traumatic brain injury detection using electrophysiological methods
}

\author{
Paul E. Rapp ${ }^{1}$, David O. Keyser ${ }^{1 *}$, Alfonso Albano ${ }^{2}$, Rene Hernandez ${ }^{3}$, Douglas B. Gibson ${ }^{4}$, \\ Robert A. Zambon ${ }^{5}$, W. David Hairston ${ }^{6}$, John D. Hughes ${ }^{7}$, Andrew Krystal $^{8}$ and Andrew S. Nichols ${ }^{5}$ \\ ' Uniformed Services University of the Health Sciences School of Medicine, Bethesda, MD, USA \\ 2 Bryn Mawr College, Bryn Mawr, PA, USA \\ ${ }^{3}$ US Navy Bureau of Medicine and Surgery, Frederick, MD, USA \\ ${ }^{4}$ U.S. Army Research Institute, Fort Belvoir, VA, USA \\ ${ }^{5}$ Booz Allen Hamilton Inc., McLean, VA, USA \\ ${ }^{6}$ U. S. Army Research Laboratory, Aberdeen Proving Ground, Aberdeen, MD, USA \\ ${ }^{7}$ Naval Medical Research Center, Silver Spring, MD, USA \\ ${ }^{8}$ Duke University, Durham, NC, USA
}

\section{Edited by:}

John J. Foxe, Albert Einstein College of Medicine, USA

Reviewed by:

John Van Horn, University of California Los Angeles, USA

I-Wei Shu, San Diego Veterans Affairs

Medical Center, USA

*Correspondence:

David O. Keyser, Department of Military and Emergency Medicine, USUHS, 4301 Jones Bridge Road, Bethesda, MD 20814, USA e-mail:david.keyser@usuhs.edu
Measuring neuronal activity with electrophysiological methods may be useful in detecting neurological dysfunctions, such as mild traumatic brain injury (mTBI). This approach may be particularly valuable for rapid detection in at-risk populations including military service members and athletes. Electrophysiological methods, such as quantitative electroencephalography (qEEG) and recording event-related potentials (ERPs) may be promising; however, the field is nascent and significant controversy exists on the efficacy and accuracy of the approaches as diagnostic tools. For example, the specific measures derived from an electroencephalogram (EEG) that are most suitable as markers of dysfunction have not been clearly established. A study was conducted to summarize and evaluate the statistical rigor of evidence on the overall utility of qEEG as an mTBI detection tool. The analysis evaluated qEEG measures/parameters that may be most suitable as fieldable diagnostic tools, identified other types of EEG measures and analysis methods of promise, recommended specific measures and analysis methods for further development as mTBI detection tools, identified research gaps in the field, and recommended future research and development thrust areas. The qEEG study group formed the following conclusions: (1) Individual qEEG measures provide limited diagnostic utility for mTBI. However, many measures can be important features of qEEG discriminant functions, which do show significant promise as mTBI detection tools. (2) ERPs offer utility in mTBI detection. In fact, evidence indicates that ERPs can identify abnormalities in cases where EEGs alone are non-disclosing. (3) The standard mathematical procedures used in the characterization of mTBI EEGs should be expanded to incorporate newer methods of analysis including non-linear dynamical analysis, complexity measures, analysis of causal interactions, graph theory, and information dynamics. (4) Reports of high specificity in qEEG evaluations of TBI must be interpreted with care. High specificities have been reported in carefully constructed clinical studies in which healthy controls were compared against a carefully selected TBI population. The published literature indicates, however, that similar abnormalities in qEEG measures are observed in other neuropsychiatric disorders. While it may be possible to distinguish a clinical patient from a healthy control participant with this technology, these measures are unlikely to discriminate between, for example, major depressive disorder, bipolar disorder, or TBI. The specificities observed in these clinical studies may well be lost in real world clinical practice. (5) The absence of specificity does not preclude clinical utility. The possibility of use as a longitudinal measure of treatment response remains. However, efficacy as a longitudinal clinical measure does require acceptable test-retest reliability. To date, very few test-retest reliability studies have been published with qEEG data obtained from TBI patients or from healthy controls. This is a particular concern because high variability is a known characteristic of the injured central nervous system.

Keywords: event-related potentials, EEG, traumatic brain injury, qEEG, non-linear dynamical analysis 


\section{INTRODUCTION}

Mild TBI is caused by initial physical trauma that shears or compresses brain tissue. The initial trauma can lead to a cascade of delayed neurodegenerative events that may include diffuse axonal injury, activation of excitotoxic inflammatory cascades, and transneuronal degeneration. While initial damage in mild traumatic brain injury (mTBI) may be minimal or occult, the chronic neurodegenerative effects can persist for weeks or months postinjury and lead to significant cognitive, sensory, and psychiatric dysfunctions (DeKosky et al., 2010). Over $75 \%$ of the 266,000 brain injuries reported during U.S. military operations from 2000 to 2012 were classified as $\mathrm{mTBI}$, thus underscoring $\mathrm{mTBI}$ as a major health issue in the U.S. military (Hoge et al., 2008). It is anticipated that rapid and accurate mTBI detection would improve prognoses and minimize impacts to military operations; however, a technological gap exists, especially in field-based settings. To address this critical need, the Department of Defense is actively seeking new technologies capable of rapid, accurate, non-invasive, and field-capable detection of mTBI (Rigg and Mooney, 2011).

One promising avenue is measurement of brain electrical activity with quantitative electroencephalography (qEEG), in which detection of altered patterning may indicate concussion. Since qEEG is a nascent technology for mTBI detection, and significant controversy exists in the field, a comprehensive evaluation of technology/measure efficacy as a detection tool is warranted. Critically surveying the state-of-the-science also provides an opportunity to establish recommendations on specific qEEG measures or signal processing technologies of promise, thus driving advanced development decision-making.

\section{BACKGROUND ON qEEG}

The electroencephalogram (EEG) records the electrical potential difference between brain electrical activities recorded between two electrodes (a single EEG channel). Multiple scalp electrodes (generally $>20$ ) are connected in various patterns called montages, resulting in a series of channels of EEG activity. Often the scalp electrodes are compared to one or more neutral reference electrodes. Detection of a scalp electrical potential requires the synchronous activity of millions of neurons over at least $10 \mathrm{~cm}^{2}$ of cortex. The EEG detects the synchronous occurrence of dendritic synaptic potentials (excitatory and inhibitory postsynaptic potentials) principally on the apical dendrites of cortical pyramidal neurons. Therefore, the EEG records the average membrane potential of these apical dendrites, which tends to oscillate. The physiological basis of these oscillations is a manifestation of both intrinsic properties of neurons (ionic conductances) and, importantly, network interactions (connectivity). Intrinsic resonant properties permit and promote frequency range-specific oscillations based on network activity [see Berridge and Rapp (1979)]. Different frequency oscillations are governed principally by cortico-cortical connections and thalamocortical connections to varying degrees depending on the specific oscillation. EEG oscillations exist in a broad range of frequencies from well below one Hertz to several hundred Hertz. The physiology is best understood for several "classic" frequency bands including delta $(0.5-4 \mathrm{~Hz})$, theta $(4-7 \mathrm{~Hz})$, alpha $(8-13 \mathrm{~Hz})$, beta $(14-30 \mathrm{~Hz})$, and gamma (30$100 \mathrm{~Hz}$ ). These frequency ranges are not arbitrarily divided [see
Penttonen and Buzsáki (2003)], but represent different oscillatory phenomena with unique underlying physiological mechanisms, cortical topographies, and functions, of which many are still being delineated. Different combinations of frequency bands in different quantities comprise different states of the brain (e.g., attentive wakefulness, drowsiness, various stages of sleep).

The "clinical" evaluation of the EEG typically involves a visual inspection of brain electrical activity across a range of brain states and the assessment of the topography and "quantity" of stateappropriate oscillatory activity, as well as examination for the presence of pathological potentials. For the detection of epileptiform activity, the human eye actually outperforms computerized waveform analysis despite decades of attempts to automate EEG interpretation (Harner, 2010). However, when it comes to the assessment of the topography and quantity of oscillatory activity, and what constitutes a normal or abnormal distribution of such activity, visual inspection fails considerably. Very poor interrater reliability is common for visual inspections of oscillatory activity, even in determining what constitutes normal vs. abnormal. Additionally, visual inspection can shed no light whatsoever on the nature of interregional interactions, both locally and globally, which constitute the basis for cognition and consciousness (Tononi et al., 1994). This requires the use of computerized algorithmic methodologies called qEEG, which we will use as a broad encompassing term for all such analyses. For example, to obtain a quantitative assessment of the amount of oscillatory activity at any and all frequencies in a particular brain region, qEEG frequency analysis transforms the original EEG data over a period of time into a representation of its frequency content, generating a continuous EEG "power spectrum." Ultimately, however, using methodologies that require averaging of data over relatively long periods of time will be insensitive to the rich dynamics of the cortex, which operates on a multitude of timescales down to the order of milliseconds (see below).

\section{EEG IN mTBI}

Pathologically, mTBI is a complex process, resulting in neuronal dysfunction that may be manifested in EEG changes apparent even to visual inspection for a duration ranging from hours to up to a few weeks post-injury. Beyond the acute and subacute stages, the structural pathology of mTBI is characterized by diffuse axonal injury involving the white matter as well as simplification of the dendritic architecture of neurons in cortical gray matter, with a relative absence of neural loss, leading to varying and often subtle degrees of cortical atrophy or thinning (Bigler and Maxwell, 2011). Such effects below a certain threshold of severity will not manifest on standard magnetic resonance imaging (MRI) at any stage. Newer MRI methods, such as diffusion tensor imaging, may be capable of detecting these more subtle structural disturbances, but these imaging techniques are not common in practice and are still in early stages of use.

Electroencephalogram, however, may be sensitive to detecting the physiological effects of these processes. The simplified dendritic system of neurons may result in a decrease in power of fast frequencies. Even subtle relative deafferentation from the thalamus or ascending neuromodulator systems (i.e., cholinergic, noradrenergic, dopaminergic) due to axonal injury will increase 
the power of slow frequencies, due to an alteration of firing properties of thalamic and cortical neurons (resulting in a net increase in theta frequency activity), and due to the release of intrinsically generated network oscillatory activity normally suppressed by cholinergic afferents (from the basal forebrain) and glutamatergic afferents (from the thalamus). Additionally, and importantly, axonal injury will reduce the effectiveness of synchronization of distributed cell assemblies located throughout the cerebral cortex, which are essential for cognition. The physiological basis of the EEG, as described above, makes qEEG methodologies potentially well-suited to detect these physiological alterations in the "free-running" EEG oscillatory activity. Additionally, these pathological changes can alter the timing and amplitude of slower non-oscillatory electrical potentials, which are caused by the phase resetting of these oscillatory rhythms during the performance of cognitive tasks, the so-called event-related potentials (ERPs). Thus, the assessment of ERPs is another potentially valuable tool in the qEEG repertoire for the study of altered cortical physiology in the setting of mTBI.

What is the function of EEG oscillations, and how can a quantitative analysis of EEG activity provide insight into impaired brain function in TBI? For several decades from 1960s to 1990s, the prevailing view was that EEG activity/oscillations were epiphenomenal and unrelated to moment-to-moment cerebral cortical function, but simply reflected the general state of the brain (e.g., awake and alert, drowsy, asleep). The tide has turned dramatically and it is now understood that moment-to-moment brain function is directly linked to EEG oscillations. Cognitive processes are a function of the rapid formation and subsequent dissolution of distributed cell communication assembles on the order of several hundred milliseconds in duration (Breakspear et al., 2004), and these assemblies form transiently based on a functional (as opposed to structural) connectivity patterns established by the synchronization patterns of EEG oscillations. This synchronization allows effective communication among the members of the transient assembly (Fries, 2005). True synchronization of neuronal activities only occurs within a few millimeters. A better term may be "polychronization" (Izhikevich, 2006), as most functionally connected neurons are not truly synchronized, but that term will suffice for our purposes. Fast frequencies (especially gamma) are involved in the synchronization of relatively local cell assemblies in the processing of specific cortical representations and slower frequencies synchronize highly distributed cell assemblies that span many centimeters of cortex and may involve both hemispheres. Theta and delta frequency activity also support the synchronization of faster frequencies among multiple localized assemblies via the phenomenon of "cross-frequency coupling" (Canolty and Knight, 2010). Computerized signal analysis of EEG data has evolved significantly to address the complex interregional interactions of brain connectivity, including the causal relationships among interacting regions of brain during a cognitive act and how these relationships may be deranged. For example, in brain injury one could demonstrate altered causal relationships in which control of action is more reactive or stimulus-based, such that cortical sensory networks predominantly influence frontal-executive networks instead of vice versa. A so-called "small-world" connectivity analysis can determine whether or not the cerebral cortices in a population of patients is performing with a functional connectivity pattern that optimizes the ratio of local to long-range functional connectivity. This ratio has shown to be altered in TBI (Cao and Slobounov, 2010; Tsirka et al., 2011). Overall, recent developments in the analysis of EEG activity to characterize brain function hold tremendous promise for our ability to understand the physiology of cognitive processes and their pathophysiological derangement in neurological disorders such as traumatic brain injury.

The effects of TBI can be significant and long-lasting. Fazel et al. (2014) compared mortality rates 6 months or more after injury against a control population. They found that TBI is associated with substantially elevated risks of premature mortality, particularly from suicide, injuries, and assaults. Similarly, TBI is a significant risk factor for neuropsychiatric disorders (Rapp et al., 2013a). These results argue against the view that TBI, even mTBI, typically resolves without lasting consequences. In addition, these results establish the need to identify individuals at-risk of delayed onset neuropsychiatric disorders following brain injury. Quantitative measures of altered brain electrical behavior may provide quantitative prodromes of neuropsychiatric disorders. This possibility is encouraged by noting that changes in brain electrical behavior following TBI can be persistent. Slobounov et al. (2012) found that $85 \%$ of the mTBI patients who presented significant EEG alterations in the immediate post-injury period still presented altered EEGs up to 12 months post-injury. Segalowitz et al. (2001) found that ERPs were altered in mTBI patients in a patient group that was on average 6.4 years post-injury. De Beaumont et al. (2009) examined healthy former athletes in late adulthood (mean age 61 years) who had sustained their last sports related concussion in early adulthood (mean age at time of last injury 26 years). These participants were compared against healthy former athletes who did not have a history of concussion (average age 69 years). Participants with a history of concussion had significantly different ERPs. These results must be considered with care; however, as they represent a problem that is common to studies in this area: in almost all cases, pre-injury data are not available. It is possible, for example, that central nervous system (CNS) abnormalities in the athletes in the de Beaumont study were present prior to injury and were themselves a factor leading to injury. Nonetheless, these results and other studies summarized in this report suggest that measurement of brain electrical behavior may be a valuable complement to other assessment procedures.

\section{COMPARATIVE UTILITY OF qEEG FOR mTBI DETECTION}

Aside from the direct connection between qEEG and the physiological responses described above, EEG supplements conventional medical approaches to imaging the structure and function of the brain. EEG as a neuroimaging modality holds several advantages over more conventional medical approaches. Computed tomography (CT) and MRI are current the "gold standards" for imaging assessment of neurophysiological trauma. These techniques provide excellent spatial resolution for easily identifying lesions; however, significant limitations of CT and MRI reduce the practical utility for mTBI detection. For instance, both approaches require very large and expensive equipment, special facilities for their use, and dedicated technicians for operation. CT uses small 
doses of radiation, which may carry potential risks for long-term side effects if patients are scanned often. MRI uses an extremely strong magnetic field ( $>1 \mathrm{~T}$ ), necessitating careful operating procedures. Perhaps most limiting for MRI is the contraindication of medical devices, implants, and any foreign ferrous metal objects in the patient's body. Since service members may have metal fragments lodged in their bodies from the same injury event, this limitation is particularly difficult to reconcile for military use. In contrast to CT and MRI, equipment used for EEG is substantially more portable, less expensive, requires no special facilities, and, in most cases, can be applied by personnel with very minimal training. All of these characteristics contribute to a substantially higher level of fieldability and a broader operational effectiveness beyond dedicated medical centers. The fieldability of qEEG also facilitates neuroscience research outside of laboratory environments, for which more accurate "real world" data can be captured and compared to findings in the laboratory, thus driving advancements in neurotechnology applications (McDowell et al., 2013).

The data derived from EEG are also fundamentally distinct as compared to CT and MRI data. In particular, while CT and MRI have excellent spatial resolution, the resulting images (which take several minutes to acquire) are temporally static, and thus provide no direct measurement of functional, ongoing brain activity. Even the best current methods of "functional MRI" are limited to multiple seconds for the acquisition of whole-brain images. In contrast, EEG is extremely high-resolution in the time domain (EEG can be sub-millisecond) and, as described above, is a direct measurement of neuronal activity. This allows a great number of analyses (as described above and in the following sections), which capitalize on direct responses to stimuli, cognitive responses, inter-relatedness of continuous signals, and the oscillation of both discrete and cross-regional networks of brain areas.

\section{LITERATURE INDEX OF qEEG STUDIES RELEVANT TO mTBI LITERATURE SEARCH METHODOLOGY}

A literature search was conducted in peer-reviewed primary sources from PubMed and the "gray" literature (i.e., documents not peer-reviewed) from the defense technical information center (DTIC) technical report database. Keyword searches were chosen to identify studies that specifically measured qEEG in head injured groups. See Supplementary Material for keyword search terms and record returns. Studies using established statistical approaches to demonstrate differential qEEG between injured and control groups were considered particularly important. Statistical methods of high value included effect size statistics such as Cohen's $d$, odds ratio, and area under receiver operating characteristic curve. In addition, studies exploring test-retest reliability were flagged. To efficiently filter the large number of initial hits and maintain a pertinent collection for TWG review, the following study characteristics resulted in exclusion from the primary qEEG literature index:

1. Studies that used severe TBI or comatose patients,

2. Studies exploring pharmacologic or biologic agent efficacy,

3. Rehabilitation or therapeutic studies (those not diagnostic in nature),

4. Studies using animal models of neurological injury, and
5. Studies exploring the use of qEEG in dysfunctions besides head injury (e.g., neurodegenerative diseases, psychological dysfunctions).

The primary qEEG literature index was further down selected to focus on studies that provide statistical evidence for $q E E G$ measures as detection tools for mTBI. Therefore, the following study characteristics resulted in removal from the qEEG-refined literature index:

1. Retrospective studies (i.e., symptom catalogs)

2. Studies without direct statistical comparisons.

\section{LITERATURE SEARCH RESULTS}

Using the methodology described above, the primary qEEG literature index consisted of 40 studies (Supplementary Material). Twenty-five of these studies were further down selected as providing direct statistical evidence related to qEEG measure discriminatory ability. The refined literature index was subsequently used by the TWG to evaluate major qEEG measure types, power spectra, connectivity measures, and the use of discriminant functions. Each analysis of the measure types and the use of discriminant functions includes a general description of the approach, the potential utility for detection of mTBI, an evaluation of the statistical evidence to discriminate between injured and non-injured persons, research gaps and future directions to improve upon the evidentiary data, and conclusions on the overall prospects for use as an mTBI detection method. Section "Advanced Signal Processing Technologies" extends the scope of the original literature search to introduce important approaches with high perceived value (based on the opinion of this TWG) as mTBI diagnostic tools, but with low evidentiary support to date.

\section{MEASURES REPRESENTED IN THE DOWN SELECTED qEEG LITERATURE INDEX}

Examination of the down selected literature index revealed two main types of qEEG analysis investigated for mTBI detection efficacy: spectral analysis (see Table 1) and functional connectivity analysis. Each type of analysis is introduced below, followed by critical evaluation of the literature-based evidence and recommendations for future research.

\section{SPECTRAL ANALYSIS \\ Definition (spectral analysis)}

Spectral analysis is a common form of EEG interpretation in which the distribution of signal is evaluated over various EEG frequencies. Spectral analysis is usually limited to a narrow frequency band from 0.1 to $100 \mathrm{~Hz}$, which is further subdivided into several sub-bands (e.g., delta, theta, alpha, beta, and gamma bands). The boundaries of the sub-bands can differ slightly among various researchers, resulting in potential variation of results across studies. A typical sub-band range, used by Prichep et al. (2012a,b), is as follows: delta $(1.5-2.5 \mathrm{~Hz})$, theta $(3.5-7.5 \mathrm{~Hz})$, alpha $(7.5-$ $12.5 \mathrm{~Hz})$, alpha1 $(7.5-10.0 \mathrm{~Hz})$, alpha2 $(10.0-12.5 \mathrm{~Hz})$, beta1 $(12.5-25.0 \mathrm{~Hz})$, beta2 $(25.0-35.0 \mathrm{~Hz})$, gamma $(35.0-50.0 \mathrm{~Hz})$. The spectral power for each band is obtained either by (1) calculating the power spectrum of the total signal recorded at an electrode site 
Table 1 | Studies using spectral analysis.

General study information

(spectral analysis)
Study design

\begin{tabular}{llllll}
\hline $\begin{array}{l}\text { mTBI } \\
\text { group }(\boldsymbol{n})\end{array}$ & $\begin{array}{l}\text { Control } \\
\text { group }(\boldsymbol{n})\end{array}$ & $\begin{array}{l}\text { qEEG recording } \\
\text { condition }\end{array}$ & $\begin{array}{l}\text { Criteria for } \\
\text { TBI patient }\end{array}$ & Measures \\
60 & 30 & $\begin{array}{l}\text { Eyes closed, resting, } \\
\text { wakeful }\end{array}$ & $\begin{array}{l}\text { Glasgow coma } \\
\text { scores (13-15) }\end{array}$ & Frequency band average \\
& power
\end{tabular}

"Electroencephalogram and evoked potential parameters examined in

Chinese mild head injury patients for forensic medicine"

Notes: this study supports qEEG as a more sensitive method for detecting mTBI compared to evoked potential recording (auditory and flash). This conclusion is somewhat contradictory to other studies in the field

Coutin-Churchman et al. (2003) "Quantitative spectral analysis of EEG in psychiatry revisited: drawing signs out of numbers in a clinical setting" Notes: qEEG was reported to bin normal subjects and psychiatric patients with good specificity and sensitivity. However, this study does not find any clear association between particular qEEG measures and specific disorders. In addition, the patient group mostly consisted of individuals with mood and psychological disorders, not cognitive impairments due to injury

che

6 With othe

urological

sorders

67

Eyes closed, resting,

wakeful

Frequency band power

ratios

Frequency band power

ratios and average power

4 \\ 4}

Results

Statistical test/

comparison/significance

Unpaired $t$-test

1. $\alpha 1(p<0.001)$

2. $\theta, \alpha 2, \beta 1, \beta 2$ (all $p>0.05$ ) (NS)

Unpaired $t$-test

1. $\theta / \alpha 1$ and $\theta / \alpha 2$ (both $p<0.05$ )

2. $\alpha 1 / \alpha 2(p<0.01)$

Paired $t$-test

Initial vs. 3 month retest ( $p>0.05$

for all comparisons) (NS)

\begin{tabular}{|c|c|c|c|c|c|c|}
\hline & & & & & $\begin{array}{l}\text { Slow band decrease (all } \\
\text { disorders combined) }\end{array}$ & $\begin{array}{l}\text { (Pearson } \chi^{2}=7.865, \mathrm{df}=1, \\
p=0.005) \\
\text { Pearson's correlation } \\
\text { Medication use in all patients } \\
\left(\chi^{2}=2.963, \mathrm{df}=1, p=0.085\right) \\
\text { (NS) }\end{array}$ \\
\hline $\begin{array}{l}\text { Gosselin et al. (2009) } \\
\text { "Sleep following sport-related } \\
\text { concussions" }\end{array}$ & 10 & 11 & $\begin{array}{l}\text { Eyes closed, resting, } \\
\text { wakeful } \\
\text { Eyes closed, asleep }\end{array}$ & $\begin{array}{l}\text { Glasgow coma } \\
\text { scores (13-15) }\end{array}$ & $\begin{array}{l}\text { Relative spectral power } \\
\text { (all frequencies) (eyes } \\
\text { closed asleep) }\end{array}$ & $\begin{array}{l}\text { Two-way ANOVA (no significance } \\
\text { for any region) }\end{array}$ \\
\hline $\begin{array}{l}\text { Notes: while this report did not find } \\
\text { differences in sleep architecture } \\
\text { (frequency activities) between } \\
\text { concussed and control athletes, } \\
\text { concussed athletes showed significant }\end{array}$ & & & $\begin{array}{l}\text { Frontal region (Fz, F3, } \\
\text { F4), central region } \\
(\mathrm{CZ}, \mathrm{C} 3, \mathrm{C} 4) \text {, parietal } \\
\text { region }(\mathrm{Pz}, \mathrm{P} 3, \mathrm{P} 4) \text {, } \\
\text { occipital region }(\mathrm{O} 1\end{array}$ & & $\begin{array}{l}\text { Relative delta power (eyes } \\
\text { closed, wakefulness) } \\
\text { Relative alpha power } \\
\text { (eyes closed, } \\
\text { wakefulness) }\end{array}$ & $\begin{array}{l}\text { Two-way ANOVA }\left(F_{1,14}=12.7\right. \\
p<0.01 \text { ) (all regions) } \\
\text { Two-way ANOVA }\left(F_{1,14}=8.8\right. \\
p<0.05 \text { ) (all regions) }\end{array}$ \\
\hline $\begin{array}{l}\text { increased delta and reduced alpha } \\
\text { activities in the waking qEEG analysis. } \\
\text { This study also demonstrates effective } \\
\text { combinatorial technology use (fMRI } \\
\text { and ERP) }\end{array}$ & & & $\begin{array}{l}\text { and } \mathrm{O} 2) \text {, temporal } \\
\text { region }(\mathrm{T} 7, \mathrm{~T} 8, \mathrm{P} 7, \mathrm{P} 8)\end{array}$ & & $\begin{array}{l}\text { Slow to fast frequencies } \\
\text { ratio (eyes closed, } \\
\text { wakefulness) }\end{array}$ & $\begin{array}{l}\text { Two-way ANOVA }\left(F_{1}, 14=11.5\right. \\
p<0.01 \text { ) (all regions) }\end{array}$ \\
\hline $\begin{array}{l}\text { Haglund and Persson (1990) } \\
\text { "Does Swedish amateur boxing lead to } \\
\text { chronic brain damage? A retrospective } \\
\text { clinical neurophysiological study" } \\
\text { Notes: study reports no differences in } \\
\text { qEEG measures between patient } \\
\text { groups, but the effort was exploratory } \\
\text { and used grand averages for each } \\
\text { frequency band. Importantly, inter-rater } \\
\text { reliability was reported to be sufficient }\end{array}$ & $\begin{array}{l}47 \\
22 \text { High-match } \\
\text { boxers } \\
25 \text { Low-match } \\
\text { boxers }\end{array}$ & $\begin{array}{l}50 \\
25 \text { Soccer } \\
\text { players } \\
25 \text { Track and } \\
\text { field players }\end{array}$ & $\begin{array}{l}\text { Eyes closed, resting, } \\
\text { wakeful }\end{array}$ & $\begin{array}{l}\text { High number of } \\
\text { boxing matches } \\
(>25)\end{array}$ & $\begin{array}{l}\text { Average power spectrum } \\
\text { (grand averages from } \\
\text { each frequency) }\end{array}$ & $\begin{array}{l}\text { Chi square (no significant } \\
\text { differences between all groups) }\end{array}$ \\
\hline
\end{tabular}

(Continued) 


\section{Table 1 | Continued}

General study information (spectral analysis)
Study design

\begin{tabular}{llll}
\hline $\begin{array}{l}\text { mTBI } \\
\text { group }(\boldsymbol{n})\end{array}$ & $\begin{array}{l}\text { Control } \\
\text { group }(\boldsymbol{n})\end{array}$ & $\begin{array}{l}\text { qEEG recording } \\
\text { condition }\end{array}$ & $\begin{array}{l}\text { T } \\
17\end{array}$ \\
17 & N/A
\end{tabular}

Korn et al. (2005)

"Focal cortical dysfunction and

blood-brain barrier disruption in patients

with post-concussion syndrome"

Notes: the main purpose of this study

was to correlate abnormal EEG, brain

imaging, and blood-brain barrier

disruptions, especially as related to

localization. Arciniegas' (2011) review

provides critical perspective on this

study (classification of some

experimental group subjects as having

mTBI, but CT scans suggest a more

severe form of TBI)

Montgomery et al. (1991)

"The psychobiology of minor head

injury"

Notes: the theta band was the only

abnormal frequency in the qEEG

analysis. However, no normative

sampling or pre-injury measures, or

control group measures were used.

The comparison was only between

immediate post-injury (approximately

$24 \mathrm{~h}$ ) and 6 weeks later. So, reduction in

theta power may be considered

persistent

Slobounovet ar. (2012)

Slobounov et al. (2012)
"Residual brain dysfunction observed

1 year post-mild traumatic brain injury: combined EEG and balance study"

Notes: this study suggests qEEG and

balance analysis as good prognostic

tools; efficacy as a diagnostic tool was

not explored

Tebano et a (1988)

Tebano et al. (1988)
"EEG spectral analysis after minor
head injury in man"

head injury in man"

Notes: this report suggests differences

in power band frequencies occur

between healthy and patients with

mTBI. This is an early study and may be

considered exploratory

$\begin{array}{ll}26 & \text { Eyes closed, resting, } \\ & \text { wakeful }\end{array}$

Criteria fo

Glasgow coma

scale $>12$,

post-concussion

syndrome (PCS)

diagnosis 1 month

to 7 years

post-injury
Results

\begin{tabular}{ll}
\hline Measures & $\begin{array}{l}\text { Statistical test/ } \\
\text { comparison/sign }\end{array}$
\end{tabular}

Delta frequency power Student's $t$-test

Alpha frequency power Increased delta $(p<0.01)$

Student's $t$-test

Lower alpha $1(p<0.05)$

Lower alpha $2(p<0.05)$ 
Table 1 | Continued

General study information (spectral analysis)
Study design

\begin{tabular}{lll}
\hline $\begin{array}{l}\text { mTBI } \\
\text { group }(\boldsymbol{n})\end{array}$ & $\begin{array}{l}\text { Control } \\
\text { group }(\boldsymbol{n})\end{array}$ & $\begin{array}{l}\text { qEEG recording } \\
\text { condition }\end{array}$ \\
\hline 162 & None & N/A
\end{tabular}

Thatcher et al. (1991)

"Comprehensive Predictions of

Outcome in Closed Head-Injured

Patients"

Notes: a gradient of prognostic

strength of diagnostic measures was

EEG phase $>E E G$ coherence $>$

$\mathrm{GCS}-\mathrm{T}>\mathrm{CT}$ scan $>\mathrm{EEG}$ relative power

Thornton (2003)

"The electrophysiological effects of a

brain injury on auditory memory

functioning. The QEEG correlates of

impaired memory"

Notes: twenty-seven patients of the

mTBI group were on various

medications. Age was statistically

different between groups (mTBI group

was slightly older)

Tomkins et al. (2011)

"Blood-brain barrier breakdown

following traumatic brain injury: a

possible role in posttraumatic epilepsy"

Notes: study focuses mostly on

blood-brain barrier localization with

qEEG abnormalities

\section{5}

$85 \quad 56$

56

resting, wakefu,

during auditory

memory task

Eyes open,

resting, wakeful,

during auditory

memory task
Results

Criteria for

TBI patient

Measures

Closed head injury EEG relative

and admittance to power

Neurotrauma

hospital center
Statistical test/

comparison/significance

Prediction accuracy (extreme outcome scores) (1 year) $67.1 \%$

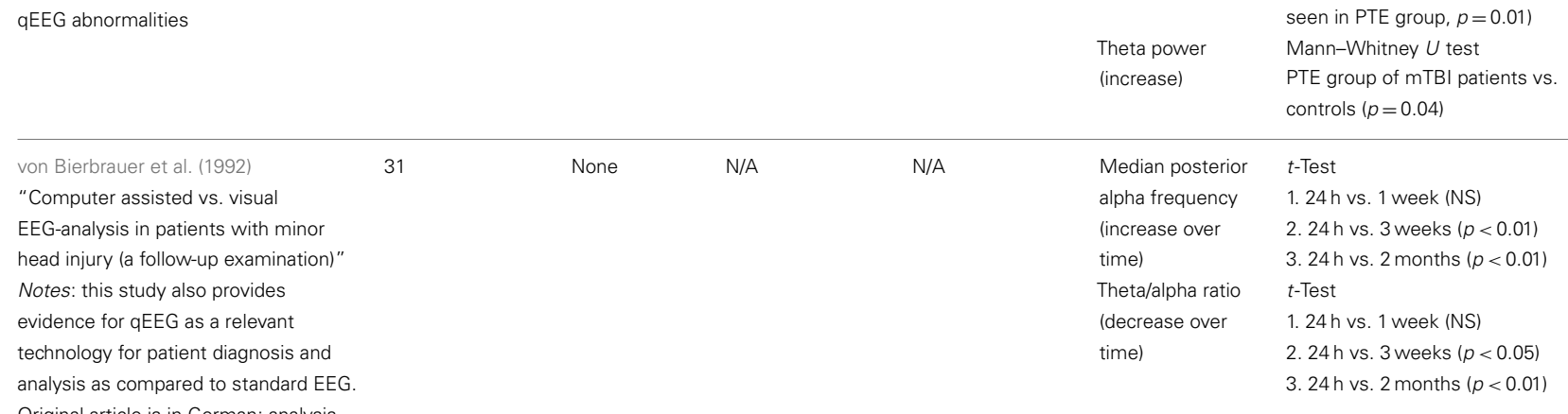

Original article is in German; analysis

adapted from review article (Nuwer

et al., 2005)

Watson (1995)
"The post-concussional state:
neurophysiological aspects"
Notes: study suggests combined use
of qEEG power spectral analysis and
brainstem audio evoked potential
(BAEP) I-V latency analysis could
provide utility to diagnose mTBI
symptoms (both organic and
psychological)

Williams et al. (2008)
"Polysomnographic and quantitative

"Polysomnographic and quantitative
EEG analysis of subjects with long-term

$\begin{array}{ll}25 \quad \text { None } & \text { Eyes closed, } \\ & \text { resting, wakeful }\end{array}$

Men; aged 14-30; Alpha/theta ratio

(at day 0 , day 10 ,

and 6 weeks

head injury with

yith

post-injury)

Paired two-tailed $t$-test (day 0 vs. day

10 post-injury)

1. Right temporal (T4-T6), $p<0.006$

post-traumatic

2. Right parieto-occiptal (P4-O2),

$p<0.02$ (day 10 vs. 6 weeks) - not

significant for any region

insomnia complaints associated with

mild traumatic brain injury"

Notes: this study shows limited ability

of $q E E G$ power spectra analysis to

differentiate among mTBI patients

suffering from sleep disorders and

control groups

9

9

9

Eyes closed,
resting, asleep

Glasgow coma

scale 13-15; loss

of consciousness

$<20$ min;

hospitalization

$<48 \mathrm{~h}$; reported

sleep dysfunction
Beta 2 power
(decrease in
injured patients)
Variability in power
(greater variability
in mTBI patients)
Two-tailed $t$-tests with Welch's corrections (Wilcoxon rank sum test also used if outliers were apparent) 1. Beta $2(F(1,16)=8.9, p=0.008)$

Two-tailed $t$-tests with Welch's corrections (Wilcoxon rank sum test also used if outliers were apparent)

1. Sigma $\left(F_{1,16}=10.5, p=0.005\right)$

2. Theta $\left(F_{1,16}=6.8, p=0.019\right)$

3. Delta $\left(F_{1,16}=9.2, p=0.008\right)$ 
and then summing the contributions of the frequencies included in the band, or (2) subjecting the total signal to an appropriate passband filter and then calculating the power spectrum of the filtered signal. The resulting band power is typically averaged over electrode sites and reported either as "absolute power" or as "relative power," which is the ratio of the band power to the total power over all bands. Other common parameters of spectral analysis include median frequency and spectral edge frequency (Dressler et al., 2004).

\section{Utility for mTBI detection (spectral analysis)}

A key feature of spectral analysis that allows for strong utility as an mTBI detection tool is that spectral data can be obtained from as few as two electrodes. Therefore, fielded devices do not require the costs or burden of large montages of electrodes. This feature reduces equipment burden, administration time, and cost. Simplified devices also allow for faster training and simplified analysis.

\section{Evidence of efficacy (spectral analysis)}

Of the 25 studies comprising the down selected qEEG literature index, 15 studies used spectral analysis as a measure to compare injured and control groups. Most of the studies report statistically significant alteration in at least one frequency band in mTBI patients compared to control groups. To visualize the overall trends in results, Table 2 summarizes the reported changes to spectral power (either absolute or relative power) across frequency subbands from relevant studies. The table also displays the recording montage and statistical significance from each finding. Measurements were made under eyes closed, no task, but awake conditions, with few exceptions [e.g., Tebano et al., 1988 - eyes open; Gosselin et al. (2009) - asleep condition; Thornton (2003) - EEG recorded during memory task]. While results are somewhat varied, generalizations can be inferred. For instance, mTBI injury is often associated with a decrease in alpha power and an increase in delta, beta, and theta bands. We note this evidence is not based entirely on well-designed studies with large sample groups and strong statistical significance. As an example, Thornton (2003) reported increased beta activity in the injured group, but used 27 mTBI patients that were on some type of medication. Furthermore, the age difference between injured and control groups was statistically significant. These inconsistencies could potentially skew EEG recordings. Korn et al. (2005), which reported decreased alpha and increased delta power in the injured group, has been criticized due to the potential misclassification of moderate-severe TBI patients as mTBI patients (Arciniegas, 2011). The absence of a uniformly applied criterion for defining mild TBI is a significant complicating factor. Tebano et al. (1988), inconsistent with several other studies, reported results based on very small sample sizes and recorded brain activity with a single bipolar derivation (O1-T5) using an eyes open paradigm. Other inconsistencies in the findings may be attributed to the various montages and derivations used during data acquisition sessions (see Table 2 for details). Overall, differential spectral power in injured patients is strongly suggested in the literature, but specific findings need to be confirmed based on robust studies that use similar recording conditions.
Several additional studies from the literature index investigated spectral measures, but did not compare results to a control group. For example, Montgomery et al. (1991), Slobounov et al. (2012), von Bierbrauer et al. (1992), and Watson (1995) reported spectral changes in injured patients over time (theta reduction, alpha power reduction plus theta/alpha ratio changes, and alpha/theta ratio changes, respectively). Contradicting these studies, Chen et al. (2006a) reported all spectral power measures returned to normal levels after a three month retest (alpha1, theta/alphal ratio, theta/alpha2 ratio, and alpha1/alpha2 ratio). These results suggest spectral analyses may have utility for longitudinal evaluations, but confirmatory experiments must be matched with respect to time post-injury and recording condition.

Additionally, some studies reported no spectral differences between injured and control groups when a broad frequency window was used (Haglund and Persson, 1990; Coutin-Churchman et al., 2003; Gosselin et al., 2009). Such findings suggest power spectral analysis using sub-bands is preferred to observe significant differences in mTBI patients. We note that the patient group in the Coutin-Churchman et al. (2003) study included individuals with a wide range of psychiatric disorders (only 4/340 patients were classified with "post-traumatic headache") and patients were not controlled for medication usage. Therefore, the study should only be considered a demonstration of the ability of spectral analysis to uncover dysfunction across many neurological conditions. Finally, Williams et al. (2008) reported higher variability in power in mTBI patients compared to normal participants (sigma, $p=0.005$; theta, $p=0.019$; delta, $p=0.008$ ), but only limited ability of power spectra analysis to differentiate among injured and normal. Refer to Table 2 for a full listing of the 15 studies reporting use of spectral analysis.

\section{Research gaps and future directions (spectral analysis)}

The variability of qEEG recording conditions across studies severely impedes the formulation of strong conclusions on spectral analysis utility or effectiveness. While studies strongly suggest spectral analysis may be used as an mTBI detection tool, efforts should be made to corroborate previous findings using highquality studies with controlled recording conditions and injured group selection criteria. In addition, the use of smaller electrode montages should be emphasized if field-based qEEG recording devices are expected to be preferred for U.S. military operations.

Spectral power averaged over all electrode sites is a global measure. It provides no information about the energy generated at individual sites or about the connectivities of different sites. This more detailed information is provided, in part, by functional connectivity measures, such as coherence and phase difference (see below), and by inter- and intra-hemispheric power asymmetries. Research should be devoted to identify the most promising spectral measures, but with the overall goal to use spectral measures in combination with other measures.

\section{Summary of analysis (spectral analysis)}

There are some examples in the literature suggesting that spectral analysis can be used to detect mTBI. Studies generally report altered alpha, delta, beta, and theta power as potential indicators of mTBI. However, while trends of specific spectral power 
Table 2 | Summary of changes in spectral power associated with mTB| ${ }^{\mathrm{a}}$.

\begin{tabular}{|c|c|c|c|}
\hline Frequency range & Decrease in spectral power & Increase in spectral power & Unchanged spectral power \\
\hline Theta $(3.5-7.5 \mathrm{~Hz})$ & & $\begin{array}{l}\text { Tomkins et al. (2011) }(p=0.04,23 \text { channels); } \\
\text { Montgomery et al. (1991) }(p<0.025, \text { T4-T6; } \\
p<0.01 \text {, P4-O2; } p<0.01 \text {, T3-T5; } p<0.01 \\
\text { P3-01) }\end{array}$ & $\begin{array}{l}\text { Tebano et al. (1988) (O1-T5, } \\
\text { relative power); Chen et al. } \\
\text { (2006a) (16 channels, specific } \\
\text { locations unknown) }\end{array}$ \\
\hline Alpha1 $(7.5-10 \mathrm{~Hz})$ & $\begin{array}{l}\text { Korn et al. (2005) ( } p<0.05 ; 128 \\
\text { channels, relative power) }\end{array}$ & $\begin{array}{l}\text { Tebano et al. (1988) ( } p<0.01 \text {; O1-T5); Chen } \\
\text { et al. (2006a) ( } p<0.01 ; 16 \text { channels, specific } \\
\text { locations unknown) }\end{array}$ & \\
\hline Alpha $(7.5-12.5 \mathrm{~Hz})$ & $\begin{array}{l}\text { Gosselin et al. (2009) }(p<0.05 \text {, asleep, } \\
\text { relative power); Tomkins et al. (2011) } \\
\text { ( } p=0.005 \text {,only in post-traumatic } \\
\text { epilepsy mTBI subgroup) }\end{array}$ & & $\begin{array}{l}\text { Tebano et al. (1988) (O1-T5, } \\
\text { relative power) }\end{array}$ \\
\hline Beta $(12.5-25 \mathrm{~Hz})$ & & & $\begin{array}{l}\text { Tebano et al. (1988) (O1-T5, } \\
\text { relative power) }\end{array}$ \\
\hline Beta1 $(13-32 \mathrm{~Hz})$ & & $\begin{array}{l}\text { Thornton (2003) ( } p<0.02 \text {, auditory memory } \\
\text { task) }\end{array}$ & $\begin{array}{l}\text { Chen et al. (2006a) (16 channels, } \\
\text { specific locations unknown) }\end{array}$ \\
\hline
\end{tabular}

Gamma $(35-50 \mathrm{~Hz})$

Theta/alpha

Watson (1995) $(p<0.006$, T4-T6; $p<0.02$

$\mathrm{P} 4-\mathrm{O} 2, \mathrm{P} 3-\mathrm{O} 1)^{\mathrm{C}}$

Theta/alpha1 Chen et al. (2006a) $(p<0.05 ; 16$

channels, specific locations unknown)

Theta/alpha2

Chen et al. (2006a) ( $p<0.05 ; 16$ channels,

specific locations unknown)

Alpha1/alpha2

Chen et al. (2006a) ( $p<0.01 ; 16$ channels,

specific locations unknown)

${ }^{a}$ EEGs were measured in 19 channels during eyes closed, awake recording sessions, unless otherwise noted. Reported changes are in absolute power relative to normal controls, unless otherwise noted.

${ }^{b}$ Montgomery et al. (1991) noted a decrease in theta power of the same subject from day 0 to 6 weeks post-concussion suggesting that theta power may have increased as a result of the concussion and was trending back to normal 6 weeks later as the patient recovered.

"Watson (1995) found that for channel pairs T4-T6, P4-O2, P3-O1, the theta/alpha ratio had decreased from day 0 to day 10 post-injury for the same subjects suggesting that the ratio may have increased as a result of the concussion and was trending back to normal 10 days later as the patient recovered.

alterations are apparent (decreased alpha and increased delta, beta, and theta in injured groups), the literature contains a high degree of contradictory results. This uncertainty is most likely due to poor study design and a lack of recording condition consistency.
Therefore, additional studies with carefully controlled conditions must be conducted to identify the best spectral measures for mTBI detection. We anticipate spectral analysis would not be a sufficient detection tool in isolation, and, in fact, multiple studies suggest 
improved accuracy only when combined with other qEEG measures (Thatcher et al., 1989, 1991; Trudeau et al., 1998; Thornton, 1999, 2003; McCrea et al., 2010; Barr et al., 2012; Prichep et al., $2012 a, b)$. Additionally, there is some evidence that depression is also marked by a decrease in alpha power and an increase in beta power similar to those seen in mTBI patients (Thornton, 2003). This finding raises the possibility of confounding test results in patient populations that may be prone to depression or PTSD. In summary, spectral analysis in and of itself does not appear to be a viable tool for mTBI detection.

\section{FUNCTIONAL CONNECTIVITY MEASURES Definition (functional connectivity)}

Analysis of functional connectivity quantifies the relationships between EEG signals recorded simultaneously at different sites. EEG connectivity measures fall into three groups: time domain measures, frequency-domain measures, and measures calculated from the geometry of embedded data.

Time domain measures quantify the correlation between EEG time series. They can be used to assess the connectivity of discrete feedback loops and the stereotyped propagation of signals across neural networks (Koenig et al., 2005). There are four commonly used time domain measures of functional connectivity to assess the correlation between pairs of observations: (1) Pearson product moment correlation, (2) Spearman rank order correlation, (3) Kendall rank order correlation, and (4) mutual information. Additional time domain measures of note include a normalization of mutual information [recently constructed by Reshef et al. (2011)] and EEG microstate topography, in which the occurrence of spontaneous short-lasting brain states is assessed (Koenig et al., 2005).

Frequency-domain measures quantify the correlation between spectra rather than between the original time series, or quantify the relationship between the phases of two signals. Variations on these themes that have been applied to EEG signals include coherence (Nunez et al., 1997, 1999), phase synchronization (Aviyente et al., 2011), phase locking index (Hurtado et al., 2004; Sazonov et al., 2009; Stam et al., 2009), phase locking value (Lachaux et al., 1999), imaginary coherency (Nolte et al., 2004; Stam et al., 2007), synchronization index (Gross et al., 2004), and phase lag index (Stam et al., 2007, 2009).

Measures of embedded data are more recent additions to the assessment of functional connectivity. Consider a scalar voltage time series measures at a scalp electrode, $\left(v_{1}, v_{2}, \ldots, v_{\mathrm{N}}\right)$. This time series is used to construct points in m-dimensional space, $Z_{\mathrm{i}}=\left(v_{\mathrm{i}}\right.$, $\left.v_{\mathrm{i}+1}, \ldots, v_{\mathrm{i}+(\mathrm{m}-1)}\right)$. While there are more complicated versions of the embedding process, in each version the original time series in this example becomes a directed trajectory in m-dimensional space, as motivated by the Takens embedding theorem (Takens, 1981). This powerful result demonstrates that, to an approximation, an intimate relationship exists between the geometry of the embedded set and the dynamical structure of the system that generated the observed time series. Now suppose two time series are measured simultaneously and used to generate two separate $\mathrm{m}$-dimensional trajectories. Functional connectivity between the two original time series may be assessed by constructing measures relating the two trajectories. Examples include synchronization likelihood (Stam and van Dijk, 2002; Wendling et al., 2009) and cross recurrence diagrams (Romano et al., 2004; Richardson et al., 2008).

Distinction must also be made between connectivity measures and measures of causal relationships. Functional connectivity measures are computed from voltage signals recorded at different electrodes to determine if there is a relationship between two signals. These measures are adirectional. In contrast, causality measures specifically assess the direction of information movement. Measuring causality for mTBI detection is examined in Section "Analysis of Causal Relationships" of this report.

\section{Utility for mTBI detection (functional connectivity)}

Alterations in the functional connectivity of multichannel EEG have been reported in a range of neuropsychiatric disorders, including TBI (Table 3). This suggests reasonable utility of using functional connectivity measures for mTBI detection. It should

Table 3 | Pathological conditions associated with altered functional connectivity (adapted from Bonita et al., 2014).

\begin{tabular}{lll}
\hline Disorder/dysfunction & \multicolumn{1}{c}{ Relevant publications } \\
\hline Alzheimer's disease & Georgopoulos et al. & \multicolumn{1}{c}{ Rosenbaum et al. } \\
& (2007) & (2008) \\
& Güntekin et al. (2008) & Stam et al. (2006, 2007, \\
& & 2009) \\
& Locatelli et al. (1998) & Zhou et al. (2008)
\end{tabular}

Epileptic seizures

Ponten et al. (2007)

Intra-arterial

Douw et al. (2010)

amobarbital injection

Autism spectrum

Belmonte et al. (2004)

disorder

Just et al. (2004)

Kana et al. (2007)

Murias et al. (2007)

Rippon et al. (2007)

Vidal et al. (2006)

Brain tumors

Bartolomei et al. (2006)

Bosma et al. (2008)

Multiple sclerosis

Georgopoulos et al.

(2007)

Lenne et al. (2012)

Preterm birth

Mullen et al. (2011)

PTSD

Lanius et al. (2004)

Shaw (2002)

Schizophrenia

Breakspear et al. (2004)

Georgopoulos et al.

(2007)

Lawrie et al. (2002)

Lynall et al. (2010)

Michelyannis et al.

(2006)

Symond et al. (2005)

Stroke

Grefkes and Fink (2012)

Traumatic brain injury

Cao and Slobounov

Kumar et al. (2009a,b)

(2010)

Castellanos et al. (2010, Nakamura et al. (2009)

2011a,b)

Ham and Sharp (2012) Sponheim et al. (2011)

Kasahara et al. (2010) Tsirka et al. (2011) 
be noted, however, that multichannel EEG usually requires more complex electrode montages and advanced computational capacity for data analysis. These features may be contrary to simple, lightweight devices capable of field-based use and easy operation. Additionally, the signal analysis and neuroinformatics challenges of these investigations should not be underestimated (Irimia et al., 2009, 2012; Goh et al., 2014).

\section{Evidence of efficacy (functional connectivity)}

The various functional connectivity measures described above offers specific advantages and disadvantages as detection tools of neurological dysfunction. For example, Bonita et al. (2014) recently compared the four classical measures of time domain connectivity (Pearson product moment correlation, Spearman rank order correlation, Kendall rank order correlation, and mutual information) with multichannel EEGs obtained in two behavioral states (eyes open, no task and eyes closed, no task) from healthy control participants. It was found that mutual information distinguished between behavioral states with less data and was more robust to noise. This result was not unanticipated since mutual information is a non-linear measure that captures relationships not detected by the other three time domain measures. In addition, time domain measures have been most commonly applied to event-related data, since common reference points in time are often required for calculations (Koenig et al., 2005). EEG microstate topography analysis, however, does not require external time reference points and may be used with spontaneous qEEG recording to assess individuals with varied cognitive states or dysfunctions (Koenig et al., 1999; Lehmann et al., 2005; Müller et al., 2005). Frequency-domain measures are not robust to naïve application. For example, Schiff (2005) showed coherence calculations can produce misleading results and Guevara et al. (2005) reported synchronization values can be sensitive to the common reference signal used in EEG recordings. Insofar as we know, a comparative study of frequency-domain measures, analogous to the Bonita et al. (2014) time domain measure study, has not been conducted. Similarly, essential comparative studies have not been reported for measures of embedded data.

Specific evidence related to mTBI detection is relatively sparse: only three studies from the refined literature index investigated the efficacy of functional connectivity measures (see Table 4). Sponheim et al. (2011) reported reduced synchrony between specific frontal electrode positions for delta, beta, and gamma frequency bands. The results were statistically significant with a strong criterion (limited to $p<0.05$ for all comparisons; Cohen's $d=0.92-1.20$ ), but we note the study used small sample group sizes (nine injured and eight normal) and follow-up studies with larger groups could improve significance. Interestingly, the use of neurocognitive assessment tools (battery of multiple tests) failed to properly classify individuals as injured or uninjured, suggesting that this new method may uncover dysfunctions below the thresholds of current mTBI detection methods. Thatcher et al. (1991) reported EEG phase was reasonably accurate in predicting outcome scores of patients 1 year post-injury (90.2\% accuracy). This study also ranked the prognostic strength of EEG phase and EEG coherence above CT scan and spectral relative power. The Thatcher et al. (1991) study was longitudinal and no control group was used to assess diagnostic capacity of the functional connectivity measures. Finally, Thornton (2003) used an audio memory task paradigm and reported that phase and coherence were lowered for beta 1 and beta 2 spectral bands $(p<0.05$ for each test). This study involved reasonable sample groups ( 85 injured, 56 controls), but has been challenged since 27 patients from the mTBI group were on medications and there was a statistically significant difference in age between the groups. Nevertheless, this study suggests functional connectivity should be further investigated as a diagnostic approach for mTBI. Details on the three studies investigating functional connectivity in $\mathrm{mTBI}$ are presented in Table 4.

\section{Research gaps and future directions (functional connectivity)}

Since a limited number of studies have specifically investigated detection efficacy of $\mathrm{mTBI}$, future research should be directed to corroborate previous findings. Concerns of study quality are abundant; therefore, future studies should ensure robust study design and limited reliance on medicated patient groups. The signal processing methods for coherence should also be investigated, since studies have reported misleading results depending on the analysis method.

\section{Summary of analysis (functional connectivity)}

In the context of mTBI, functional connectivity has not been investigated to the same extent as spectral analysis. The small number of available studies report that coherence may be a useable measure for accurate mTBI detection. However, the studies are fundamentally weak in their experimental design and need to be corroborated. Furthermore, the strongest positive results were reported for a longitudinal study. Similar to spectral analysis, coherence may be best suited as a contributing measure of a discriminant function for mTBI detection.

\section{DISCRIMINANT FUNCTIONS}

While not specific to qEEG, discriminant functions were identified during the literature search as a common methodology for mTBI detection. Discriminant functions in this context comprise more than one qEEG measure and so deserve consideration here. Similar to the evaluation of spectral analysis and functional connectivity, discriminant functions are defined below, followed by an analysis of the evidentiary support for use as an mTBI detection tool.

\section{Definition (discriminant functions)}

The term "discriminant functions" refers to an entire class of analysis approaches in which a specific model is used to classify a set of data as belonging to a specific group (or not). Broadly defined, this involves the use of a specific rule (or set of rules), which define members of a class, and applying the rule to a set of data where membership is unknown in order to classify where the target member belongs. This is most commonly a discrete decision, but can even be used to estimate the location within a categorized continuum. Within the domain of TBI, discriminant functions may be used to classify a patient based on level of severity (e.g., severe TBI vs. mTBI) or the presence of injury (e.g., TBI vs. no injury) through the combination of various metrics (such as spectral or functional connectivity features) within a single discriminant model. 
Table 4 | mTBI studies using connectivity measures.

\begin{tabular}{|c|c|c|c|c|c|c|}
\hline \multirow{2}{*}{$\begin{array}{l}\text { General study information } \\
\text { (spectral analysis) }\end{array}$} & \multicolumn{4}{|c|}{ Study design } & \multicolumn{2}{|r|}{ Results } \\
\hline & $\begin{array}{l}\text { mTBI } \\
\text { group }(n)\end{array}$ & $\begin{array}{l}\text { Control } \\
\text { group }(n)\end{array}$ & $\begin{array}{l}\text { qEEG recording } \\
\text { condition }\end{array}$ & $\begin{array}{l}\text { Criteria for } \\
\text { TBI patient }\end{array}$ & Measures & $\begin{array}{l}\text { Statistical test/ } \\
\text { comparison/significance }\end{array}$ \\
\hline $\begin{array}{l}\text { Sponheim et al. (2011) } \\
\text { "Evidence of disrupted functional } \\
\text { connectivity in the brain after } \\
\text { combat-related blast injury" } \\
\text { Notes: this study uses a new method } \\
\text { for calculating phase synchrony in } \\
\text { qEEG recordings, and identifies several } \\
\text { statistically significant synchrony } \\
\text { disruptions in mTBI patients. } \\
\text { Neurocognitive assessment tools } \\
\text { (battery of multiple tests) were unable } \\
\text { to distinguish between groups }\end{array}$ & 9 & 8 & $\begin{array}{l}\text { Eyes closed, resting, } \\
\text { wakeful }\end{array}$ & $\begin{array}{l}\text { American Congress of } \\
\text { Rehabilitation } \\
\text { Medicine Special } \\
\text { Interest Group on Mild } \\
\text { Traumatic Brain Injury } \\
\text { and the concussion } \\
\text { grading system by the } \\
\text { American Academy of } \\
\text { Neurology }\end{array}$ & $\begin{array}{l}\text { EEG synchrony between } \\
\text { F7 and Fp2 (reduced) } \\
\text { EEG synchrony between } \\
\text { F7 and F4 (reduced) } \\
\text { EEG synchrony between } \\
\text { F8 and Fp1 (reduced) }\end{array}$ & $\begin{array}{l}\text { Wilcoxon ranksum test and Cohen's } d \\
\text { 1. Delta frequency: } p<0.05, d=1.19 \\
\text { 2. Theta: } p<0.05, d=1.07 \\
\text { 3. Beta-1: } p<0.05, d=1.06 \\
\text { 4. Beta-2: } p<0.05, d=1.20 \\
\text { Wilcoxon ranksum test and Cohen's } d \\
\text { 1. Delta: } p<0.05, d=1.00 \\
\text { Wilcoxon ranksum test and Cohen's } d \\
\text { 1. Gamma: } p<0.05, d=0.92\end{array}$ \\
\hline $\begin{array}{l}\text { Thatcher et al. (1991) } \\
\text { "Comprehensive Predictions of } \\
\text { Outcome in Closed Head-Injured } \\
\text { Patients" } \\
\text { Notes: a gradient of prognostic } \\
\text { strength of diagnostic measures was } \\
\text { EEG phase > EEG coherence }> \\
\text { GCS- } T>C T \text { scan }>\text { EEG relative power }\end{array}$ & 162 & None & N/A & $\begin{array}{l}\text { Closed head injury } \\
\text { and admittance to } \\
\text { Neurotrauma hospital } \\
\text { center }\end{array}$ & EEG phase & $\begin{array}{l}\text { Prediction accuracy (extreme } \\
\text { outcome scores) (1 year) } 90.2 \% \\
\text { Correlation (intermediate scores) } \\
R=0.664\end{array}$ \\
\hline $\begin{array}{l}\text { Thornton (2003) } \\
\text { "The electrophysiological effects of a } \\
\text { brain injury on auditory memory } \\
\text { functioning. The QEEG correlates of } \\
\text { impaired memory" } \\
\text { Notes: twenty-seven patients of the } \\
\text { mTBI group were on various } \\
\text { medications. Age was statistically } \\
\text { different between groups (mTBI group } \\
\text { was slightly older) }\end{array}$ & 85 & 56 & $\begin{array}{l}\text { Eyes closed, resting, } \\
\text { wakeful, during } \\
\text { auditory memory task } \\
\text { Eyes open, resting, } \\
\text { wakeful, during } \\
\text { auditory memory task }\end{array}$ & $\begin{array}{l}\text { Loss of } \\
\text { consciousness } \\
<20 \text { min }\end{array}$ & $\begin{array}{l}\text { Connectivity measures } \\
\text { (includes phase and } \\
\text { coherence) }\end{array}$ & $\begin{array}{l}t \text {-Test } \\
\text { 1. Lowered beta } 1 \text { phase and } \\
\text { coherence }(p<0.05) \\
\text { 2. Lowered beta } 2 \text { phase and } \\
\text { coherence }(p<0.05)\end{array}$ \\
\hline
\end{tabular}

\section{Evidence of efficacy (discriminant functions)}

Nine studies were identified that investigate the utility of discriminant function analysis of qEEG data for the detection of mTBI (Table 5). Four studies investigate the efficacy of the same discriminant function currently under development by BrainScope, Inc. (McCrea et al., 2010; Naunheim et al., 2010a,b; Naunheim and Casner, 2010; Barr et al., 2012; O'Neil et al., 2012; Prichep et al., 2012a,b). McCrea et al. (2010) introduces the BrainScope method and device in which seven qEEG features comprise the discriminant function. The group does not provide complete details in this paper, but report the discriminant function consists of measures of asymmetry, coherence, and spectral power in the beta frequency range. Of note, the device only acquires data from three frontal electrode sites, and thus discrimination cannot be based on large network interactions. Twenty-eight concussed athletes were compared to age-matched controls and the data indicated statically significant differences between injured and control groups immediately after injury and 8 days post-injury, but not at day 45 post-injury. While specifics of the discriminant function are missing, the study is sound and provides evidence that the BrainScope discriminant function is efficacious as a detection tool immediately after injury.
The Barr et al. (2012) study is similar to the McCrea study, but recorded qEEG from a larger cohort of mTBI patients and healthy controls and used a five electrode montage. Similar results were reported as well; statistically significant discriminant function indices were observed on the day of injury and at day 8 post-injury, but not at day 45 post-injury. A larger difference (yielding higher significance criterion) was observed compared to the McCrea et al. (2010) study, implying that the discriminant function was altered compared to the McCrea version. However, no details were provided about the specific measures that comprise the function; thus this possibility cannot be confirmed.

O'Neil et al. (2012) also report on the utility of the BrainScope discriminant function, but do not use a control group. The study compares the classification outcome of the discriminant function (called the TBI-index) to classification by medical examination and CT scan. The sensitivity of the discriminant function was good $(94.7 \%)$, but specificity and positive predictive value were poor (approximately 50\%). Problems with the study design are not evident, but the results suggest improvement of the BrainScope discriminant function is required to attain reasonable specificity and avoidance of false negatives. 
Table 5 | mTBI studies using discriminant functions.

General study information

(spectral analysis)

Barr et al. (2012)
"Measuring brain electrical activity to
track recovery from sport-related
concussion"
Notes: this study provides further
evidence for the BrainScope
discriminant function as a potential
mTBI diagnostic tool and may suggest
utility after acute phases of injury.
Commercial funds (BrainScope) were
used to complete this study

Leon-Carrion et al. (2008)

"A QEEG index of level of functional dependence for people sustaining acquired brain injury: the Seville independence index (SINDI)" Notes: investigates validity and reliability of a $\mathrm{qEEG}$ discriminant function for evaluating patient functional dependence. This function is less likely to be accurate for various levels of $\mathrm{mTBI}$ severity

\begin{tabular}{llll} 
& Study design & \\
\hline $\begin{array}{l}\text { mTBI } \\
\text { group }(\boldsymbol{n})\end{array}$ & $\begin{array}{l}\text { Control } \\
\text { group }(\boldsymbol{n})\end{array}$ & $\begin{array}{l}\text { qEEG recording } \\
\text { condition }\end{array}$ & $\begin{array}{l}\text { Criteria for } \\
\text { TBI patient }\end{array}$ \\
59 & 31 & Eyes closed, resting, & $\begin{array}{l}\text { Concussion } \\
\text { (diagnosed at hospital } \\
\text { admittance) }\end{array}$
\end{tabular}

\begin{tabular}{ll} 
& Results \\
\hline Measures & $\begin{array}{l}\text { Statistical test/ } \\
\text { comparison/significance }\end{array}$ \\
\hline $\begin{array}{ll}\text { BrainScope index } \\
\text { (proprietary discriminant }\end{array}$ & $\begin{array}{l}t \text {-Test, corrected for unequal } n \text { 's (TBI } \\
\text { vs. control) }\end{array}$ \\
1. Day of injury $(t=3.75, p=0.0004)$ \\
2. Day $8(t=2.76, p=0.008)$ \\
3. Day $45(t=1.49, p=0.15)(\mathrm{NS})$
\end{tabular}

Course of recovery (day of One-way ANOVA (TBI group)

injury to day 8-45) 1. Day of injury compared to day 8 and day $45(F=3.2 ; p=0.046)$

Course of recovery, One-way ANOVA (control group)

control group 1. Day of injury compared to day 8 and day 45 ( $F=0.5 ; p=0.67$ ) (NS)

40 (TBI) $\quad 40$ (TBI
patients,
FIM + FAM
score binning)
Group 1:
complete
dependence
Group 2:
modified
dependence
Group 3:
independence

Eyes closed, resting, CT or MRI scan Mean SINDI score

One-way ANOVA

Group 1 vs. Group 2 vs. Group 3

$(F=48.9, p<0.0001)$

Correlation between new Pearson coefficient

discriminant and $\quad R=0.81(p<0.001)$

FIM + FAM scores

Correlation between Pearson coefficient

predicted scores from $\quad R=0.85(p<0.0001)$

multiple regression and

$\mathrm{FIM}+\mathrm{FAM}$ scores

Leave-one-out method

(discriminant function

validation)

External validation (33 Classification accuracy (75\%)

patient group)

McCrea et al. (2010)
"Acute effects and recovery after
sport-related concussion: a
neurocognitive and quantitative brain
electrical activity study"
Notes: this study used the BrainScope
device, currently under commercial
development. The BrainScope TBI index
discriminant is based on 7 qEEG
variables identified as good measures
for comparison and differentiation (by
ANOVA) and converted to standard
z-scores

\section{O'Neil et al. (2012)}

$28 \quad 28$

28

Eyes closed, resting,
wakeful
Frontal electrode site
data acquisition only
(FP1, FP2, AFz)
Concussion diagnosis Neurology Guideline for Management of Sports Concussion)

Multivariate discriminant (BrainScope TBI index) combining various measures across frequency bands (main variables included measures of asymmetry, coherence, high beta power, and low beta power)
Classification accuracy (96.65\%)

\section{MANOVA}

Comparison between injured and control groups

1. Baseline: $F=1.65, p=0.164$ (NS)

2. At injury: $F=4.4, p=0.002$

3. Day 8: $F=2.53, p=0.04$
4. Day 45: $F=0.6, p=0.74$ (NS)

"Quantitative brain electrical activity in the initial screening of mild traumatic brain injuries"

Notes: this study describes the BrainScope Index (a qEEG discriminant function) as an effective screening tool for emergency room patients with suspected TBI. Note that BrainScope funded this study and authors are BrainScope employees or consultants

\begin{tabular}{|c|c|c|c|c|c|}
\hline \multirow[t]{16}{*}{119} & None & Eyes closed, resting, & American congress of & TBI-Index & Sensitivity $=94.7$ \\
\hline & & wakeful & rehabilitation criteria & & Specificity $=49.4$ \\
\hline & & & & & Positive predictive value $=47.4$ \\
\hline & & & & & Negative predictive value $=95.3$ \\
\hline & & & & & Positive likelihood value $=1.92$ \\
\hline & & & & & Negative likelihood value $=0.10$ \\
\hline & & & & & Odds ratio $=18.5$ \\
\hline & & & & TBI-Index plus New & Sensitivity $=97.0$ \\
\hline & & & & Orleans Criteria (NOC) & Specificity $=50.6$ \\
\hline & & & & & Positive predictive value $=48.05$ \\
\hline & & & & & Negative predictive value $=97.62$ \\
\hline & & & & & Positive likelihood value $=1.97$ \\
\hline & & & & & Negative likelihood value $=0.06$ \\
\hline & & & & & Odds ratio $=36.1$ \\
\hline & & & & Correlation between & Pearson correlation \\
\hline & & & & TBI-Index and NOC & $R=0.33, p<0.0001$ \\
\hline
\end{tabular}

(Continued) 


\section{Table 5 | Continued}

\section{General study information (spectral analysis)}

\begin{tabular}{|c|c|c|c|c|c|}
\hline \multicolumn{4}{|c|}{ Study design } & \multicolumn{2}{|r|}{ Results } \\
\hline $\begin{array}{l}\text { mTBI } \\
\text { group (n) }\end{array}$ & $\begin{array}{l}\text { Control } \\
\text { group }(n)\end{array}$ & $\begin{array}{l}\text { qEEG recording } \\
\text { condition }\end{array}$ & $\begin{array}{l}\text { Criteria for } \\
\text { TBI patient }\end{array}$ & Measures & $\begin{array}{l}\text { Statistical test/ } \\
\text { comparison/significance }\end{array}$ \\
\hline 633 & None & $\begin{array}{l}\text { Eyes closed, resting, } \\
\text { wakeful }\end{array}$ & $\begin{array}{l}\text { Glasgow coma scale }>8 \\
\text { Category } 1 \text { : no evidence } \\
\text { of acute injury and no } \\
\text { visible CT scan } \\
\text { abnormality) } \\
\text { Category 2: no visible } \\
\text { CT scan abnormality; } \\
\text { neurocognitive } \\
\text { assessment } \\
\text { abnormalities } \\
\text { Category 3: presence of } \\
\text { acute injury (visible CT } \\
\text { scan abnormality) }\end{array}$ & $\begin{array}{l}\text { Custom algorithm } 1 \\
\text { (captures wide range of } \\
\text { measures) } \\
\text { Custom algorithm } 2 \\
\text { (captures wide range of } \\
\text { measures) }\end{array}$ & $\begin{array}{l}\text { Classification of Category } 3 \text { from } \\
\text { Categories } 1 \text { and } 2 \\
\text { Sensitivity }=96.3 \% \\
\text { Specificity }=77.5 \% \\
\text { Positive predictive value }=47.1 \% \\
\text { Negative predictive value }=99.0 \% \\
\text { AUC }=0.911 \\
\text { Cohen's } d=1.94 \\
\text { Classification of Category } 1 \text { from } \\
\text { Categories } 2 \text { and } 3 \\
\text { Sensitivity }=80.5 \% \\
\text { Specificity }=73.9 \% \\
\text { Positive predictive value }=85.4 \% \\
\text { Negative predictive value }=66.5 \% \\
\text { AUC }=0.797 \\
\text { Cohen's } d=1.29\end{array}$ \\
\hline
\end{tabular}

Thatcher et al. (2001)

\begin{tabular}{|c|c|c|c|}
\hline $\begin{array}{l}108(40 \\
\text { mTBI, } 25\end{array}$ & None & $\begin{array}{l}\text { Eyes closed, resting, } \\
\text { wakeful }\end{array}$ & $\begin{array}{l}\text { mTBI subgroup: } \\
\text { Glasgow coma score }\end{array}$ \\
\hline moderate & & & 13-15; posttraumatic \\
\hline $\begin{array}{l}\text { TBI, } 2 \\
\text { severe TBI) }\end{array}$ & & & $\begin{array}{l}\text { amnesia }<1 \mathrm{~h} \text {; loss of } \\
\text { consciousness }<20 \mathrm{~min}\end{array}$ \\
\hline
\end{tabular}

EEG severity index (discriminant function)

Classification accuracy

mTBI accuracy $=95.08 \%$

Pearson correlation

1. EEG index and neuropsychological performance (various tests) $(p<0.05)$ $t$-Test

1. Mild vs. moderate $(p<0.0001)$

2. Mild vs. severe $(p<0.000001)$

3. Moderate vs. severe $(p<0.00001)$

known to effect EEG results, contrary validation)
1. 204 mTBI subjects vs. 83 controls (94.8\% accuracy)

2. $130 \mathrm{mTBI}$ subjects vs. 21 controls (95.4\% accuracy for $\mathrm{mTBI}, 90.5 \%$ for normals)

3. Test-retest classification accuracy using 93 patients ranged from 77.8 to $92.3 \%$

4. Off-site test with 70 new patients (92.8\% accuracy for TBI patients and $100 \%$ for normals)

Thatcher discriminant score Pearson correlation change (for injured patients) $\quad R^{2}=29.9 \%, p<0.68$ (NS) over 2 weeks

Thatcher discriminant score Pearson correlation change (for injured patients) $\quad R^{2}=48.3 \%, p<0.38$ (NS) vs. number of days from injury to EEG test

\begin{tabular}{|c|c|c|c|c|c|c|}
\hline Thornton (1999) & 32 & 52 & Eyes closed, resting, & Hit head on part of car & Thatcher discriminant (over & Accuracy (79\% for injured group) \\
\hline “Exploratory investigation into mild & & & wakeful & during car accident; loss & 1 year post-injury) & \\
\hline brain injury and discriminant analysis & & & & of consciousness & New high-frequency (up to & Accuracy (89\% for injured group \\
\hline with high frequency bands $(32-64 \mathrm{~Hz}) "$ & & & & $<2 \min$ or none & $64 \mathrm{~Hz}$ ) discriminant & across all time periods; $100 \%$ for \\
\hline Notes: introduces a discriminant & & & & & & injured group within 1 year of injury) \\
\hline function for mTBI based on high & & & & & & False hit rate (normal sample $=52 \%$ \\
\hline frequency frontal coherence $(2945$ & & & & & New high-frequency & Accuracy $=100 \%$ \\
\hline variables). Author acknowledged the & & & & & discriminant plus Thatcher & \\
\hline study as exploratory and preliminary. & & & & & discriminant & \\
\hline Combination of both Thatcher and new & & & & & FP1 position variables & Levene's test for homogeneity of \\
\hline discriminant functions resulted in & & & & & Relative power & variances \\
\hline \multirow[t]{3}{*}{ perfect accuracy } & & & & & Coherence theta & $p<0.05$ for all variables \\
\hline & & & & & Coherence beta 2 & \\
\hline & & & & & Phase beta2 & \\
\hline
\end{tabular}




\begin{tabular}{|c|c|c|c|c|c|c|}
\hline \multirow{2}{*}{$\begin{array}{l}\text { General study information } \\
\text { (spectral analysis) }\end{array}$} & \multicolumn{4}{|c|}{ Study design } & \multicolumn{2}{|r|}{ Results } \\
\hline & $\begin{array}{l}\text { mTBI } \\
\text { group }(n)\end{array}$ & $\begin{array}{l}\text { Control } \\
\text { group }(n)\end{array}$ & $\begin{array}{l}\text { qEEG recording } \\
\text { condition }\end{array}$ & $\begin{array}{l}\text { Criteria for } \\
\text { TBI patient }\end{array}$ & Measures & $\begin{array}{l}\text { Statistical test/ } \\
\text { comparison/significance }\end{array}$ \\
\hline $\begin{array}{l}\text { Trudeau et al. (1998) } \\
\text { "Findings of mild traumatic brain injury } \\
\text { in combat veterans with PTSD and a } \\
\text { history of blast concussion" } \\
\text { Notes: this study provides data that } \\
\text { suggests the Thatcher discriminant } \\
\text { function can be used to differentiate } \\
\text { previous blast-induced mTBI among } \\
\text { veterans suffering from PTSD from } \\
\text { those PTSD patients who did not suffer } \\
\text { a blast mTBI. While the discriminant } \\
\text { function was not able to accurately bin } \\
\text { TBI vs. non-TBI, the sample size was } \\
\text { small and the range in age and } \\
\text { post-injury timeframe was quite large }\end{array}$ & $\begin{array}{l}27 \text { (blast } \\
\text { history) }\end{array}$ & $\begin{array}{l}16 \text { (no-blast } \\
\text { history) }\end{array}$ & Eyes closed, wakeful & $\begin{array}{l}\text { PTSD patient with blast } \\
\text { history (note: control } \\
\text { group also PTSD } \\
\text { patients) }\end{array}$ & $\begin{array}{l}\text { Thatcher discriminant } \\
\text { score }\end{array}$ & $\begin{array}{l}t \text {-Test } \\
\text { Blast group vs. no-blast group } \\
(t=5.4, \mathrm{df}=41, p<0.0001 \text { ) } \\
t \text {-Test } \\
\text { Regrouping of TBI history vs. no-TBI } \\
\text { history ( } t=0.32, \mathrm{df}=41, p=0.75 \text { ) } \\
\text { (NS) } \\
\text { ANOVA } \\
\text { ADHD, other mTBI history, TBI } \\
\text { history, or psychoactive substance } \\
\text { abuse (no significance) }\end{array}$ \\
\hline
\end{tabular}

Prichep et al. (2012a) provides data from a large mTBI group of 633 patients. Although the study design was similar to O'Neil et al. (2012), the project was substantially improved by including comparison to other approaches and improving the complexity of the analysis. For example, Prichep et al. compared the BrainScope discriminant function to a more relevant group of common TBI assessment tools (e.g., military acute concussion evaluation) and inclusion of an "artifact detection module" to minimize EEG noise and artifacts. The discriminant function itself was significantly more complex and includes variables such as spectral analysis measures, information theory-based measures, scale-free brain activity measures, fractal dimension measures, functional connectivity measures, and various multivariate measures. Two algorithms were devised to separate various levels of severity of TBI and specificity was improved compared to O'Neil et al. (2012). Specifically, the new discriminant function was able to differentiate between mTBI and moderate/severe TBI patients with a sensitivity of $80.5 \%$ and a specificity of $73.9 \%$. Positive predictive value was also improved compared to the O'Neil data (85.4\%), but negative predictive value was poorer $(66.5 \%)$. These results indicated the newer BrainScope discriminant function was able to detect mTBI, differentiate it from more severe forms, and decrease incidence of false negative classification. Overall, this paper provides excellent evidence that a well-designed discriminant function may be a serviceable mTBI detection tool.

Leon-Carrion et al. (2008) described another discriminant function not associated with BrainScope. However, this discriminant function, the Seville independence index (SINDI), was built to classify patients according to the level of functional dependence, such as complete dependence, modified dependence, and independence. These classifications are less meaningful for initial detection of injury, but rather are used to predict the level of care required during the rehabilitation phase. The discriminant function comprised nine qEEG variables including four coherence variables, three phase lag variables, one absolute amplitude variable, and one absolute asymmetry variable at specific frequency bands. Accuracy was $100 \%$ for classification between complete dependence $(n=15)$ and independence $(n=14)$, which may correlate with severe TBI and mTBI, respectively. In addition, the SINDI scores correlated well $(p<0.0001)$ with established tests of functional dependence (Functional Independence Measure + Functional Assessment Measure). Overall, this paper reports the qEEG-based discriminant function may be used to predict the level of functional dependence in injured patients, but does not investigate the diagnostic potential of SINDI.

The remaining papers in the literature index present results based on a collection of discriminant functions from the same group. The original discriminant function comprised 20 measures of coherence, phase, amplitude asymmetry, and relative power at various frequency bands (Thatcher et al., 1989). The function was reported to be $>90 \%$ accurate in discriminating mTBI patients (Glasgow coma score 13-15; loss of consciousness $<20 \mathrm{~min}$ ) from healthy controls in a large dataset (total of $608 \mathrm{mTBI}$ patients and 108 controls). It also reported good test-retest accuracy using 93 patients (77.8-92.3\%). The paper, however, has received strong criticism since the TBI patients were on a variety of medications (Nuwer et al., 2005). The same group published another report on another discriminant function that used 16 measures of EEG coherence, phase, and amplitude asymmetry (Thatcher et al., 2001). Notably, none of the measures used in the 2001 study were the same as those in the 1989 study. This discriminant function was able to classify mTBI from moderate TBI with high probability of success $(t$-test, $p<0.0001)$. Overall classification accuracy of mTBI patients from controls was also high (95\%). This study was criticized since it was assumed that medications did not alter EEG, even though such an effect is widely accepted in the field (Nuwer et al., 2005). Nuwer's argument does not, however, question the overall study design or methodology [unlike the criticism leveled against Thatcher et al. (1989)]. The Thatcher et al. (1999) discriminant function was also tested in concert with another 
discriminant function and the authors found the discriminant to maintain reasonable classification accuracy (79\%) over 1 year post-injury. Supplementation with a new high-frequency discriminant function improved accuracy to $100 \%$ in a sample group of 32 mTBI injured patients and 52 controls. Use of the high-frequency discriminant function alone was reported to provide not only high accuracy (89\%) but also a high false hit rate (52\%). These studies also suggest high potential value of using a discriminant function as a mTBI detection tool.

\section{Research gaps and future directions (discriminant functions)}

The primary challenge in the use of discriminant functions with qEEG is in deciding the most appropriate functions to use, which is directly tied to which features are most relevant. The problems here are threefold. First, there are an extremely large number, potentially hundreds, of possible analytic approaches and data features, which could be used as the basis for classification. These range from time-based measures, such as ERPs, to frequency-domain analytics, to more complex time-frequency hybrid features such as cross-channel phase relationships described above. Second, the function or class of functions used for discrimination must be relatively specific to the state being detected, so as to include both a high successful "hit" rate, and decrease as much as possible the occurrence of false-identifications. That is, in the example of mTBI, the functions must be precise enough to discriminate not only the occurrence of mTBI from no trauma but also the occurrence of trauma from other states such as extreme exhaustion, sleepiness, or cognitive fatigue, which may share similar response features. Finally, in most cases discrimination requires either some level of ad hoc adjustment or comparison against a known baseline in order to perform accurately for multiple individuals, due to the high variability between individuals, and between situations. Access to a state considered to be "ground truth" is required. While this is generally not a problem in research, gaming, or repeatedaccess medical applications in which the conditions of detection system can be predicted and controlled, access to the patient will most likely occur only after trauma has occurred.

\section{Summary of analysis (discriminant functions)}

qEEG-based discriminant functions represent a promising solution for detecting mTBI, since the use of multiple measures in the evaluation process improves specificity and sensitivity. Studies with large sample sizes have reported strong discriminatory abilities of discriminant functions (Thatcher et al., 2001; Prichep et al., 2012a). Criticism of earlier studies has been warranted due to the known effects of medication on the EEG, but improved study design of more recent studies (i.e., Prichep et al., 2012a) suggests discriminant functions may be considered highly valuable mTBI detection tools.

\section{ADDITIONAL MEASURES NOT REPRESENTED IN THE DOWN SELECTED qEEG LITERATURE}

Additional EEG-related technologies not represented in the original literature search are also relevant to mTBI detection and deserve consideration here. Many of these technologies are based on newer mathematical analysis techniques not previously investigated with respect to mTBI. Relevant technologies include assessment using ERPs, information dynamics, symbolic dynamics, analysis of causal relationships, and graph theory. Each technology is introduced below and includes a summary of the available evidence for mTBI detection utility based on additional literature reviews.

\section{EVENT-RELATED POTENTIALS}

Event-related potentials are stereotyped responses to a discrete sensory, cognitive, or motor event. An ERP is distinguished from an evoked potential (EP) by having a longer latency and in being altered by the cognitive significance of the stimulus to the subject. EPs may be referred to as "exogenous" because they are strongly dependent on the physical properties of the stimulus being used to elicit the response (e.g., auditory vs. visual stimulation). Conversely, ERPs may be described as "endogenous" in nature because, although they are also related to some external event, they are heavily influenced by higher level cognitive processes and are less dependent on the stimulus modality or physical characteristics of the stimulus. Can ERPs reliably diagnose mTBI? Gaetz and Bernstein (2001) reviewed the use of ERPs in the assessment of traumatic brain injury. Specifically, they considered alterations in the amplitudes and latencies of well characterized components of ERPs, for example, the P3, as indicators of injury. They concluded:

Visual P3 latency seems to be the most sensitive electrophysiologic procedure covered in this review. All studies using this technique to assess $\mathrm{mTBI}$ have found differences in P3 latency compared with normal controls. In addition, the P3 word technique may be very useful for the simultaneous assessment of PTSD, malingering, and brain injury. This procedure seems to be sensitive to injury while resistant to false positives when a $2.5 \mathrm{SD}$ normal limit is used.

and,

An electrophysiologic assessment battery may be the most effective method to detect differences in MTBI subjects who experience cognitive dysfunction.

In addition, Lew et al. (2006) also suggested that "longer latency ERP components hold promise in predicting recovery of higher cognitive functions." Since deficits in emotional processing may be an element in the clinical presentation of TBI, ERP investigations using emotionally valenced stimuli (Catani, 2003; Lew et al., 2005b; Solbakk et al., 2005) may be particularly informative with this patient population.

There are, however, two notable caveats that are unique to the collection of ERPs. First, because responses are analyzed in respect to the occurrence of a specific event, there is a necessity for a more complex data acquisition system than in the passive collection of qEEG data (Spencer, 2005). Specifically, a secondary device, system, or method must be available to provide the stimulus used to drive the ERP (examples include a PC and monitor, audio amplifier, LED driver, or vibrotactile stimulator). The stimulation device must be very tightly coordinated with the EEG data acquisition system (on a sub-millisecond time scale), so that accurate time-locking of the ERP to the original event(s) can be achieved. While this level of integration is not technically challenging, it adds bulk, complexity, and additional use effort on behalf of the device operator and requires special EEG acquisition hardware, 
which is designed for integration with other devices. It should be noted, however, that ERPs may be used in clinical settings with fairly minimalistic equipment.

A second caveat of ERPs that stems from the reliance upon a stimulation paradigm is the intimate, but somewhat limiting, specificity between the stimulus used and the type of brain activity, which will occur in response to that event. By definition, the response elected by an ERP is related to a specific event, and (in a good paradigm) will include response only to that event, because of the extreme complexity and high specificity of various sensory regions of the brain. For example, at least in a normal healthy brain, auditory-evoked-potentials will not activate the occipital cortex (which is primarily dedicated to vision), while visual-evokedpotentials tend to be isolated to this very region. As a result, the type of paradigm used to elicit ERPs is critical to their understanding and analysis, and leaves opportunity for abnormalities in other, non-stimulated brain regions to be overlooked. In the case of mTBI, which can manifest in a wide variety of manners and stem from many possible neurophysiological dysfunctions, it is a substantial challenge to identify a single paradigm, which might be sufficient to cover all, or even the majority of potential cases.

Besides the studies referenced above, a large number of other published reports have obtained ERPs from TBI patients (Table 6). However, the collective experience does not yet provide a definitive answer as to whether ERP is an accurate diagnostic tool (Rapp and Curley, 2012). To date, the examination of ERPs obtained from TBI patients has been limited to reports of differences in amplitude and latencies of identified components of the ERP.

\section{ADVANCED SIGNAL PROCESSING TECHNOLOGIES}

This section provides evidence that the clinical utility of qEEG may be advanced significantly by expanding the set of measures that are computed from EEG signals. The mathematical field of dynamical systems theory has expanded dramatically during the past 30 years. Research activity is continuing and, indeed, accelerating. To date, the application of these new methods has been mostly confined to the analysis of physical and financial systems. These methods have not yet received systematic application in EEG. Four areas are particularly promising: information dynamics, symbolic dynamics, measures of causal relationships, and measures of network dynamics derived from graph theory.

\section{Information dynamics}

A digitized EEG signal is a sequence of voltage measurements. As classically defined, the Shannon entropy (Shannon, 1948) of this signal is insensitive to the sequential order of the voltage measurements. That is, if the voltage measurements are randomly shuffled, the same value of Shannon entropy will be obtained. Kolmogorov $(1958,1959)$ and Sinai (1959) extended the concept of entropy by constructing a generalization of the original concept that quantifies the sequential structure of a signal. Kolmogorov-Sinai (K-S) entropy has been described as the rate at which a system generates information (Eckmann and Ruelle, 1985), which may also be considered the central function of the CNS. K-S entropy and related measures provide the mathematical foundation of information dynamics (Deco and Schürmann, 2001). While K-S entropy is a
Table 6 | Index of ERP studies of traumatic brain injury

\begin{tabular}{lll}
\hline $\begin{array}{l}\text { Arciniegas and Topkoff } \\
\text { (2004) }\end{array}$ & $\begin{array}{l}\text { Gaetz and Weinberg } \\
\text { (2000) }\end{array}$ & Olbrich et al. (1986) \\
Arciniegas et al. (2005) & Gaetz and Bernstein & Onofrj et al. (1991) \\
& (2001) & \\
Baguley et al. (1997) & Geisler et al. (1999) & Papanicolaou et al. (1984) \\
Bennouna et al. (2007) & Giaquinto (2004) & Perlstein et al. (2006) \\
Broglio et al. (2009) & Gosselin et al. (2006) & Polo et al. (2002) \\
Campbell et al. (1986) & Gosselin et al. (2011) & Pontifex et al. (2009) \\
Campbell et al. (1990) & Gosselin et al. (2012) & Potter and Barrett (1999) \\
Campbell and DeLugt & Heinze et al. (1992) & Potter et al. (2001)
\end{tabular}

(1995)

Catani (2003)

Kaipio et al. (1999)

Potter et al. (2002)

Chen et al. (2006a)

Kaipio et al. (2001)

Pratap-Chand et al. (1988)

Clark et al. (1992)

Cremona-Meteyard and Geffen (1994)

Curry (1980)

Kane et al. (1996)

Keren et al. (1998)

Rappaport et al. (1990)

Reinvang (1999)

Lachapelle et al.

(2008)

Curry et al. (1986)

Lavoie et al. (2004)

Reinvang et al. (2000)

Deacon-Elliott and

Lew (2001)

Reuter and Linke (1989)

Campbell (1987)

Deacon-Elliott et al.

Lew (2005)

Rizzo et al. (1978)

(1987)

Deacon et al. (1991)

Lew et al. (1999)

Rugg et al. (1988)

Deacon et al. (1991)

Lew et al. (2002)

Rugg et al. (1993)

De Beaumont et al.

Lew et al. (2003)

Sangal and Sangal (1996)

Segalowitz et al. (1992)

(2007a)

De Beaumont et al.

Lew et al. (2004)

Segalowitz et al. (1997)

(2007b)

De Beaumont et al.

Lew et al. (2005a)

Segalowitz et al. (2001)

(2009)

di Russo and Spinelli

Lew et al. (2005b)

Solbakk et al. (1999)

(2010)

Drake and John (1987)

Lew et al. (2008)

Solbakk et al. (2000)

Duncan et al. (2003)

Lew et al. (2006)

Duncan et al. (2005)

Lew et al. $(2007 a, b)$

Dupuis et al. (2000)

Mazzini (2004)

Dywan and

Mazzini et al. (1999)

Segalowitz (1996)

Elting et al. (2008)

Mazzini et al. (2001)

Folmer et al. (2011)

Münte and Heinze (1994)

Ford and Khalil (1996a) Olbrich et al. (1986)

Solbakk et al. (2002)

Solbakk et al. (2005)

Spikman et al. (2004)

Unsal and Segalowitz

(1995)

\section{Viggiano (1996)}

von Bierbrauer and Weissenborn (1998)

Wang et al. (2004)

Ford and Khalil (1996b) Onofrj et al. (1991)

Werner and Vanderzant (1991)

Gaetz et al. (2000)

Papanicolaou et al.

(1984)

Perlstein et al. (2006) 
limiting process requiring, by definition, an infinite amount of data, it is possible to construct approximations computed with finite data sets. The most commonly utilized approximations are approximate entropy (Pincus, 1991) and sample entropy (Richman and Moorman, 2000). Approximate entropy and sample entropy have been used to quantify EEG records (Bruhn et al., 2000; Abásolo et al., 2005; Sabeti et al., 2009; Yuan et al., 2011; Yun et al., 2012), heart interbeat interval sequences (Pincus and Goldberger, 1994; Ho et al., 1997), and human postural sway data (Ramdani et al., 2009). Insofar as we know, they have not been used in the analysis of EEGs obtained from TBI patients.

A variant of sample entropy is multiscale entropy (Costa et al., 2002). The original time series is used to construct a sequence of coarse-grained time series. The Scale 2 time series is obtained by averaging every two values. The Scale 3 time series is obtained by averaging every three values, and so on. The sample entropy is calculated for each time series to produce entropy as a function of temporal scale. The procedure was originally applied to the analysis of heart interbeat interval sequences and was found to discriminate between healthy controls and patients presenting congestive heart failure, atrial fibrillation or advanced age (Costa et al., 2002, 2005). The same method has been used in the analysis of EEG signals to discriminate between control participants and those with autism spectrum disorder (Bosl et al., 2011; Catarino et al., 2011), Alzheimer's disease (Park et al., 2007; Mizuno et al., 2010), schizophrenia (Takahashi et al., 2010), and Parkinson's disease (Chung et al., 2013) patients. Insofar as we know, multiscale entropy has not been used to analyze EEG records obtained from TBI patients. The approach was, however, used to analyze intracranial pressure records obtained from TBI patients where it was found that multiscale entropy correlates with outcome.

There are technical issues associated with estimation of multiscale entropy that require attention. Nikulin and Brismar (2004) argued (in our view, correctly) that the scaling length in the embedding space used to calculate sample entropy should be adjusted with the temporal scale of the time series. In their calculations with simulated data, the temporal scale dependence of entropy was lost when this modification was introduced. Costa et al. (2004) replied and argued that in the case of the heart interbeat interval data analyzed in their paper, scale dependence is preserved. Wu et al. (2013) noted that the coarse graining procedure used in Costa et al. (2002), and in other papers using the method, reduces the length of the data set with each increase in temporal scale length. Substituting a moving average retains much of the multiscale characteristics of the original implementation of multiscale entropy without introducing the loss of reliability that results from attempting entropy calculations with small data sets. Systematic validation calculations are required to confirm this assertion.

\section{Symbolic dynamics}

As will be seen, the terms entropy and complexity lose specificity, rather than gain it, as a function of time. Complexity measures derived from symbolic dynamics share the important property of sequence sensitivity with $\mathrm{K}-\mathrm{S}$ entropy and its variants. As the term complexity is used here, there is a fundamental difference between symbolic dynamic measures and K-S entropy. Approximate entropy and sample entropy are computed directly from the voltage values. In the case of symbolic dynamic measures, the original sequence of voltages is converted to a symbol sequence. Complexity is a measure of the orderliness or lack of orderliness of this symbol sequence. The procedure for converting voltages to a symbol sequence can be simple. For example, the symbol " $\mathrm{A}$ " is entered into the sequence if the value of the voltage is greater than the median or the symbol " $\mathrm{B}$ " is entered if the voltage value is less than the median (note that the use of the median, rather than the mean, is statistically important). More elaborate procedures for generating a symbol sequence from a voltage are possible. A complicating clarification must be introduced, while the immediate emphasis here is on measures computed from symbol sequences, some of these measures, such as mutual information, can be recast in versions that utilize continuous variables such as voltages. Sequence sensitive measures of symbol sequences include topological entropy (Crutchfield and Packard, 1983), metric entropy [also in Crutchfield and Packard (1983)], forbidden word entropy (D'Alessandro and Politi, 1990), context free grammar complexity (Jiménez-Montanó, 1984), Lempel-Ziv complexity (Lempel and Ziv, 1976), mutual information (Gallager, 1968; Cellucci et al., 2006), $n$-th order entropy (Ebeling, 1997), and conditional entropy (Steuer et al., 2001).

Xu et al. (1994) found that the forbidden word complexity of EEG data is sensitive to the participant's behavioral state (e.g., eyes open vs. eyes closed recording conditions), mental load, and sleep stage. Watanabe et al. (2003) found that EEG Lempel-Ziv complexity changes in response to work load and eyes open vs. eyes closed recording conditions. Symbol sequence complexity measures have also been used in the analysis of clinical EEG records including assessment of schizophrenia and depression (Li et al., 2008; Sabeti et al., 2009), diagnosis of Alzheimer's disease (Abásolo et al., 2006), anesthetic depth (Fan et al., 2011), and seizure detection (Hu et al., 2006). Our limited literature review on symbolic dynamics did not locate papers using these methods in the analysis of EEG data obtained from TBI patients.

\section{Analysis of causal relationships}

The measures of functional connectivity described in Section "Functional Connectivity Measures" are used to establish the degree of association between two simultaneously recorded signals. However, these measures are insensitive to the direction of information movement. Measures of causal relationship extend the analysis of functional connectivity by addressing directionality. The operationalization of causality that was used to construct mathematical measures of directionality was published by Wiener in 1956 (Wiener, 1956). Stated simply, if measuring Signal A improves the prediction of Signal B, then the process generating Signal A is, to some degree, a causal driver of the process generating Signal B. This relationship is not necessarily unidirectional, as measuring Signal B may also improve the prediction of Signal A. The relative magnitude of these relationships can be used to define net information flow.

Mathematical methods of assessing the direction of information movement fall into four groups: linear regression methods (Granger, 1969; Sims, 1972; Kaminski et al., 2011), information theory methods (Kaneko, 1986; Vastano and Swinney, 1988; Schreiber, 2000), frequency-domain methods (Baccalá and 
Sameshima, 2001; Nolte et al., 2008), and methods constructed with embedded data (Rulkov et al., 1995; Le Van Quyen et al., 1998, 1999; Arnhold et al., 1999).

There is a prior literature describing the application of these methods to scalp EEG signals (Inouye et al., 1983, 1993; Mars and Lopes da Silva, 1983; Mars et al., 1985; Hesse et al., 2003; Chen et al., 2006b). It would seem plausible to speculate that TBI alters network relationships, and that post-injury alterations of information flow direction would provide a sensitive assessment of CNS damage. Unfortunately, this optimistic anticipation has not been realized. To this end, several problems must be addressed. The first set of difficulties is specific to EEG analysis. Haufe et al. (2011) showed that because of volume conduction, all EEG channels drive each other. Their simulations indicate that Granger causality used with the usual statistical tests can lead to spurious relationships. The same authors subsequently constructed procedures that can, to a degree, address these difficulties (Haufe et al., 2013). The second set of difficulties exists independently of the special problems associated with EEG. Namely, mathematical analysis shows that spurious identifications of causality can occur (He and Maekawa, 2001; Breitung and Swanson, 2002; Albo et al., 2004).

An additional complication should be considered: causal relationships are not static. Consider two processes, Process A and Process B. Suppose that Process A is a strong causal driver of Process $\mathrm{B}$ from time $t_{0}$ to time $t_{1}$. Now suppose this relationship reverses and Process $B$ is a strong driver of process $A$ from time $t_{1}$ to time $t_{2}$. If the analysis is conducted over time $t_{0}$ to time $t_{2}$, evidence of any causal relationship may be lost. Therefore, the identification of transitions between domains of dynamical behavior is a first step in causal analysis. The identification of transitions between different dynamical regimes is not, however, as straightforward as one might suppose, and this characteristic difficulty is particularly true of EEG data. While noise contamination can be a main cause, the problem can be more subtle. For example, transitions in CNS activity form a temporal hierarchy (Kiebel et al., 2008; Perdikis et al., 2011a,b; Papo, 2013), and a transition that is dynamically significant on a time scale of $1 \mathrm{~s}$ may not be significant on a time scale of $1 \mathrm{~min}$ (Rapp et al., 2013b). Causal relationships will show similar time-scale dependence. Therefore, as is often the case, the translation of an elegant mathematical concept to practical application in EEG can be more difficult than initially anticipated.

\section{Graph theory}

Viewed mathematically, a network is a collection of nodes and edges (lines). When applied to EEG, the nodes are electrodes and the edges are the connections between them. There are three possible characterizations of edges. In the simplest case, the edge is either present or absent. This is implemented by selecting a connectivity measure from the previously described measures and selecting a threshold. A connection between two electrodes is deemed to be present if the connectivity measure's value exceeds the threshold and absent if the value is less than the threshold. A second possible characterization of an edge is a weighted edge where the strength of the connection between two electrodes is determined by the value of the selected connectivity measure. The third characterization of an edge is the directed edge where, in
Table 7 | Studies reporting altered network geometries in neuropsychiatric disorders.

\begin{tabular}{ll}
\hline Disorder/dysfunction & Relevant publications \\
\hline Alzheimer's disease & Stam et al. (2007) \\
CNS tumor & Bartolomei et al. (2006) \\
Depression & Leistedt et al. (2009), Park et al. (2014) \\
Epilepsy & Bernhardt et al. (2011), Ponten et al. (2007), \\
& van Dellen et al. (2009) \\
Schizophrenia & Li et al. (2008), Rubinov et al. (2009) \\
Traumatic brain injury & Cao and Slobounov (2010), Castellanos et al. \\
& (2011a), Castellanos et al. (2011b), Nakamura \\
& et al. (2009), Tsirka et al. (2011), Zourdakis \\
& et al. (2011), Irimia et al. (2013a), Irimia et al. \\
& (2013b), Goh et al. (2014)
\end{tabular}

addition to a weighting, the direction of information transfer is determined using a causality measure.

Once the geometry of the network has been determined, it is possible to use the methods of graph theory to provide a concise, quantitative description. The most commonly employed metrics are the clustering coefficient and the path length (Watts and Strogatz, 1998). The validity of these measures in characterizing the CNS is suggested by Smit et al. (2008). The investigators examined EEG records from 574 monozygotic or dizygotic twins and found that $46-89 \%$ of individual differences in the clustering coefficient and $37-62 \%$ of individual differences in path length are heritable. Alterations of network geometries as determined by EEG, magnetoencephalography (MEG), or MRI have been found in clinical populations, including TBI patients (Table 7).

Once again, however, initial enthusiasm must be tempered by analyses showing spurious identifications of network properties. Bialonski et al. (2011) examined binary networks (an edge is either present or absent) constructed by a simple threshold criterion. These results suggest that "small world" topologies in networks constructed from empirical data "may be partly or solely due to finite length and frequency content of time series." They suggest that random networks constructed from surrogate data may provide important comparisons for results obtained from multichannel EEG [surrogate data calculations are an important statistical procedure for validating the results obtained with experimental data, Theiler et al. (1992), Prichard and Theiler (1994)]. It should be noted, however, that inappropriately constructed surrogates can result in the false-positive rejection of the surrogate null hypothesis, that is, the procedure can indicate the presence of deterministic non-linear structure in a signal constructed from linearly filtered random numbers (Rapp et al., 2001). Blinowska and Kaminski (2013) found that networks constructed from adirectional measures (correlation, coherence, mutual information, synchronization likelihood, transfer entropy) can result in spurious correlations. Indeed, they report that spurious correlations can outnumber true correlations. Giving all connections an equal weight (a binary network) exacerbates this problem. They recommend directional, causally dependent measures 
(directed transfer function, partial directed coherence), but as noted above volume conduction in the CNS introduces significant problems when directional measures are applied to EEG signals.

\section{DISCUSSION}

\section{CONTROVERSY WITHIN THE qEEG FIELD}

The earlier literature describing the application of qEEG technologies in the assessment of TBI has been marked by strident disagreement. In 1989, Thatcher et al. published a study based on EEG records obtained from 608 patients with mTBI and 108 healthy control participants. In this study, qEEG-derived measures discriminated between the two groups with a sensitivity of $96.6 \%$ and specificity of $89.1 \%$ (as outlined presently, the reports of specificity require reconsideration). Subsequently, the same group constructed a qEEG-based Severity Index of TBI and obtained a sensitivity of $95.5 \%$ and specificity of $97 \%$ (Thatcher et al., 2001).

In 1997, in part in response to the Thatcher et al. (1989) report, a highly critical review of clinical qEEG was published (Nuwer, 1997). Nuwer concluded "on the basis of current clinical literature, opinions of most experts, and proposed rationales for their use, qEEG remains investigational for clinical use in post-concussion syndrome, mild or moderate head injury, learning disability, attention disorders, schizophrenia, depression, alcoholism, and drug abuse..." Nuwer continued, "Because of the very substantial risk of erroneous interpretations, it is unacceptable for EEG brain mapping or other qEEG techniques to be used clinically by those who are not physicians highly skilled in clinical EEG interpretation."

Vigorous responses to the 1997 Nuwer paper were published by Thatcher et al. (1999), and by Hoffman et al. (1999). The Nuwer paper has been an element in court actions, for example, County Court at Law No. 1, Travis County Texas, Cause No. 227,520. As summarized by Thatcher et al. (2003), the judge in the Travis County case admitted qEEG evidence in a TBI case and denied admission of the 1997 Nuwer paper (see also Zawski v. Giggs). In 2005, Nuwer et al. returned to the subject and focused specifically on the application of qEEG in the assessment of TBI. Nuwer et al. concluded that "overall the disadvantages of qEEG panels and diagnostic discriminants presently outweigh the advantages of these studies in the diagnosis of MTBI." In spite of this assessment, qEEG as a potential TBI detection tool has still received a great deal of attention since Nuwer's 2005 paper. This more recent research argues against an unreservedly negative assessment of qEEG utility. Indeed, while the evidence supporting the sole use of qEEG (as defined by the TWG) for the assessment of mTBI is weak it would be unwarranted to conclude that EEG is not a valued metric in the search for the proper assessment protocol for mTBI. Upon expansion of the definition of " $\mathrm{qEEG"} \mathrm{to} \mathrm{include}$ other EEG-based datasets (e.g., ERPs and EPs), EEG will most likely be a necessary component of any assessment protocol for mTBI. In addition, evidence suggests that the value of qEEG in the assessment of mTBI will increase as the methods used in the analysis of these signals become more sophisticated.

Evidence supporting the value of more elegant analysis procedures for EEG in the assessment of mTBI comes in part from McCrea et al. (2010), Prichep et al. (2012a,b), and Tsirka et al. (2011). Prichep et al. (2012a,b) and McCrea et al. (2010) used a modest EEG montage to collect short epochs of EEG that were subjected to rigorous artifact detection algorithms: traditional and non-traditional univariate and multivariate analysis procedures that feed into an informed data reduction protocol. This protocol controls for replicability, over-fitting, and cross-validation of metrics. In addition, we see the value of integration of various demographic, neurocognitive, and self-report datasets along with the physiological datasets to achieve increased sensitivity and specificity for assessment of mTBI. Tsirka et al. (2011) adds positive assessment value to this approach by using small world network metrics, which utilize mean power analysis, and synchronization likelihood parameters to assess suboptimal network organization in EEGs obtained from mTBI victims.

\section{SPECIFICITY OF EEG BASED mTBI DETECTION}

Published reports suggest that dynamical measures calculated from EEGs are altered following TBI, that is, the sensitivity of these measures to TBI is supported. Reports of high specificity must, however, be interpreted with care. While high specificities have been obtained in carefully constructed clinical studies, which compare TBI patients against healthy control participants, dynamical measures calculated from EEG records thus far are not specific to TBI. This lack of specificity is indicated by the results summarized in Table 8. Altered EEG synchronization is observed following traumatic brain injury, but it is also observed in most neuropsychiatric disorders. Therefore, while it may be possible to discriminate between TBI patients and healthy individuals using these measures alone, it will probably not be possible to discriminate between TBI and depression, schizophrenia, or several other clinical conditions.

Importantly, the absence of specificity does not preclude clinical utility of qEEG as an evaluation tool. Non-specific measures are particularly important in longitudinal assessment. The classical example is body temperature. Fever is non-specific, but body temperature is nonetheless a central clinical measure. Nevertheless, an important technical point on reliability must be emphasized here. Temperature would not be an effective longitudinal measure if it varied randomly between $85^{\circ}$ and $105^{\circ}$. Stated differently, meaningful longitudinal application requires acceptable test-retest reliability. To date, very few test-retest reliability studies of dynamical measures calculated from EEGs have been published. Thus, systematic test-retest determinations in healthy participants are essential next steps in the construction of a clinically useful qEEG technology.

\section{RELIABILITY OF qEEG MEASURES}

The reliability of quantitative EEG measures is crucial to their clinical utility. This has been recognized at least since the pioneering work of Kennard and Schwartzman (1957). Nonetheless, test-retest reliabilities are not typically reported and this deficiency is a significant factor limiting the widespread application of qEEG. EEG reliabilities depend on the electrode site(s), the kind of electrode technology used, the frequency band, sampling frequency, the resolution of the digitizer, the duration of the recording epoch, the behavioral task implemented during the recording, the qEEG measure computed, the procedure used to compute it, and the retest interval. Additionally, there has been 
Table 8 | Studies reporting altered synchronization of EEGs in various neuropsychiatric disorders

\begin{tabular}{|c|c|}
\hline Disorder/dysfunction & Relevant publications \\
\hline AD/HD & Barry et al. $(2002,2003,2005)$ \\
\hline Alcohol abuse & Georgopoulos et al. (2007), Kamarajan et al. (2005) \\
\hline Alexithymia & Matsumoto et al. (2006), Symond et al. (2005) \\
\hline Autism & Grice et al. (2001), Just et al. (2004), Orekhova et al. (2007), Rippon et al. (2007), Welsh et al. (2005), Wickelgren (2005) \\
\hline Bipolar disorders & O’Donnell et al. (2004) \\
\hline Dementia & $\begin{array}{l}\text { Adamis et al. (2005), Adler et al. (2003), Brunovsky et al. (2003), Georgopoulos et al. (2007), Koenig et al. (2005), } \\
\text { Leuchter et al. (1987), Prichep et al. (2006), Stam et al. (2003) }\end{array}$ \\
\hline Depression & Armitage et al. (1999), Lee et al. (2007), Linkenkaer-Hansen et al. (2005), Llinás et al. (1999), Park et al. (2007) \\
\hline Hallucinations & Baldeweg et al. (1998) \\
\hline HIV dementia & Fletcher et al. (1997) \\
\hline Migraine & Angelini et al. (2004) \\
\hline Multiple sclerosis & Georgopoulos et al. (2007) \\
\hline $\begin{array}{l}\text { Neuropsychiatric disorders: } \\
\text { general reviews }\end{array}$ & $\begin{array}{l}\text { Herrmann and Demiralp (2005), Llinás et al. (1999), Schnitzler and Gross (2005), Stam et al. (2003), Stam (2005), } \\
\text { Uhlhaas and Singer (2006) }\end{array}$ \\
\hline Parkinson's disease & Akbari and Gharibzadeh (2009), Levy et al. (2000), Raz et al. (2000), Stoffers et al. (2007) \\
\hline Post-traumatic stress disorder & Kolassa and Elbert (2007) \\
\hline $\begin{array}{l}\text { Schizophrenia and other } \\
\text { psychotic disorders }\end{array}$ & $\begin{array}{l}\text { Basar-Eroglu et al. (2009), Bob (2007), Bob et al. (2008), Breakspear et al. (2004), Brenner et al. (2003), Bressler } \\
\text { (2003), Cho et al. (2006), Ferrarelli et al. (2012), Ford and Mathalon (2005), Ford et al. (2007, 2008), Georgopoulos et al. } \\
\text { (2007), Green et al. (1999), Hirano et al. (2008), Koukkou et al. (1995), Kwon et al. (1999), Lee et al. (2003a,b), Lewis } \\
\text { et al. (1999, 2005), Light et al. (2006), Pinault (2008), Ramos-Loyo et al. (2009), Rockstroh et al. (2007), Roopun et al. } \\
\text { (2008), Siegel et al. (2006), Spencer et al. (2003), Spencer et al. (2004, 2008a,b), Spencer and McCarley (2006), } \\
\text { Symond et al. (2005), Tononi and Edelman (2000), Uhlhaas and Singer (2006), Uhlhaas et al. (2008), van der Stelt and } \\
\text { Belger (2007), Vierling-Claassen et al. (2008), Whittington (2008), Williams et al. (2008), Winterer et al. (2000) }\end{array}$ \\
\hline Traumatic brain injury & $\begin{array}{l}\text { Dockree et al. (2004), Hoffman et al. (1995), Kumar et al. (2009a,b), Roche et al. (2004), Slewa-Younan et al. (2002), } \\
\text { Thatcher et al. (1999, 2001), Thatcher (2000, 2006) }\end{array}$ \\
\hline
\end{tabular}

no agreement in the literature concerning the choice of statistical measure used to quantify EEG reliability. Measures that have been used in EEG studies include Cornbach alpha (Burgess and Gruzelier, 1993; Lund et al., 1995), rank correlation (Gasser et al., 1985; Van Albada et al., 2007), intraclass correlation coefficient (Fein et al., 1983; Tomarken et al., 1992; Gudmussen et al., 2007; Ambrosius et al., 2008; Gram et al., 2014), Pearson correlation coefficient (Fein et al., 1984; Salinsky et al., 1991; Tomarken et al., 1992; Kondacs and Szabo, 1999), Fisher's $r$ (Pollock et al., 1991), two-way analysis of variance (Sloan and Fenton, 1993), coefficient of variation (Maltez et al., 2004; Fingelkurts et al., 2006), and the coefficient of determination (Fingelkurts et al., 2006). This diversity of statistical analysis has made it impossible to obtain a clear understanding of the reliability of many qEEG measures.

We recommend using the intraclass correlation coefficient to report test-retest reliability. Several considerations have motivated this recommendation including the intraclass correlation coefficient's immediate relationship to the standard error of measurement and the minimal detectable difference. These variables in turn help inform the identification of the minimal clinically important difference, where it is explicitly recognized that clinical significance is determined only in part by statistical significance (Jaeschke et al., 1989; Crosby et al., 2003).
Important conditions should be met when using the intraclass correlation coefficient in reliability studies. This is not a single measure but a class of measures. Shrout and Fleiss (1979) constructed six intraclass correlation measures and McGraw and Wong (1996) constructed ten. The choice of intraclass correlation coefficient is crucial to the analysis. Depending on the formula used, large differences in the numerical value of the coefficient can be obtained with the same data. Guidelines for the choice of appropriate statistical model for a given study, and hence the choice of the appropriate intraclass correlation coefficient, are given in Müller and Büttner (1994) who included a decision tree to summarize the selection process. As noted by Krebs (1986), it is therefore essential to identify the form of coefficient when reporting results. A specification of the coefficient's confidence interval is also a critical element in the data report (Stratford, 1989). Identification of the confidence interval is important because the interval must be considered when interpreting the coefficient. For example, Morrow and Jackson (1993) have shown that a high value of the coefficient, which suggests that the measure is reliable, can have a large confidence interval, which argues against this interpretation. Donner and Wells (1986) provide a comparison of procedures for constructing confidence intervals for the coefficient. We suggest the Wald method that was used by Zou (2012) to construct an 
algorithm for estimating the sample size required in studies that use the intraclass correlation coefficient as the statistical measure of reliability.

Two additional issues should be considered in reliability studies. First, reliability is population dependent. A measure that presents adequate reliability in one population may fail to do so in a different population. Examples are found in a study of EEG reliability (Lund et al., 1995) comparing healthy controls and schizophrenics and in a study by Fein et al. (1983) that compared EEG reliabilities obtained with healthy controls and dyslexic participants. Population-dependent determination of reliability is particularly important in the investigation of traumatic brain injury because it has long been recognized that high variability is a characteristic of an injured CNS (Head, 1926; Bleiberg et al., 1997). Second, distributions presented by EEG measures can be markedly non-normal (Gasser et al., 1982). Non-normal distributions can reduce test-retest reliability (Dunlap et al., 1994). Van Albada and Robinson (2007) have shown that a transformation to a near normal distribution can improve EEG test-retest reliability.

\section{CONCLUSION AND RECOMMENDATIONS ELECTROPHYSIOLOGICAL ASSESSMENT AND mTBI DETECTION}

Based on our critical evaluations of qEEG as an mTBI assessment tool, the following general conclusions are made:

1. qEEG provides, at best, an imperfect assessment of mTBI. The published literature does indicate, however, that it can be an important complement to other assessment procedures.

2. TBI is not a discrete clinical entity. Different injury events can initiate very different pathophysiological processes. It follows that, just as there is not a single test for cancer, there is not a single test for TBI.

3. Reports of high specificity of qEEG evaluations of TBI must be interpreted with care. High specificities have been reported in carefully constructed clinical studies in which healthy control participants were compared against a carefully selected TBI population. The published literature indicates, however, that similar abnormalities in qEEG measures are observed in other neuropsychiatric disorders. While it may be possible to distinguish a clinical patient form a healthy control with this technology, these measures are unlikely to discriminate between, for example, major depressive disorder, bipolar disorder, or TBI. The specificities observed in these clinical studies may well be lost in real world clinical practice.

4. The absence of specificity does not preclude clinical utility. Efficacy as a longitudinal clinical measure does, however, require acceptable test-retest reliability. To date, very few test-retest reliability studies have been published with qEEG data obtained from TBI patients. This is a particular concern because high variability is a known characteristic of the injured CNS.

5. Specific measures and analysis methods were qualitatively assessed based on the degree of testing in mTBI patients, the usefulness for mTBI detection as a unique entity, and the usefulness as a component in a discriminant function for mTBI detection. Table 9 provides a summary of our findings. For example, spectral analysis has been tested extensively in mTBI
Table 9 | Summary of TWG conclusions on electrophysiological measures for $\mathrm{mTBI}$ detection $(0<1<2<3<4)$.

\begin{tabular}{|c|c|c|c|}
\hline $\begin{array}{l}\text { Measure/ } \\
\text { analysis method }\end{array}$ & $\begin{array}{l}\text { History of } \\
\text { testing } \\
\text { in } \mathrm{mTBI} \\
\text { patients }\end{array}$ & $\begin{array}{l}\text { Usefulness } \\
\text { for mTBI } \\
\text { detection } \\
\text { as a unique } \\
\text { entity }\end{array}$ & $\begin{array}{l}\text { Usefulness } \\
\text { for } \mathrm{mTBI} \\
\text { detection as part } \\
\text { of a discriminant } \\
\text { function }\end{array}$ \\
\hline Spectral analysis & 4 & 0 & 2 \\
\hline Connectivity measures & 3 & 1 & 3 \\
\hline ERPs & 4 & 2 & 4 \\
\hline Information dynamics & 0 & Unknown ${ }^{a}$ & Unknown ${ }^{a}$ \\
\hline Symbolic dynamics & 2 & 3 & Unknown ${ }^{a}$ \\
\hline $\begin{array}{l}\text { Analysis of casual } \\
\text { relationships }\end{array}$ & 2 & 2 & Unknown ${ }^{a}$ \\
\hline Graph theory & 1 & 3 & Unknown ${ }^{a}$ \\
\hline
\end{tabular}

anknown, but high perceived potential.

patients, but its usefulness as a mTBI detection tool (in isolation) is low. The usefulness of spectral analysis as a component in a discriminant function, however, is more promising. Note that some methods require additional investigation before qualitative scores of usefulness can be assigned, but the TWG considers the methods to hold considerable promise.

\section{RECOMMENDATIONS FOR RESEARCH AND CONTINUED ADVANCED DEVELOPMENT}

The qEEG TWG recommends the following actions to best advance qEEG and other electrophysiological assessment methods as mTBI detection tools:

1. Reliability in a healthy population is a necessary, but not sufficient, property of a useful clinical measure. Systematic testretest reliability studies of qEEG measures should be conducted as the first step in the rigorous development of a clinical qEEG technology. Reliability must be established for each candidate measure.

2. We define the clinical validity of a measure as its ability to discriminate between a clinical population and healthy controls and, ideally, its ability to discriminate between different clinical populations. For any given measure, systematic validity studies are required once reliability has been established as outlined in the first recommendation. In the first instance, these studies should compare results obtained with well characterized TBI patients and healthy controls. If the results of these studies are positive, they can be expanded to include other psychiatric populations.

3. Evidence indicates that ERPs can identify abnormalities in cases where EEGs alone are non-disclosing. It should be noted that the same signal amplifiers are used for EEGs and ERPs. Thus, there is no technical barrier to incorporating ERP measurements in an EEG evaluation, as long as careful considerations are made to ensure precise time-locking between stimulus and recording instrumentation. Reliability and validity evaluations must also be performed with ERP-derived measures. 
4. The mathematical methods used in signal analysis in other application areas have expanded enormously during the past 30 years. Important growth areas include non-linear dynamical analysis, complexity measures, analysis of causal interactions, graph theory, and information dynamics. These methods have received limited application in the analysis of EEG records obtained from TBI patients. It seems possible that, as was the case in other research domains, the systematic application of these methods in the analysis of mTBI will be similarly useful. The standard mathematical procedures used in the characterization of mTBI EEG abnormalities should be expanded to incorporate these methods of analysis.

5. Reliability and validity study data should, following deidentification, be made available on a publically accessible website for download and reanalysis by other investigators. As this is standard practice in genomics research and astronomy, it should also be standard practice in neuropsychiatry. This recommendation is motivated in part by the rapid advances being made in signal analysis. Public access to well documented EEG records will make it possible for investigators throughout the world to test the reliability and validity of new mathematical measures as they are developed.

6. As argued in the second conclusion, the diversity of underlying neuropathology in the TBI population precludes the development of a single test for TBI. As a potential solution, an integrated neuropsychiatric assessment platform can be developed that will permit simultaneous acquisition of EEG records including ERPs, heart rate variability data, and eye tracking records during a neuropsychological assessment. This system should include an onboard signal analysis capability and be capable of incorporating additional data types including genomic, epigenetic, proteomic/biomarker, and imaging data. The result would be a comprehensive, statistically valid characterization of the CNS.

\section{ACKNOWLEDGMENTS}

The opinions and assertions contained herein are the private opinions of the authors and are not to be construed as official or reflecting the views of the United Sates Navy, Department of Defense nor the US Government. This research effort was supported by the Combat Casualty Care Research Program (CCCRP) of the U.S. Army Medical Research \& Materiel Command (USAMRMC). Paul E. Rapp and David O. Keyser would like to acknowledge support from the Traumatic Injury Research Program of the Uniformed Services University of the Health Sciences, from the Defense Medical Research and Development Program and from the United States Marine Corps Systems Command. Drs. John D. Hughes and Rene Hernandez are military service members. This work was prepared as part of their official duties. Title 17 U.S.C. $\$ 105$ provides that "Copyright protection under this title is not available for any work of the United States Government.” Title 17 U.S.C. $\$ 101$ defines a U.S. Government work as a work prepared by a military service member or employee of the U.S. Government as part of that person's official duties.

\section{SUPPLEMENTARY MATERIAL}

The Supplementary Material for this article can be found online at http://www.frontiersin.org/Journal/10.3389/fnhum.2015.00011/ abstract

\section{REFERENCES}

Abásolo, D., Hornero, R., Espino, P., Alvarez, D., and Poza, J. (2006). Entropy analysis of the EEG background activity in Alzheimer's disease patients. Physiol. Meas. 27, 241-253. doi:10.1088/0967-3334/27/3/003

Abásolo, D., Hornero, R., Espino, P., Poza, J., Sánchez, C. I., and de la Rosa, R. (2005). Analysis of regularity in the EEG background activity of Alzheimer's disease patients with approximate entropy. Clin. Neurophysiol. 116, 1826-1834. doi:10.1016/j.clinph.2005.04.001

Adamis, D., Sahu, S., and Treloar, A. (2005). The utility of EEG in dementia: a clinical perspective. Int. J. Geriatr. Psychiatry 20, 1038-1045. doi:10.1002/gps.1393

Adler, G., Brassen, S., and Jajcevic, A. (2003). EEG coherence in Alzheimer's dementia. J. Neural Transm. 110, 1051-1058. doi:10.1007/s00702-003-0024-8

Akbari, A., and Gharibzadeh, S. (2009). Beta oscillations as the cause of both hyperand hypokinetic symptoms of movement disorders. J. Neuropsychiatry Clin. Neurosci. 21, 352. doi:10.1176/jnp.2009.21.3.352

Albo, Z., Di Prisco, G. V., Chen, Y., Rangarajan, G., Truccolo, W., Feng, J., et al. (2004). Is partial coherence a viable technique for identifying generators of neural oscillations? Biol. Cybern. 90, 318-326. doi:10.1007/s00422-004-0475-5

Ambrosius, U., Lietzenmaier, S., Wehrle, R., Wichniak, A., Kalus, S., and Winkelmann, J. (2008). Hereditability of sleep electroencephalogram. Biol. Psychiatry 64, 344-348. doi:10.1016/j.biopsych.2008.03.002

Angelini, L., de Tommaso, M., Guido, M., Hu, K., Ivanov, PCH, Marinazzo, D., et al. (2004). Steady state visual evoked potentials and phase synchronization in migraine patients. Phys. Rev. Lett. 93, 038103. doi:10.1103/PhysRevLett.93. 038103

Arciniegas, D. B. (2011). Cholinergic dysfunction and cognitive impairment after traumatic brain injury. Part 2: evidence from basic and clinical investigations. $J$. Head Trauma Rehabil. 26, 319-323. doi:10.1097/HTR.0b013e31821ebfb3

Arciniegas, D. B., Anderson, C. A., Topkoff, J., and Mcallister, T. W. (2005). Mild traumatic brain injury: a neuropsychiatric approach to diagnosis, evaluation, and treatment. Neuropsychiatr. Dis. Treat. 1, 311-327.

Arciniegas, D. B., and Topkoff, J. L. (2004). Applications of the P50 evoked response to the evaluation of cognitive impairments after traumatic brain injury. Phys. Med. Rehabil. Clin. N. Am. 15, 177-203. doi:10.1016/S1047-9651(03)00104-9

Armitage, R., Hoffman, R. F., and Rush, A. J. (1999). Biological rhythm disturbance in depression. Psychol. Med. 29, 1435-1448. doi:10.1017/S0033291799001300

Arnhold, J., Grassberger, P., Lehnertz, K., and Elger, C. E. (1999). A robust method for detecting interdependences: application to intracranially recorded EEG. Physica D 134, 419-430. doi:10.1016/S0167-2789(99)00140-2

Aviyente, S., Bernat, E. M., Evans, W. S., and Sponheim, S. R. (2011). A phase synchrony measure for quantifying functional integration in the brain. Hum. Brain Mapp. 32, 80-93. doi:10.1002/hbm.21000

Baccalá, L. A., and Sameshima, K. (2001). Overcoming the limitations of correlation analysis for many simultaneously processed neural structures. Prog. Brain Res. 130, 33-47. doi:10.1016/S0079-6123(01)30004-3

Baguley, I. J., Felmingham, K. L., Lahz, S., Gordon, E., Lazzaro, I., and Schotte, D. E. (1997). Alcohol abuse and traumatic brain injury: effect on event related potentials. Arch. Phys. Med. Rehabil. 78, 1248-1253. doi:10.1016/S0003-9993(97) 90339-7

Baldeweg, T., Spence, S., Hirsch, S. R., and Bruzelier, J. (1998). Gamma-band electroencephalographic oscillations in a patient with somatic hallucinations. Lancet 352, 620-621. doi:10.1016/S0140-6736(05)79575-1

Barr, W. B., Prichep, L. S., Chabot, R., Powell, M. R., and McCrea, M. (2012). Measuring brain electrical activity to track recovery from sport-related concussion. Brain Inj. 26, 58-66. doi:10.3109/02699052.2011.608216

Barry, R. J., Clarke, A. R., and Johnstone, S. J. (2003). A review of electrophysiology in attention-deficit/hyperactivity disorder: I. Qualitative and quantitative electroencephalography. Clin. Neurophysiol. 114, 171-183. doi:10.1016/S13882457(02)00362-0

Barry, R. J., Clarke, A. R., McCarthy, R., and Selikowitz, M. (2002). EEG coherence in attention-deficit/hyperactivity disorder: a comparative study of two DSM-IV types. Clin. Neurophysiol. 113, 579-585. doi:10.1016/S1388-2457(02)00036-6 
Barry, R. J., Clarke, A. R., McCarthy, R., Selikowitz, M., Johnstone, S. J., Hsu, C.-I., et al. (2005). Age and gender effects in EEG coherence: II. Boys with attention deficit/hyperactivity disorder. Clin. Neurophysiol. 116, 977-984. doi:10.1016/j. clinph.2004.10.002

Bartolomei, F., Bosma, I., Klein, M., Baayen, J. C., Reijneveld, J. C., Postma, T. J., et al. (2006). Distributed functional connectivity in brain tumour patients: evaluation by graph analysis and synchronization matrices. Clin. Neurophysiol. 117, 2039-2049. doi:10.1016/j.clinph.2006.05.018

Basar-Eroglu, C., Schmidt-Fehr, C., Mathes, B., Zimmermann, J., and Brand, A. (2009). Are oscillatory brain responses generally reduced in schizophrenia during long sustained attentional processing? Int. J. Psychophysiol. 71, 75-83. doi:10.1016/j.ijpsycho.2008.07.004

Belmonte, M. K., Allen, G., Beckel-Mitchner, A., Boulanger, L. M., Carper, R. A., and Webb, S. H. (2004). Autism and abnormal development of brain connectivity. J. Neurosci. 24, 9228-9231. doi:10.1523/JNEUROSCI.3340-04.2004

Bennouna, M., Greene, V. B., and Defranoux, L. (2007). Cholinergic hypothesis in psychosis following traumatic brain injury and cholinergic hypothesis in schizophrenia: a link? Encephale 34(4 Pt 1), 616-620. doi:10.1016/S0013-7006(07) 92062-X

Bernhardt, B. C., Chen, Z., He, Y., Evans, A. C., and Bernasconi, N. (2011). Graphtheoretical analysis reveals disrupted small-world organization of cortical thickness correlation networks in temporal lobe epilepsy. Cereb. Cortex 21,2147-2157. doi:10.1093/cercor/bhq291

Berridge, M. J., and Rapp, P. E. (1979). A comparative survey of the function, mechanism and control of cellular oscillators. J. Exp. Biol. 81, 217-279.

Bialonski, S., Wendler, M., and Lehnertz, K. (2011). Unraveling spurious properties of interaction networks with tailored random networks. PLoS ONE 6:e22826. doi:10.1371/journal.pone.0022826

Bigler, E. D., and Maxwell, W. L. (2011). Neuroimaging and neuropathology of TBI. Neurorehabilitation 28, 63-74. doi:10.3233/NRE-2011-0633

Bleiberg, J., Garmoe, W. S., Halpern, E. L., Reeves, D. L., and Nadler, J. D. (1997). Consistency of within-day and across-day performance after mild brain injury. Neuropsychiatry Neuropsychol. Behav. Neurol. 10, 247-253.

Blinowska, K. J., and Kaminski, M. (2013). Functional brain networks: random, "small world" or deterministic? PLoS ONE 8:e78763. doi:10.1371/journal.pone. 0078763

Bob, P. (2007). Consciousness and co-consciousness, binding problem and schizophrenia. Neuro Endocrinol. Lett. 28, 723-726.

Bob, P., Palus, M., Susta, M., and Glaslova, K. (2008). EEG phase synchronization in patients with paranoid schizophrenia. Neurosci. Lett. 447, 73-77. doi:10.1016/j.neulet.2008.09.055

Bonanni, E., Borghetti, K. D., Fabbrini, M., Maestri, M., Cignoni, F., Sartucci, F., et al. (2006). Quantitative EEG analysis in post-traumatic anosmia. Brain Res. Bull. 71, 69-75. doi:10.1016/j.brainresbull.2006.08.004

Bonita, J. D., Ambolode, L. C., Rosenberg, B. M., Cellucci, C. J., Watanabe, T. A., Rapp, P. E., et al. (2014). Time domain measures of inter-channel EEG correlations: a comparison of linear, nonparametric and nonlinear measures. Cogn. Neurodyn. 8, 1-15. doi:10.1007/s11571-013-9267-8

Bosl, W., Tierney, A., Tager-Flusberg, H., and Nelson, C. (2011). Response: infant EEG activity as a biomarker for autism: a promising approach or a false promise? BMC Med. 20:60. doi:10.1186/1741-7015-9-60

Bosma, I., Douw, L., Bartolomei, F., Heimans, J. J., van Dijk, B. W., Postma, J., et al. (2008). Synchronized brain activity and neurocognitive function in patients with low grade glioma: a magnetoencephalography study. Neuro Oncol. 10, 734-744. doi:10.1215/15228517-2008-034

Breakspear, M., Brammer, M. J., Bullmore, E. T., Das, P., and Williams, L. M. (2004). Spatiotemporal wavelet resampling for functional neuroimaging data. Hum. Brain Mapp. 23, 1-25. doi:10.1002/hbm.20045

Breakspear, M., Williams, L. M., and Stam, C. J. (2004). A novel method for the topographic analysis of neural activity reveals the formation and dissolution of 'dynamic cell assmeblies'. J. Comput. Neurosci. 16, 49-68. doi:10.1023/B:JCNS. $0000004841.66897 .7 \mathrm{~d}$

Breitung, J., and Swanson, N. R. (2002). Temporal aggregation and spurious instantaneous causality in multiple time series models. J. Time Ser. Anal. 23, 651-665. doi:10.1111/1467-9892.00284

Brenner, C. A., Sporns, O., Lysaker, P. H., and O’Donnell, B. F. (2003). EEG synchronization to modulated auditory tones in schizophrenia, schizoaffective disorder, and schizotypal personality disorder. Am. J. Psychiatry 160, 2238-2240. doi:10.1176/appi.ajp.160.12.2238
Bressler, S. L. (2003). Cortical coordination dynamics and the disorganization syndrome in schizophrenia. Neuropsychopharmacology 28, 535-539.

Broglio, S. P., Pontifex, M. B., O’Connor, P., and Hillman, C. H. (2009). The persistent effects of concussion on neuroelectric indices of attention. J. Neurotrauma 26, 1463-1470. doi:10.1089/neu.2008-0766

Bruhn, J., Röpcke, H., Rehberg, B., Bouillon, T., and Hoeft, A. (2000). Electroencephalogram approximate entropy correctly classifies the occurrence of burst suppression pattern as increasing anesthetic drug effect. Anesthesiology 93, 981-985. doi:10.1097/00000542-200010000-00018

Brunovsky, M., Matousek, M., Edman, A., Cerrena, K., and Krajea, V. (2003). Objective assessment of the degree of dementia by means of EEG. Neuropsychobiology 48, 19-26. doi:10.1159/000071824

Burgess, A., and Gruzelier, J. (1993). Individual reliability of amplitude distribution in topographical mapping of EEG. Electroencephalogr. Clin. Neurophysiol. 86, 219-223. doi:10.1016/0013-4694(93)90101-Z

Campbell, K., Houle, S., Lorrain, D., Deacon-Elliott, D., and Proulx, G. B. (1986). Event-related potentials as an index of cognitive functioning in head-injured patients. Electroencephalogr. Clin. Neurophysiol. 38(Suppl.), 486-488.

Campbell, K. B., and DeLugt, D. R. (1995). "Event related potential measures of cognitive deficits following closed head injury," in Event Related Potentials and Cognition: Handbook of Neuropsychology, Vol. 10, ed. R. Johnson Jr. (New York, NY: Elsevier), 269-297.

Campbell, K. B., Suffield, J. B., and Deacon, D. L. (1990). Electrophysiological assessment of cognitive disorder in closed head-injured outpatients. Electroencephalogr. Clin. Neurophysiol. Suppl. 41, 202-215. doi:10.1016/B978-0-44481352-7.50025-X

Canolty, R. T., and Knight, R. T. (2010). The functional role of cross-frequency coupling. Trends Cogn. Sci. (Regul. Ed.) 14, 506-515. doi:10.1016/j.tics.2010.09.001

Cao, C., and Slobounov, S. (2010). Alteration of cortical functional connectivity as a result of traumatic brain injury revealed by graph theory, ICA and sLORETA analyses of EEG signals. IEEE Trans. Neural. Syst. Rehabil. Eng. 18, 11-19. doi:10.1109/TNSRE.2009.2027704

Castellanos, N. P., Bajo, R., Cuesta, P., Villacorta-Atienza, J. A., Paúl, N., GarciaPrieto, J., et al. (2011a). Alteration and reorganization of functional networks: a new perspective in brain injury study. Front. Hum. Neurosci. 5:90. doi:10.3389/fnhum.2011.00090

Castellanos, N. P., Leyva, I., Buldú, J. M., Bajo, R., Paúl, N., Cuesta, P., et al. (2011b). Principles of recovery from traumatic brain injury: reorganization of functional networks. Neuroimage 55, 1189-1199. doi:10.1016/j.neuroimage.2010.12.046

Castellanos, N. P., Paúl, N., Ordóñez, V. E., Demuynck, O., Bajo, R., Campo, P., et al. (2010). Reorganization of functional connectivity as a correlate of cognitive recovery in acquired brain injury. Brain 133, 2365-2381. doi:10.1093/brain/ awq174

Catani, C. (2003). Affective Stimulus Processing Following Traumatic Brain Injury. Doctoral Dissertation, Universität Konstanz, Konstanz.

Catarino, A., Churches, O., Baron-Cohen, S., Andrade, A., and Ring, H. (2011). Atypical EEG complexity in autism spectrum conditions: a multiscale entropy analysis. Clin. Neurophysiol. 122, 2375-2383. doi:10.1016/j.clinph.2011.05.004

Cellucci, C. J., Albano, A. M., and Rapp, P. E. (2006). Statistical validation of mutual information calculations: comparisons of alternative numerical algorithms. Phys. Rev. E Stat. Nonlin. Soft Matter Phys. 71(6 Pt 2), 066208. doi:10.1103/PhysRevE.71.066208

Chen, X. P., Tao, L. Y., and Chen, A. C. (2006a). Electroencephalogram and evoked potential parameters examined in Chinese mild head injury patients for forensic medicine. Neurosci. Bull. 22, 165-170.

Chen, Y., Bressler, S. L., and Ding, M. (2006b). Frequency decomposition of conditional Granger causality and application to multivariate neural field potential data. J. Neurosci. Methods 150, 228-237. doi:10.1016/j.jneumeth.2005.06.011

Cho, R. Y., Konecky, R. O., and Carter, C. S. (2006). Impairments in frontal cortical gamma synchrony and cognitive control in schizophrenia. Proc. Natl. Acad. Sci. U.S.A. 103, 19878-19883. doi:10.1073/pnas.0609440103

Chung, C. C., Kang, J. H., Yuan, R. Y., Wu, D., Chen, C. C., Chi, N. F., et al. (2013). Multiscale entropy analysis of electroencephalography during sleep in patients with Parkinson disease. Clin. EEG Neurosci. 44, 221-226. doi:10.1177/ 1550059412475066

Clark, C. R., O’Hanlon, A. P., Wright, M. J., and Geffen, G. M. (1992). Eventrelated potential measurements of deficits in information processing following moderate to severe closed head injury. Brain Inj. 6, 509-520. doi:10.3109/ 02699059209008148 
Costa, M., Goldberger, A. L., and Peng, C.-K. (2002). Multiscale entropy analysis of complex physiologic time series. Phys. Rev. Lett. 89, 068102. doi:10.1103/ PhysRevLett.89.068102

Costa, M., Goldberger, A. L., and Peng, C.-K. (2004). Costa, Goldberger and Peng reply. Phys. Rev. Lett. 92, 089804. doi:10.1103/PhysRevLett.92.089804

Costa, M. J., Goldberger, A. L., and Peng, C.-K. (2005). Multiscale entropy of biological signals. Phys. Rev. E Stat. Nonlin. Soft Matter Phys. 71, 021906. doi:10.1103/PhysRevE.71.021906

Coutin-Churchman, B., Anez, Y., Uzcategui, M., Alvarez, L., Vergara, F., Mendez, L. O., et al. (2003). Quantitative spectral analysis of EEG in psychiatry revisited: drawing signs out of numbers in a clinical setting. Clin. Neurophysiol. 114, 2294-2306. doi:10.1016/S1388-2457(03)00228-1

Cremona-Meteyard, S. I., and Geffen, G. M. (1994). Event related potential indices of visual attention following moderate to severe closed head injury. Brain Inj. 8, 541-558. doi:10.3109/02699059409151006

Crosby, R. D., Kolotkin, R. L., and Williams, G. R. (2003). Defining clinically meaningful change in quality of life. J. Clin. Epidemiol. 56, 395-407. doi:10.1016/ S0895-4356(03)00044-1

Crutchfield, J. P., and Packard, N. H. (1983). Symbolic dynamics of noisy chaos. Physica 7D, 201-223.

Curry, S. H. (1980). Event-related brain potentials as indicants of structural and functional damage in closed head injury. Prog. Bain Res. 54, 507-515. doi:10.1016/S0079-6123(08)61668-4

Curry, S. H., Woods, D. L., and Low, M. D. (1986). Applications of cognitive ERPs in neurosurgical and neurological patients. Electroencephalogr. Clin. Neurophysiol. Suppl. 38, 469-484.

D'Alessandro, G., and Politi, A. (1990). Hierarchical approach to complexity with applications to dynamic systems. Phys. Rev. Lett. 64, 1609-1612. doi:10.1007/ s10916-012-9920-5

De Beaumont, L., Brisson, B., Lassonde, M., and Jolicoeur, P. (2007a). Long-term electrophysiological changes in athletes with a history of multiple concussions. Brain Inj. 21, 631-644. doi:10.1080/02699050701426931

De Beaumont, L., Lassonde, M., Leclerc, S., and Théoret, H. (2007b). Long-term and cumulative effects of sports concussion on motor inhibition. Neurosurgery 61, 329-336. doi:10.1227/01.NEU.0000280000.03578.B6

De Beaumont, L., Théoret, H., Mongeon, D., Messier, J., Leclerc, S., Tremblay, S., et al. (2009). Brain function decline in healthy retired athletes who sustained their last concussion in early adulthood. Brain 132, 695-708. doi:10.1093/brain/ awn347

Deacon, D., Breton, F., Ritter, W., and Vaughan, H. G. Jr. (1991). The relationship between N2 and N400: scalp distribution, stimulus probability, and task relevance. Psychophysiology 28, 185-200. doi:10.1111/j.1469-8986.1991.tb00411.x

Deacon-Elliott, D. L., and Campbell, K. B. (1987). P3 evoked by visual feedback in normals and closed head-injured subjects. Electroencephalogr. Clin. Neurophysiol. Suppl. 40, 664-669.

Deacon-Elliott, D., Campbell, K. B., Suffield, J. B., and Proulx, G. B. (1987). Electrophysiological monitoring of closed head injury: III. Cognitive evoked potentials. Cogn. Rehabil. 5, 12-21.

Deco, G., and Schürmann, B. (2001). Information Dynamics: Foundations and Applications. New York, NY: Springer-Verlag.

DeKosky, S. T., Ikonomovic, M. D., and Gandy, S. (2010). Traumatic brain injury football, warfare and long-term effects. N. Engl. J. Med. 363, 1293-1296. doi:10.1056/NEJMp1007051

di Russo, F., and Spinelli, D. (2010). Sport is not always healthy: executive brain dysfunction in professional boxers. Psychophysiology 47, 425-434. doi:10.1111/j. 1469-8986.2009.00950.x

Dockree, P. M., Kelly, S. P., Roche, R. A. R., Hogan, M. J., Reilly, R. B., and Robertson, I. H. (2004). Behavioral and physiological impairments of sustained attention after traumatic brain injury. Brain Res. Cogn. Brain Res. 20, 403-414. doi:10.1016/j.cogbrainres.2004.03.019

Donner, A., and Wells, G. (1986). A comparison of confidence interval methods for the intraclass correlation coefficient. Biometrics 42, 401-412. doi:10.2307/ 2531060

Douw, L., van Dellen, E., Baayen, J. C., Klein, M., Velis, D. N., Alpherts, W. C. J., et al. (2010). The lesioned brain: still a small world? Front. Hum. Neurosci. 4:174. doi:10.3389/fnhum.2010.00174

Drake, M., and John, K. (1987). Long-latency auditory evoked potentials in the postconcussive syndrome. Electroencephalogr. Clin. Neurophysiol. 5, 19-21.
Dressler, O., Schneider, G., Stockmanns, G., and Kochs, E. F. (2004). Awareness and the EEG power spectrum: analysis of frequencies. Br. J. Anaesth. 93, 806-809. doi:10.1093/bja/aeh270

Duncan, C. C., Kosmidis, M. H., and Mirsky, A. F. (2003). Event-related potential assessment of information processing after closed head injury. Psychophysiology 40, 45-59. doi:10.1111/1469-8986.00006

Duncan, C. C., Kosmidis, M. H., and Mirsky, A. F. (2005). Closed head injuryrelated information processing deficits: an event related potential analysis. Int J. Psychophysiol. 58, 133-157. doi:10.1016/j.ijpsycho.2005.05.011

Dunlap, W. P., Chen, R. S., and Greer, T. (1994). Skew reduces test-retest reliability. J. Appl. Psychol. 79, 310-313. doi:10.1037/0021-9010.79.2.310

Dupuis, F., Johnston, K. M., Lavoie, M., Lepore, F., and Lassonde, M. (2000). Concussions in athletes produce brain dysfunction as revealed by event-related potentials. Neuroreport 11, 4087-4092. doi:10.1097/00001756-200012180-00035

Dywan, M. J., and Segalowitz, S. J. (1996). Self- and family ratings of adaptive behavior after traumatic brain injury: psychometric scores and frontally generated ERPs. J. Head Trauma Rehabil. 11, 79-95. doi:10.1097/00001199-19960400000008

Ebeling, W. (1997). Prediction and entropy of nonlinear dynamical systems and symbolic sequences with LRO. Physica D 109, 42-52. doi:10.1016/S0167-2789(97) 00157-7

Eckmann, J. P., and Ruelle, D. (1985). Ergodic theory of chaos and strange attractors. Rev. Mod. Phys. 57, 617-656. doi:10.1103/RevModPhys.57.617

Elting, J. W., Maurits, N., van Weerden, T., Spikman, J., de Keyser, J., and van der Naalt, J. (2008). P300 analysis techniques in cognitive impairment after brain injury: comparison with neuropsychological and imaging data. Brain Inj. 22, 870-881. doi:10.1080/02699050802403581

Fan, Y., Ji, M., Zang, L., Wang, W., Yin, Q., Xu, J., et al. (2011). Comparison of epidural tramadol-ropivacaine and fentanyl-ropivacaine for labor analgesia: a prospective randomized study. Ups. J. Med. Sci. 116, 252-257. doi:10.3109/03009734.2011. 601532

Fazel, S., Wolf, A., Pillas, D., Lichtenstein, P., and Längström, N. (2014). Suicide, fatal injuries and other causes of premature mortality in patients with traumatic brain injury. JAMA Psychiatry 71, 326-333. doi:10.1001/jamapsychiatry.2013.3935

Fein, G., Galin, D., Johnstone, J., Yingling, C. D., Marcus, M., and Kiersch, M. F. (1983). EEG power spectra in normal and dyslexic children: reliability during passive conditions. Electroencephalogr. Clin. Neurophysiol. 55, 399-405. doi:10.1016/0013-4694(83)90127-X

Fein, G., Galin, D., Yingling, C., and Johnstone, J. (1984). EEG spectra in 10-12 year old boys are stable over 1 to 3 years. Electroencephalogr. Clin. Neurophysiol. 58, 517-518. doi:10.1016/0013-4694(84)90041-5

Ferrarelli, F., Sarasso, S., Guller, Y., Riedner, B. A., Peterson, M. J., Bellesi, M., et al. (2012). Reduced natural oscillatory frequency of frontal thalamocortical circuits in schizophrenia. Arch. Gen. Psychiatry 69, 766-774.

Fingelkurts, A. A., Fingelkurts, A. A., Ermolaev, V. A., and Kaplan, A. Y. (2006). Stability, reliability and consistency of the compositions of brain oscillations. Int. J. Psychophysiol. 59, 116-126. doi:10.1016/j.ijpsycho.2005.03.014

Fletcher, D. J., Raz, J., and Fein, G. (1997). Intra-hemispheric alpha coherence decreases with increasing cognitive impairment in HIV patients. Electroencephalogr. Clin. Neurophysiol. 102, 286-294. doi:10.1016/S00134694(96)96071-X

Folmer, R. L., Billings, C. J., Diedesch-Rouse, A. C., Gallun, F. J., and Lew, H. L. (2011). Electrophysiolgoical assessments of cognitive and sensory processing in TBI: applications for diagnosis, prognosis and rehabilitation. Int. J. Psychophysiol. 82, 4-15. doi:10.1016/j.ijpsycho.2011.03.005

Ford, J. M., Krystal, J. H., and Mathalon, D. H. (2007). Neural synchrony in schizophrenia: from networks to new treatments. Schizophr. Bull. 33, 848-852. doi:10.1093/schbul/sbm062

Ford, J. M., and Mathalon, D. H. (2005). Corrollary discharge dysfunction in schizophrenia: can it explain auditory hallucinations? Int. J. Psychophysiol. 58, 179-189. doi:10.1016/j.ijpsycho.2005.01.014

Ford, J. M., Roach, B. J., Faustman, W. O., and Mathalon, D. H. (2008). Out-of-synch and out-of-sorts: dysfunction of motor-sensory communication in schizophrenia. Biol. Psychiatry 63, 736-743. doi:10.1016/j.biopsych.2007.09.013

Ford, M. R., and Khalil, M. (1996a). Evoked potential findings in mild head traumatic head injury. 1. Middle latency component augmentation and cognitive component attenuation. J. Head Trauma Rehabil. 11, 1-15. doi:10.1097/00001199199606000-00004 
Ford, M. R., and Khalil, M. (1996b). Evoked potential findings in mild traumatic brain injury. 2. Scoring system and individual discrimination. J. Head Truma Rehabil. 11, 16-21. doi:10.1097/00001199-199606000-00005

Fries, P. (2005). A mechanism for cognitive dynamics: neuronal communication through neuronal coherence. Trends Cogn. Sci. (Regul. Ed.) 9, 474-480. doi:10.1016/j.tics.2005.08.011

Gaetz, M., and Bernstein, D. (2001). The current status of electrophysiologic procedures for the assessment of mild traumatic brain injury. J. Head Trauma Rehabil. 16, 386-405. doi:10.1097/00001199-200108000-00008

Gaetz, M., Goodman, D., and Weinberg, H. (2000). Electrophysiological evidence for the cumulative effects of concussion. Brain Inj. 14, 1077-1088. doi:10.1080/02699050050203577

Gaetz, M., and Weinberg, H. (2000). Electrophysiological indices of persistent postconcussion symptoms. Brain Inj. 14, 815-832. doi:10.1080/026990500421921

Gallager, R. G. (1968). Information Theory and Reliable Communication. New York, NY: John Wiley and Sons.

Gasser, T., Bacher, P., and Steinberg, H. (1985). Test-retest reliability of spectral parameters of the EEG. Electroencephalogr. Clin. Neurophysiol. 60, 312-319. doi:10.1016/0013-4694(85)90005-7

Gasser, T., Bucher, P., and Mochs, J. (1982). Transformation towards the normal distribution of broad band spectral parameters of the EEG. Electroencephalogr. Clin. Neurophysiol. 53, 119-124. doi:10.1016/0013-4694(82)90112-2

Geisler, M. W., Schlotfeldt, C. R., Middleton, C. B., Dulay, M. F., and Murphy, C. (1999). Traumatic brain injury assessed with olfactory event-related potentials. J. Clin. Neurophysiol. 16, 77-86. doi:10.1097/00004691-199901000-00008

Georgopoulos, A. P., Karageorgiou, E., Leuthold, A. C., Lewis, S. M., Lynch, J. K., Alonso, A. A., et al. (2007). Synchronous neural interactions assessed by magnetoencephalography: a functional biomarker for brain disorders. J. Neural Eng. 4, 349-355. doi:10.1088/1741-2560/4/4/001

Giaquinto, S. (2004). Evoked potentials in rehabilitation. A review. Funct. Neurol. $19,219-225$

Goh, S. Y., Irimia, A., Togerson, C. M., and Van Horn, J. D. (2014). Neuroinformatics challenges to the structural, connectomic, functional and electrophysiological multimodal imaging of human traumatic brain injury. Front. Neuroinformatics 8:19. doi:10.3389/fnin.2014.00019

Gosselin, N., Bottari, C., Chen, J. K., Huntgeburth, S. C., de Beaumont, L., Petrides, M., et al. (2012). Evaluating the cognitive consequences of mild traumatic brain injury and concussion by using electrophysiology. Neurosurg. Focus 33, E7:1-7. doi: $10.3171 / 2012.10$.FOCUS12253

Gosselin, N., Bttari, C., Chen, J.-K., Petrides, M., Tinawi, S., de Guise, E., et al. (2011). Electrophysiology and functional MRI in post-acute mild traumatic brain injury. J. Neurotrauma 28, 329-341. doi:10.1089/neu.2010.1493

Gosselin, N., Lassonde, M., Petit, D., Leclerc, S., Mongrain, V., Collie, A., et al. (2009). Sleep following sport-related concussions. Sleep Med. 10, 35-46. doi:10.1016/j. sleep.2007.11.023

Gosselin, N., Thériault, M., Leclerc, S., Montplaisir, J., and Lassonde, M. (2006). Neurophysiological anomalies in symptomatic and asymptomatic concussed athletes. Neurosurgery 58, 1151-1161. doi:10.1227/01.NEU.0000215953.44097.FA

Gram, M., Graversen, C., Olesen, S. S., and Drewes, A. M. (2014). Dynamic spectral indices of the electroencephalogram provide new insights into chronic pain. Clin. Neurophysiol. doi:10.1016/j.clinph.2014.07.027

Granger, C. W. J. (1969). Investigating causal relations by econometric models and cross-spectral methods. Econometrica 37, 424-438. doi:10.2307/1912791

Green, M. R., Nuechterlein, K. H., Breitmeyer, B., and Mintz, J. (1999). Backward masking in unmedicated schizophrenia patients in psychotic remission: possible reflection of aberrant cortical oscillations. Am. J. Psychiatry 156, 1367-1373.

Grefkes, C., and Fink, G. R. (2012). Disruption of motor network connectivity poststroke and its noninvasive neuromodulation. Curr. Opin. Neurol. 25, 670-675. doi:10.1097/WCO.0b013e3283598473

Grice, S. J., Spratling, W., Karmiloff-Smith, A., Halit, H., Csibra, G., de Haan, M., et al. (2001). Disordered visual processing and oscillatory brain activity in autism and Williams syndrome. Neuroreport 12, 2697-2700. doi:10.1097/00001756200108280-00021

Gross, J., Schmitz, F., Schnitzler, I., Kessler, K., Shapiro, K., Hommel, B., et al. (2004). Modulation of long range neuroal synchrony reflects temporal limitations of visual attention in humans. Proc. Natl. Acad. Sci. U.S.A. 101, 13050-13055. doi:10.1073/pnas.0404944101
Gudmussen, S., Runarsson, T. P., Sigurdsson, S., Eiriksdottir, G., and Johnsen, K. (2007). Reliability of quantitative EEG features. Clin. Neuropshysiol. 118, 2162-2171. doi:10.1016/j.clinph.2007.06.018

Guevara, R., Pérez Velazquez, J. L., Nenadovic, V., Wennberg, R., Senjanović, G., and Dominguez, L. G. (2005). Phase synchronization measurements using electroencephalographic recordings. What can we really say about neuronal synchrony? Neuroinformatics 3, 301-314.

Güntekin, B., Saatci, E., and Yener, G. (2008). Decrease of evoked delta, theta and alpha coherences in Alzheimer patients during a visual oddball task. Brain Res. 1235, 109-116. doi:10.1016/j.brainres.2008.06.028

Haglund, Y., and Persson, H. E. (1990). Does Swedish amateur boxing lead to chronic brain damage. 3. A retrospective clinical neurophysiological study. Acta Neurol. Scand. 82, 353-360. doi:10.1111/j.1600-0404.1990.tb03316.x

Ham, T. E., and Sharp, D. J. (2012). How can investigation of network function inform rehabilitation after traumatic brain injury? Curr. Opin. Neurol. 25, 662-669. doi:10.1097/WCO.0b013e328359488f

Harner, R. (2010). Automatic EEG spike detection. Clin. EEG Neurosci. 40, 262-270. doi: $10.1177 / 155005940904000408$

Haufe, S., Nikulin, V. V., Müller, K. R., and Nolte, G. (2013). A critical assessment of connectivity measures for EEG data: a simulation study. Neuroimage 64, 120-133. doi:10.1016/j.neuroimage.2012.09.036

Haufe, S., Treder, M. S., Gugler, M. F., Sagebaum, M., Curio, G., and Blankertz, B. (2011). EEG potentials predict upcoming emergency brakings during simulated driving. J. Neural Eng. 8, 056001. doi:10.1088/1741-2560/8/5/056001

He, Z., and Maekawa, K. (2001). On spurious Granger causality. Econ. Lett. 73, 307-313. doi:10.1016/S0165-1765(01)00498-0

Head, H. (1926). Aphasia and Kindred Disorders of Speech. Cambridge: Cambridge University Press.

Heinze, H.-J., Münte, T. F., Gobiet, W., Niemann, H., and Ruff, R. M. (1992). Parallel and serial visual search after closed head injury: electrophysiological evidence for perceptual dysfunctions. Neuropsychologia 30, 495-514. doi:10.1016/00283932(92)90054-P

Herrmann, C. S., and Demiralp, T. (2005). Human EEG gamma oscillations in neuropsychiatric disorders. Clin. Neurophysiol. 116, 2719-2733. doi:10.1016/j. clinph.2005.07.007

Hesse, W., Möller, E., Arnold, M., and Schack, B. (2003). The use of time-variant EEG Granger causality for inspecting directed interdependencies of neural assemblies. J. Neurosci. Methods 124, 27-44. doi:10.1016/S0165-0270(02)00366-7

Hirano, S., Hirano, Y., Maekawa, T., Obayashi, C., Oribe, N., Kuroki, T., et al. (2008). Abnormal neural oscillatory activity to speech sounds in schizophrenia: a magnetoencephalolgraphy study. J. Neurosci. 28, 4897-4903. doi:10.1523/JNEUROSCI. 5031-07.2008

Ho, K. K. L., Peng, C.-K., Mietus, J. E., Larson, M. G., Levy, D., and Goldberger, A. L. (1997). Predicting survival in heart failure cases and controls using fully automated methods for deriving nonlinear and conventional indices of heart rate dynamics. Circulation 96, 842-848. doi:10.1161/01.CIR.96.3.842

Hoffman, D. A., Lubar, J. F., Thatcher, R. W., Sterman, M. B., Rosenfeld, P. J., Striefel, S., et al. (1999). Limitations of the American Academy of Neurology and American Clinical Neurophysiology Soociety paper on QEEG. J. Neuropsychiatry Clin. Neurosci. 11, 401-407. doi:10.1176/jnp.11.3.401

Hoffman, D. A., Stockdale, S., Hicks, L. L., and Schwaninger, B. A. (1995). Diagnosis and treatment of head injury. J. Neurother. 1, 14-21. doi:10.1300/ J184v01n01_03

Hoge, C. W., McGurk, D., Thomas, J. L., Cox, A. L., Engel, C. C., and Castro, C. A (2008). Mild traumatic brain injury in U.S. soldiers returning from Iraq. N. Engl. J. Med. 358, 453-463. doi:10.1056/NEJMoa072972

$\mathrm{Hu}$, J., Gao, J., and Principe, J. C. (2006). Analysis of biomedical signals by the lempel-Ziv complexity: the effect of finite data size. IEEE Trans. Biomed. Eng. 53(12 Pt 2), 2606-2609. doi:10.1109/TBME.2006.883825

Hurtado, J. M., Rubchinskiy, L. L., and Sigvardt, K. A. (2004). Statistical method for detecting of phase locking episodes in neural oscillations. J. Neurophysiol. 91, 1883-1898. doi:10.1152/jn.00853.2003

Inouye, T., Shinosaki, K., Iyama, A., and Matsumoto, Y. (1993). Localization of activated areas and directional EEG patterns during mental arithmetic. Electroencephalogr. Clin. Neurophysiol. 86, 224-230. doi:10.1016/0013-4694(93)90102-2

Inouye, T., Shinosaki, K., and Yagasaki, A. (1983). The direction of spread of alpha activity over the scalp. Electroencephalogr. Clin. Neurophysiol. 55, 290-300. doi:10.1016/0013-4694(83)90207-9 
Irimia, A., Goh, S. Y. M., Torgerson, C. M., Chambers, M. C., Kikinis, R., and Van Horn, J. D. (2013a). Forward and inverse electroencephalographic modeling in health and in acute traumatic brain injury. Clin. Neurophysiol. 124, 2129-2145. doi:10.1016/j.clinph.2013.04.336

Irimia, A., Goh, S.-Y. M., Torgerson, C. M., Stein, N. R., Chambers, M. C., Vespa, P. M., et al. (2013b). Electroencephalographic inverse localization of brain activity in acute traumatic brain injury as a guide to surgery, monitoring and treatment. Clin. Neurol. Neurosurg. 115, 2159-2165. doi:10.1016/j.clineuro.2013.08.003

Irimia, A., Swinney, K. R., and Wikswo, J. P. (2009). Partial independence of bioelectric and biomagnetic fields and its implications for electroencephalography and cardiology. Phys. Rev. E Stat. Nonlin. Soft Matter Phys. 79, 051908 doi:10.1103/PhysRevE.79.051908

Irimia, A., Van Horn, J. D., and Halgren, E. (2012). Source cancelation profiles of electroencephalography and magnetoencephalography. Neuroimage 59, 2464-2474. doi:10.1016/j.neuroimage.2011.08.104

Izhikevich, E. M. (2006). Polychronization: computing with spikes. Neural Comput. 15, 1511-1523. doi:10.1162/089976603321891783

Jaeschke, R., Singer, J., and Guyatt, G. H. (1989). Measurement of health status: ascertaining the minimal clinically important difference. Control. Clin. Trials 10, 407-415. doi:10.1016/0197-2456(89)90005-6

Jiménez-Montanó, M. A. (1984). On the syntactic structure of protein sequences and the concept of complexity. Bull. Math. Biol. 46, 641-659. doi:10.1016/S00928240(84)80064-6

Just, M. A., Cherkassky, V. L., Keller, T. A., and Minshew, J. W. (2004). Cortical activation and synchronization during sentence comprehension in highfunctioning autism: evidence of underconnectivity. Brain 127, 1811-1821. doi:10.1093/brain/awh199

Kaipio, M. L., Alho, K., Winkler, I., Escera, C., Surma-aho, O., and Näätänen, R. (1999). Event-related brain potentials reveal covert distractibility in closed head injuries. Neuroreport 10, 2125-2129. doi:10.1097/00001756-199907130-00024

Kaipio, M. L., Novitski, N., Tervaniemi, M., Alho, K., Ohman, J., Salonen, O., et al. (2001). Fast vigilance decrement in closed head injury patients as reflected by the mismatch negativiy (MMN). Neuroreport 12, 1517-1522. doi:10.1097/ 00001756-200105250-00043

Kamarajan, C., Porjesz, B., Jones, K., Chorlian, D., Padmanabhapillai, A., Rangaswamy, M., et al. (2005). Event-related oscillations in offspring of alcoholics: neurocognitive disinhibition as a risk for alcoholism. Biol. Psychiatry 59, 625-634. doi:10.1016/j.biopsych.2005.08.017

Kaminski, J., Brzezicka, A., and Wrobel, A. (2011). Short-term memory capacity $(7 \pm 2)$ predicted by theta to gamma cycle length ratio. Neurobiol. Learn. Mem. 95, 19-23. doi:10.1016/j.nlm.2010.10.001

Kana, R. K., Keller, T. A., Minshew, N., and Just, M. A. (2007). Inhibitory control in high function autism: decreased activation and underconnectivity in inhibition networks. Biol. Psychiatry 62, 198-206. doi:10.1016/j.biopsych.2006.08.004

Kane, N. M., Curry, S. H., Rowlands, C. A., Manara, A. R., Lewis, T., Moss, T., et al. (1996). Event-related potentials - neurophysiological tools for predicting emergence and early outcome from traumatic coma. Intensive Care Med. 22, 39-46. doi:10.1007/BF01728329

Kaneko, K. (1986). Lyapunov analysis and information flow in coupled map lattices. Physica D 23, 436-477. doi:10.1016/0167-2789(86)90149-1

Kasahara, M., Menon, D. K., Salmond, C. H., Outtrim, J. G., Taylor Tavares, J. V., Carpenter, T. A., et al. (2010). Altered functional connectivity in the motor network after traumatic bain injury. Neurology 75, 168-176. doi:10.1212/WNL. 0b013e3181e7ca58

Kennard, M. A., and Schwartzman, A. E. (1957). A longitudinal study of electroencephalographic frequency patterns in mental hospital patients and normal controls. Electroencephalogr. Clin. Neurophysiol. 9, 263-274. doi:10.1016/00134694(57)90059-7

Keren, O., Ben-Dror, S., and Stern, M. J. (1998). Event related potentials as an index of cognitive function during recovery from severe closed head injury. J. Head Trauma Rehabil. 13, 13-30.

Kiebel, S. J., Dunizeau, J., and Friston, K. J. (2008). A hierarchy of time scales in the brain. PLoS Comput. Biol. 4:e1000209. doi:10.1371/journal.pcbi.1000209

Koenig, T., Lehmann, D., Merlo, M. C., Kochi, K., Hell, D., and Koukkou, M. (1999). A deviant EEG brain microstate in acute, neuroleptic-naive schizophrenics at rest. Eur. Arch. Psychiatry Clin. Neurosci. 249, 205-211. doi:10.1007/s004060050088

Koenig, T., Prichep, L., Dierks, T., Hubl, D., Wahlund, L. O., John, E. R., et al. (2005). Decreased synchronization in Alzheimer's disease and mild cognitive impairment. Neurobiol. Aging 26, 165-171. doi:10.1016/j.neurobiolaging.2004. 03.008

Kolassa, I.-T., and Elbert, T. (2007). Structural and functional neuroplasticity in relation to traumatic stress. Curr. Dir. Psychol. Sci. 16, 321-325. doi:10.1016/j. neuroimage.2011.01.024

Kolmogorov, A. N. (1958). A metric invariant of transient dynamical systems and automorphisms in Lebsegue spaces. Dokl. Acad. Nauk USSR 119, 861-864.

Kolmogorov, A. N. (1959). Entropy per unit time as a metric invariant of automorphisms. Dokl. Akad. Nauk. SSSR 124, 754-755.

Kondacs, A., and Szabo, M. (1999). Long-term intra-individual variability of the background EEG in normals. Clin. Neurophysiol. 110, 1708-1716. doi:10.1016/ S1388-2457(99)00122-4

Korn, A., Golan, H., Melamed, I., Pascual-Marqui, R., and Friedman, A. (2005). Focal cortical dysfunction and blood-brain barrier disruption in patients with postconcussion syndrome. J. Clin. Neurophysiol. 22, 1-9. doi:10.1097/01.WNP. 0000150973.24324.A7

Koukkou, M., Lehmann, D., Federspiel, A., and Merlo, M. C. (1995). EEG reactivity and EEG activity in never-treated acute schizophrenics, measured with spectral parameters and dimensional complexity. J. Neural Transm. Gen. Sect. 99, 89-102. doi:10.1007/BF01271472

Krebs, D. E. (1986). Declare your ICC type. Phys. Ther. 66, 1431

Kumar, R., Gupta, R. K., Husain, M., Chaudhry, C., Srivastava, A., Saksena, S., et al. (2009a). Comparative evaluation of corpus callosum DTI metrics in acute mild and moderate traumatic brain injury: its correlation with neuropsychometric tests. Brain Inj. 23, 675-685. doi:10.1080/02699050903014915

Kumar, S., Rao, S. L., Chandramouli, A., and Pillai, S. V. (2009b). Reduction of functional brain connectivity in mild traumatic brain injury during working memory. J. Neurotrauma 26, 665-676. doi:10.1089/neu.2008-0644

Kwon, J. S., O'donnell, B. F., Wallenstein, G. V., Greene, R. W., Hirayasu, Y., Nestor, P. G., et al. (1999). Gamma frequency-range abnormalities to auditory stimulation in schizophrenia. Arch. Gen. Psychiatry 56, 1001-1005.

Lachapelle, J., Bolduc-Teasdale, J., Ptito, A., and McKerral, M. (2008). Deficits in complex visual information processing after mild TBI: electrophsyiological markers and vocational outcome prognosis. Brain Inj. 22, 265-274. doi:10.1080/ 02699050801938983

Lachaux, J. P., Rodriguez, E., Martinerie, J., and Varela, F. J. (1999). Measuring phase synchrony in brain signals. Hum. Brain Mapp. 8, 194-208. doi:10.1002/(SICI) 1097-0193(1999)8:4<194::AID-HBM4>3.0.CO;2-C

Lanius, R. A., Wiliamson, P. C., Densmore, M., Boksman, K., Neufeld, R. W., Gati, J. S., et al. (2004). The nature of traumatic memories: a 4-T fMRI functional connectivity analysis. Am. J. Psychiatry 161, 36-44. doi:10.1176/appi.ajp.161.1.36

Lavoie, M. E., Dupuis, F., Johnston, K. M., Leclerc, S., and Lassonde, M. (2004). Visual P300 effects beyond symptoms in concussed college athletes. J. Clin. Exp. Neuropsychol. 26, 55-73. doi:10.1076/jcen.26.1.55.23936

Lawrie, S. M., Buechel, C., Whalley, H. C., Frith, C. D., Friston, K. J., and Johnstone, E. C. (2002). Reduced frontotemporal functional connectivity in schizophrenia associated with auditory hallucinations. Biol. Psychiatry 51, 1008-1011. doi:10.1016/S0006-3223(02)01316-1

Le Van Quyen, M., Adam, C., Baulac, M., Martinerie, J., and Varela, F. J. (1998). Nonlinear interdependencies of EEG signals in human intracranially recorded temporal lobe seizures. Brain Res. 792, 24-40. doi:10.1016/S0006-8993(98) 00102-4

Le Van Quyen, M., Martinerie, J., Adam, C., and Varela, F. J. (1999). Nonlinear analyses of interictal EEG map the brain interdependencies in human focal epilepsy. Physica D 127, 250-266. doi:10.1016/S0167-2789(98)00258-9

Lee, J. S., Yang, B. H., Lee, J. H., Choi, J. H., Choi, I. G., and Kim, S. B. (2007). Detrended fluctuation analysis of resting EEG in depressed outpatients and healthy controls. Clin. Neuorphysiol. 118, 2489-2496. doi:10.1016/j.clinph.2007. 08.001

Lee, K.-H., Williams, L. M., Breakspear, M., and Gordon, E. (2003a). Synchronous gamma activity: a review and contribution to an integrative neuroscience model of schizophrenia. Brain Res. Rev. 41, 57-78. doi:10.1016/S0006-8993(02) 03841-6

Lee, K.-H., Williams, L. M., Haig, A., and Gordon, E. (2003b). “Gamma (40 Hz) phase synchronicity" and symptom dimension in schizophrenia. Cogn. Neuropsychiatry 8, 57-71. doi:10.1080/713752240

Lehmann, D., Faber, P. L., Galderisi, S., Herrmann, W. M., Kinoshita, T., Koukkou, M., et al. (2005). EEG microstate duration and syntax in acute, medication-naive, 
first-episode schizophrenia: a multi-center study. Psychiatry Res. 138, 141-156. doi:10.1016/j.pscychresns.2004.05.007

Leistedt, S. J., Coumans, N., Dumont, M., Lanquart, J. P., Stam, C. J., and Linkowski, P. (2009). Altered sleep brain functional connectivity in acutely depressed patients. Hum. Brain Mapp. 30, 2207-2219. doi:10.1002/hbm.20662

Lempel, A., and Ziv, J. (1976). On the complexity of finite sequences. IEEE Trans. Inf. Theory 22, 75-81. doi:10.1109/TIT.1976.1055501

Lenne, B., Blano, J. L., Nandrino, J. L., Gallois, P., Hautecoeur, P., and Pezard, L. (2012). Decrease of mutual information in bain electrical activity of patients with relapsing-remitting multiple sclerosis. Behav. Neurol. 27, 201-212. doi:10. 3233/BEN- 120278

Leon-Carrion, J., Martin-Rodriguez, J. F., Damas-Lopes, J., Barroso, Y., Martin, J. M., and Dominguez-Morales, M. R. (2008). A QEEG index of level of functional dependence for people sustaining acquired brain injury: the Seville independence index (SINDI). Brain Inj. 22, 61-74. doi:10.1080/02699050701824143

Leuchter, A. F., Spar, J. E., Walter, D. O., and Weiner, H. (1987). Electroencephalographic spectra and coherence in the diagnosis of Alzheimer's-type multi-infarct dementia. A pilot study. Arch. Gen. Psychiatry 44, 993-998. doi:10.1001/archpsyc. 1987.01800230073012

Levy, R., Hutchison, W. D., Lozano, A. M., and Dostrovsky, J. O. (2000). Highfrequency synchronization of neuronal activity in the subthalamic nucleus of parkinsonian patients with limb tremor. J. Neurosci. 20, 7766-7775.

Lew, H. L. (2001). Combined use of cognitive P300 response and somatosensory evoked potentials (SSEP) in predicting outcomes of severe traumatic brain injury (TBI) patients. Am. J. Phys. Med. Rehabil. 80, 310-311.

Lew, H. L. (2005). Rehabilitation needs of an increasing population of patients: traumatic brain injury, polytrauma, and blast related injuries. J. Rehabil. Res. Dev. 42, xiii-xv. doi:10.1682/JRRD.2005.07.0124

Lew, H. L., Chen, C. P. C., Chen, M. J. L., Hsu, T. H. C., Tang, S. F. T., and Date, E. S. (2002). Comparing the effects of different speech targets on cognitive eventrelated potentials: theoretical implications for evaluating brain injury. Am. J. Phys. Med. Rehabil. 81, 524-528. doi:10.1097/00002060-200207000-00011

Lew, H. L., Dikmen, S., Slimp, J., Temkin, N., Lee, E. H., Newell, D., et al. (2003). The use of somatosensory evoked potentials and cogntive event-related potentials in predicting out-comes of patients with severe traumatic brain injury. Am. J. Phys. Med. Rehabil. 82, 53-61. doi:10.1097/00002060-200301000-00009

Lew, H. L., Gray, M., and Poole, J. H. (2007a). Temporal stability of auditory eventrelated potentials in healthy individuals and patients with traumatic brain injury. J. Clin. Neurophysiol. 24, 392-397. doi:10.1097/WNP.0b013e31814a56e3

Lew, H. L., Gray, M., Poole, J. H., Chow, E., Salerno, R. M., and Date, E. S. (2007b). Test-retest reliability of ERPs in TBI and healthy individuals. J. Head Trauma Rehabil. 21, 430. doi:10.1097/00001199-200609000-00050

Lew, H. L., Lee, E. H., Pan, S. S. L., and Date, E. S. (2004). Electrophysiological abnormalities of auditory and visual information processing in patients with traumatic brain injury. Am. J. Phys. Med. Rehabil. 83, 428-433. doi:10.1097/ PHM.0b013e3181911102

Lew, H. L., Poole, J. H., Alvarez, S., and Moore, W. (2005a). Soldiers with occult traumatic brain injury. Am. J. Phys. Med. Rehabil. 84, 393-398. doi:10.1097/01. phm.0000163703.91647.a7

Lew, H. D., Poole, J. H., Chiang, J. Y. P., Lee, E. H., Date, E. S., and Warden, D. (2005b). Event related potential in facial affect recognition: potential clinical utility in patients with traumatic brain injury. J. Rehabil. Res. Dev. 42, 29-34. doi:10.1682/JRRD.2004.05.0056

Lew, H. L., Pan, S. L. and Lee, E. H. (2008). "Electrophysiological assessment techniques: evoked potentials and electroencephalography," in Brain Injury Medicine: Principles and Practice, eds N. D. Zasler, D. Katz, and R. Zafonte (New York: Demos Medical Publishing), 157-165.

Lew, H. L., Poole, J. H., Castenada, A., Salerno, R. M., and Gray, M. (2006). Prognostic value of evoked potentials and event-related potentials in moderate to severe brain injury. J. Head Trauma Rehabil. 21, 350-360. doi:10.1097/00001199200607000-00006

Lew, H. L., Slimp, J., Price, R., Massagli, T. L., and Robinson, L. R. (1999). Comparison of speech-evoked v. tone-evoked P300 response: implications for predicting outcomes in patients with traumatic brain injury. Am. J. Phys. Med. Rehabil. 78, 367-371. doi:10.1097/00002060-199907000-00014

Lewis, D., Pierri, J., Volk, D., Melchitzky, D., and Woo, T. U. (1999). Altered GABA neurotransmission and prefrontal cortical dysfunction in schizophrenia. Biol. Psychiatry 46, 616-626. doi:10.1016/S0006-3223(99)00061-X
Lewis, D. A., Hashimoto, T., and Volk, D. W. (2005). Cortical inhibitory neurons and schizophrenia. Nat. Rev. Neurosci. 6, 312-324. doi:10.1038/nrn1648

Li, Y., Tong, S., Liu, D., Gai, Y., Wang, X., Wang, J., et al. (2008). Abnormal EEG complexity in patients with schizophrenia and depression. Clin. Neurophysiol. 119, 1232-1241. doi:10.1016/j.clinph.2008.01.104

Light, G. A., Hsu, J. L., Hsich, M. H., Meyer-Gomes, K., Sprack, J., Swerdlow, N. R., et al. (2006). Gamma band oscillations reveal neural network cortical coherence dysfunction in schizophrenic patients. Biol. Psychiatry 60, 1231-1240. doi:10.1016/j.biopsych.2006.03.055

Linkenkaer-Hansen, K., Monto, S., Rytsälä, H., Suominen, K., Isometsä, E., and Köhkönen, S. (2005). Breakdown of long range temporal correlations in theta oscillations in patients with major depressive disorder. J. Neurosci. 25, 10131-10137. doi:10.1523/JNEUROSCI.3244-05.2005

Llinás, R., Ribary, U., Jeanmonod, D., Kronberg, E., and Mitra, P. P. (1999). Thalamocortical dysrhythmia: a neurological and neuropsychiatric syndrome characterized by magnetoencephalography. Proc. Natl. Acad. Sci. U.S.A. 96, 15222-15227. doi:10.1073/pnas.96.26.15222

Locatelli, T., Cursi, M., Liberati, D., Franceschi, J., and Comi, G. (1998). EEG coherence in Alzheimer's disease. Electroencephalogr. Clin. Neurophysiol. 106, 229-237. doi:10.1016/S0013-4694(97)00129-6

Lund, T. R., Sponheim, S. R., Iacono, W. G., and Clementz, B. A. (1995). Internal consistency reliability of resting EEG power spectra in schizophrenic and normal subjects. Psychophysiology 32, 66-71. doi:10.1111/j.1469-8986.1995. tb03407.x

Lynall, M. E., Bassett, D. S., Kerwin, R., McKenna, P. J., Kitzbichler, M., Muller, U., et al. (2010). Functional connectivity and brain networks in schizophrenia. J. Neurosci. 30, 9477-9487. doi:10.1523/JNEUROSCI.0333-10.2010

Maltez, J., Hyllienmark, K., Nikulia, V. V., and Brismar, T. (2004). Time course and variability of power in different frequency bands of the EEG during resting conditions. Clin. Neurophysiol. 34, 195-202. doi:10.1016/j.neucli.2004.09.003

Mars, N. J. I., and Lopes da Silva, F. H. (1983). Propagation of seizure activity in kindled dogs. Electroencephalogr. Clin. Neurophysiol. 56, 194-209. doi:10.1016/ 0013-4694(83)90074-3

Mars, N. J. I., Thompson, P. M., and Wilkus, R. J. (1985). Spread of epileptic seizure activity in humans. Epilepsia 26, 85-94. doi:10.1111/j.1528-1157.1985.tb05192.x

Matsumoto, A., Ichikawa, Y., Kanayama, N., Ohira, H., and Iidaka, T. (2006). Gamma band activity and its synchronization reflect the dysfunctional emotional processing in alexithymic persons. Psychophysiology 43, 533-540. doi:10.1111/j. 1469-8986.2006.00461.x

Mazzini, L. (2004). Clinical applications of event-related potentials in brain injury. Phys. Med. Rehabil. Clin. N. Am. 15, 163-175. doi:10.1016/S1047-9651(03) 00101-3

Mazzini, L., Pisano, F., Zaccala, M., Miscio, G., Gareri, F., and Galante, M. (1999). Somatosensory and motor evoked potentials at different stages of recovery from severe traumatic brain injury. Arch. Phys. Med. Rehabil. 80, 33-39. doi:10.1016/S0003-9993(99)90304-0

Mazzini, L., Zaccala, M., Gareri, F., Giordano, A., and Angelino, E. (2001). Long latency auditory-evoked potentials in severe traumatic brain injury. Arch. Phys. Med. Rehabil. 82, 57-65. doi:10.1053/apmr.2001.18076

McCrea, M., Prichep, L. S., Powell, M. R., Chabot, R., and Barr, W. B. (2010). Acute effects and recovery after sports-related concussion: a quantitative brain electrical activity study. J. Head Trauma Rehabil. 25, 283-292. doi:10.1097/HTR. 0b013e3181e67923

McDowell, K., Chin-Teng, L., Oie, K. S., Tzyy-Ping, J., Gordon, S., Whitaker, K. W., et al. (2013). Real-world neuroimaging technologies. IEEE 1, 131-149.

McGraw, K. O., and Wong, S. P. (1996). Forming inferences about some intraclass correlation coefficients. Psychol. Methods 1, 30-46. doi:10.1037/1082-989X.1.1. 30

Michelyannis, S., Pachou, E., Stam, C. J., Breakspear, M., Bitsios, P., Vourkas, M., et al. (2006). Small-world networks and disturbed functional connectivity in schizophrenia. Schizophr. Res. 87, 60-66. doi:10.1016/j.schres.2006.06.028

Mizuno, T., Takahashi, T., Cho, R. Y., Kikuchi, M., Murata, T., Takahashi, K., et al. (2010). Assessment of EEG dynamical complexity in Alzheimer's disease using multiscale entropy. Clin. Neurophysiol. 121, 1438-1446. doi:10.1016/j.clinph. 2010.03.025

Moeller, J. J., Tu, B., and Bazil, C. W. (2011). Quantitative and qualitative analysis of ambulatory electroencephalography during mild traumatic brain injury. Arch. Neurol. 68, 1595-1598. doi:10.1001/archneurol.2011.1080 
Montgomery, E. A., Fenton, G. W., McClelland, R. J., MacFlynn, G., and Rutherford, W. H. (1991). The psychobiology of minor head injury. Psychol. Med. 21, 375-384. doi:10.1017/S0033291700020481

Morrow, J. R., and Jackson, A. W. (1993). How 'significant' is your reliability? Res. Q. Exerc. Sport 64, 352-355. doi:10.1080/02701367.1993.10608821

Mullen, K. M., Vohr, B. R., Katz, K. H., Schneider, K. C., Lacadie, C., Hampson, M., et al. (2011). Preterm birth results in alterations in neural connectivity at age 16 years. Neuroimage 54, 2563-2570. doi:10.1016/j.neuroimage.2010.11.019

Müller, R., and Büttner, P. (1994). A critical discussion of intraclass correlation coefficients. Stat. Med. 13, 2465-2476. doi:10.1002/sim.4780132310

Müller, T. J., Federspiel, A., Horn, H., Lövblad, K., Lehmann, C., Dierks, T., et al. (2005). The neurophysiological time pattern of illusionary visual perceptual transitions: a simultaneous EEG and fMRI study. Int. J. Psychophysiol. 55, 299-312. doi:10.1016/j.ijpsycho.2004.09.004

Münte, T. F., and Heinze, H. J. (1994). Brain potentials reveal deficits of language processing after closed head injury. Arch. Neurol. 51, 482-493. doi:10.1001/archneur. 1994.00540170058017

Murias, M., Webb, S. J., Greenson, J., and Dawson, G. (2007). Resting state cortical connectivity reflected in EEG coherence in individuals with autism. Biol. Psychiatry 62, 270-273. doi:10.1016/j.biopsych.2006.11.012

Nakamura, T., Hillary, F. G., and Biswal, B. B. (2009). Resting network plasticity following brain injury. PLoS ONE 4:e8220. doi:10.1371/journal.pone.0008220

Naunheim, R. S., and Casner, T. (2010). Novel method for detecting brain abnormality in a patient with epidural hematoma: a case report. Am. J. Emerg. Med. 28, e1-e386. doi:10.1016/j.ajem.2009.05.008

Naunheim, R. S., Treaster, M., English, J., Casner, T., and Chabot, R. (2010a). Use of brain electrical activity to quantify traumatic brain injury in the emergency department. Brain Inj. 24, 1324-1329. doi:10.3109/02699052.2010.506862

Naunheim, R. S., Treaster, M., English, J., and Casner, T. (2010b). Automated electroencephalogram (EEG) identifies abnormalities in the Emergency Department. Am. J. Emerg. Med. 29, 845-848. doi:10.1016/j.ajem.2010.03.010

Nikulin, V. V., and Brismar, T. (2004). Comment on "Multscale entropy analysis of complex physiologic time series”. Phys. Rev. Lett. 92, 089803. doi:10.1103/ PhysRevLett.92.089803

Nolte, G., Bai, O., Wheaton, L., Mari, Z., Vorbach, S., and Hallet, M. (2004). Identifying true brain interaction from EEG data using the imaginary part of coherency. Clin. Neurophsyiol. 115, 2292-2307. doi:10.1016/j.clinph.2004.04.029

Nolte, G., Ziehe, A., Nikulin, V. V., Schlögl, A., Krämer, N., Brismar, T., et al. (2008). Robustly estimating the flow direction of information in complex physical systems. Phys. Rev. Lett. 100, 234101. doi:10.1103/PhysRevLett.100.234101

Nunez, P. L., Silberstein, R. B., Shi, Z. P., Carpenter, M. R., Srinivasan, R., Tucker, D. M., et al. (1999). EEG coherency II: experimental comparisons of multiple measures. Clin. Neurophsyiol. 110, 469-486. doi:10.1016/S1388-2457(98)00043-1

Nunez, P. L., Srinivasan, R., Westdorp, A. F., Wijesinghe, R. S., Tucker, D. M., Silberstein, R. B., et al. (1997). EEG coherency. I: statistics, reference electrode, volume conduction, Laplacians, cortical imaging and interpretation at multiple scales. Electroencephalogr. Clin. Neurophysiol. 103, 499-515. doi:10.1016/S00134694(97)00066-7

Nuwer, M. (1997). Assessment of digital EEG, quantitative EEG, and EEG brain mapping: report of the American Academy of Neurology and the American Clinical Neurophysiology Society. Neurology 49, 277-292. doi:10.1212/WNL.49.1.277

Nuwer, M. R., Hovda, D. A., Schrader, L. M., and Vespa, P. M. (2005). Routine and quantitative EEG in mild traumatic brain injury. Clin. Neurophysiol. 116, 2001-2025. doi:10.1016/j.clinph.2005.05.008

O’Donnell, B. F., Hetrick, W. P., Vohs, J. L., Krisnan, G. P., Carroll, C. A., and Shekhar, A. (2004). Neural synchronization deficits to auditory stimulation in bipolar disorder. Neuroreport 15, 1369-1372. doi:10.1097/01.wnr.0000127348.64681.b2

Olbrich, H. M., Nau, H. E., Zerbin, D., Lanczos, L., Lodemann, E., Engelmeier, M. P., et al. (1986). Clinical application of event related potentials in patients with brain tumours and traumatic head injuries. Acta Neurochir. (Wien) 80, 116-122. doi:10.1007/BF01812285

O’Neil, B., Prichep, L. S., Naunheim, R., and Chabot, R. (2012). Quantitative brain electrical activity in the initial screening of mild traumatic brain injuries. West. J. Emerg. Med. 13, 394-400. doi:10.5811/westjem.2011.12.6815

Onofrj, M., Curatola, L., Malatesta, G., Bazzano, S., Colamartino, P., and Flugente, T. (1991). Reduction of P3 latency during outcome of post-traumatic amnesia. Acta Neurol. Scand. 83, 273-279. doi:10.1111/j.1600-0404.1991.tb04700.x

Orekhova, E. V., Stroganova, T. A., Nygren, G., Tsetlin, M. M., Posikera, I. W., Gillberg, C., et al. (2007). Excess of high frequency electroencephalogram oscillations in boys with autism. Biol. Psychiatry 62, 1022-1029. doi:10.1016/j.biopsych.2006. 12.029

Papanicolaou, A. C., Levin, H. S., Eisenberg, H. M., Moore, B. D., Goethe, K. E., and High, WM Jr (1984). Evoked potential correlates of posttraumatic amnesia after closed head injury. Neurosurgery 14, 676-678. doi:10.1097/00006123198406000-00005

Papo, D. (2013). Time scales in cognitive neuroscience. Front. Physiol. 4:86. doi:10.3389/fphys.2013.00086

Park, C.-A., Kown, R.-J., Kim, S., Jang, H.-R., Chae, J.-H., Kim, T., et al. (2007) "Decreased phase synchronization of the EEG in patients with major depressive disorder," in IFMBE Proceedings, Vol. 14, eds R. Magjurevic and J. H. Nagel (Seoul: World Congress on Medical Physics and Biomedical Engineering), 1095-1098.

Park, C. H., Wang, S. M., Lee, H. K., Kweon, Y. S., Lee, C. T., Kim, K. T., et al. (2014). Affective state-dependent changes in the brain functional network in major depressive disorder. Soc. Cogn. Affect. Neurosci. 9, 1404-1412. doi:10.1093/scan/nst126

Penttonen, M., and Buzsáki, G. (2003). Natural logarithmic relationship between brain oscillators. Thalamus Relat. Syst. 2, 145-152. doi:10.1016/S1472-9288(03) 00007-4

Perdikis, D., Huys, R., and Jirsa, V. (2011a). Complex processes from dynamical architectures with time-scale hierarchy. PLoS ONE 6:e16589. doi:10.1371/journal. pone. 0016589

Perdikis, D., Huys, R., and Jirsa, K. (2011b). Time scale hierarchies in the functional organization of complex behaviors. PLoS Comput. Biol. 7:e1002198. doi:10.1371/journal.pcbi.1002198

Perlstein, W. M., Larson, M. J., Dotson, V. M., and Kelly, K. G. (2006). Temporal dissociation of components of cognitive control dysfunction in severe TBI: ERPs and the cued-Stroop task. Neuropsychologia 44, 260-274. doi:10.1016/j. neuropsychologia.2005.05.009

Pinault, D. (2008). N-methyl d-aspartate receptor antagonists ketamine and MK-801 induce wake related aberrant $\gamma$ oscillations in the rat neocortex. Biol. Psychiatry 63, 730-735. doi:10.1016/j.biopsych.2007.10.006

Pincus, S. M. (1991). Approximate entropy as a measure of system complexity. Proc. Natl. Acad. Sci. U.S.A. 88, 2297-2301. doi:10.1073/pnas.88.6.2297

Pincus, S. M., and Goldberger, A. L. (1994). Physiological time-series analysis: what does regularity quantify? Am. J. Physiol. 266, H1643-H1656.

Pollock, V. E., Schneider, L. S., and Lyness, S. A. (1991). Reliability of topographic quantitative EEG amplitude in healthy late-middle-aged and elderly subjects. Electroencephalogr. Clin. Neurophysiol. 79, 20-26. doi:10.1016/0013-4694(91) 90152-T

Polo, M. D., Newton, P., Rogers, D., Escera, C., and Butler, S. (2002). ERPs and behavioural indices of long-term preattentive and attentive deficits following closed skull head injury. Neuropsychologia 40, 2350-2359. doi:10.1016/S0028-3932(02) 00127-6

Ponten, S. C., Bartolemi, F., and Stam, C. J. (2007). Small-world networks and epilepsy: graph theoretical analysis of intracerebrally recorded mesial temporal lobe seizures. Clin. Neurophysiol. 118,918-927. doi:10.1016/j.clinph.2006.12.002

Pontifex, M. B., O'Connor, P. M., Broglio, S. P., and Hillman, C. H. (2009). The association between mild traumatic brain history and cognitive control. Neuropsychologia 47, 3210-3216. doi:10.1016/j.neuropsychologia.2009.07.021

Potter, D. D., and Barrett, K. (1999). Assessment of mild head injury with ERPs and neuropsychological tasks. J. Psychophysiol. 13, 173-189. doi:10.1027//0269-8803. 13.3.173

Potter, D. D., Bassett, M. R., Jory, S. H., and Barrett, K. (2001). Changes in eventrelated potentials in a three-stimulus auditory oddball task after mild head injury. Neuropsychologia 39, 1464-1472. doi:10.1016/S0028-3932(01)00057-4

Potter, D. D., Jory, S. H., Bassett, M. R. A., Barrett, K., and Mychalkiw, W. (2002). Effect of mild head injury on event related potentials of Stroop task performance. J. Int. Neuropsychol. Soc. 8, 828-837. doi:10.1017/S1355617702860118

Pratap-Chand, R., Sinniah, M., and Salem, F. (1988). Cognitive evoked potential (P300): a metric for cerebral concussion. Acta Neurol. Scand. 78, 185-189. doi:10.1111/j.1600-0404.1988.tb03643.x

Prichard, D., and Theiler, J. (1994). Generating surrogate data for time series with several simultaneously measured variables. Phys. Rev. Lett. 73, 951-954. doi:10.1103/PhysRevLett.73.951

Prichep, L. S., Jacquin, A., Filipenko, J., Dastidar, S. G., Zabele, S., Vodencarevic, A., et al. (2012a). Classification of traumatic brain injury severity using informed data reduction in a series of binary classifier algorithms. IEEE Trans. Neural Syst. Rehabil. Eng. 20, 806-822. doi:10.1109/TNSRE.2012.2206609 
Prichep, L. S., McCrea, M., Barr, W., Powell, M., and Chabot, R. J. (2012b). Time course of clinical and electrophysiological recovery after sportrelated concussion. J. Head Trauma Rehabil. 28, 266-273. doi:10.1097/HTR. 0b013e318247b54e

Prichep, L. S., John, E. R., Ferris, S. H., Rausch, L., Fang, Z., Cancro, R., et al. (2006). Prediction of longitudinal cognitive decline in normal elderly with subjective complaints using electrophysiological imaging. Neurobiol. Aging 27, 471-481. doi:10.1016/j.neurobiolaging.2005.07.021

Ramdani, S., Seigle, B., Lagarde, J., Bouchara, F., and Bernard, P. L. (2009). On the use of sample entropy to analyze human postural sway data. Med. Eng. Phys. 31, 1023-1031. doi:10.1016/j.medengphy.2009.06.004

Ramos-Loyo, J., González-Garrido, A. A., and Sánchez-Loyo, L. M. (2009). Eventrelated potentials and event-related oscillations during identity and facial emotional processing in schizophrenia. Int. J. Psychophysiol. 71, 84-90. doi:10.1016/ j.ijpsycho.2008.07.008

Rapp, P. E., Cellucci, C. J., Watanabe, T. A. A., Albano, A. M., and Schmah, T. I. (2001). Surrogate data pathologies and the false-positive rejection of the null hypothesis. Int. J. Bifurcat. Chaos 11, 983-997. doi:10.1142/S021812740100250X

Rapp, P. E., and Curley, K. C. (2012). Is a diagnosis of "mild traumatic brain injury" a category mistake? J. Trauma Acute Care Surg. 73(2 Suppl. 1), S13-S23. doi:10.1097/TA.0b013e318260604b

Rapp, P. E., Rosenberg, B. M., Keyser, D. O., Nathan, D., Toruno, K. M., Cellucci, C. J., et al. (2013a). Patient characterization protocols for psychophysiological studies of traumatic brain injury and post-TBI psychiatric disorders. Front Neurol. 4:91. doi:10.3389/fneur.2013.00091

Rapp, P. E., Darmon, D. M., and Cellucci, C. J. (2013b). "Hierarchical transition chronometries in the human central nervous system," in Proceedings International Conference on Nonlinear Theory and Applications, Santa Fe, NM.

Rappaport, M., Hemmerle, A. V., and Rappaport, M. L. (1990). Intermediate and long latency SEPs in relation to clinical disability in traumatic brain in jury patients. Clin. Electroencephalogr. 21, 188-191. doi:10.1177/ 155005949002100406

Raz, A., Vaadia, E., and Bergman, H. (2000). Firing patterns and correlations of spontaneous discharge of pallidal neurons in the normal and the tremulous 1-methyl-4-phenyl-1,2,3,6-tetrahydropyridine vervet model of parkinsonism. J. Neurosci. 20, 8559-8571.

Reinvang, I. (1999). Cogntive event-related potentials in neuropsychological assessment. Neuropsychol. Rev. 9, 321-348. doi:10.1023/A:1021638723486

Reinvang, I., Nordby, H., and Nielsen, C. S. (2000). Information processing deficits in head injury assessed with ERPs reflecting early and late processing stage. $\mathrm{Neu}$ ropsychologia 38, 995-1005. doi:10.1016/S0028-3932(99)00153-0

Reshef, D. N., Reshef, Y. A., Finucane, H. K., Grossman, S. R., Mcvean, G., Turnbaugh, P. J., et al. (2011). Detecting novel associations in large data sets. Science 334, 1518-1524. doi:10.1126/science. 1205438

Reuter, B. M., and Linke, D. B. (1989). "P300 and coma," in Topographic Brain Mapping of EEG and Evoked Potentials, ed. K. Maurer (New York, NY: SpringerVerlag), 192-196.

Richardson, M. J., Lopresti-Goodman, S., Mancini, M., Kay, B., and Schmidt, R. C. (2008). Comparing the attractor strength of intra- and interpersonal interlimb coordination using cross recurrence analysis. Neurosci. Lett. 438, 340-345. doi:10.1016/j.neulet.2008.04.083

Richman, J. S., and Moorman, J. R. (2000). Physiological time-series analysis using approximate entropy and sample entropy. Am. J. Physiol. Heart Circ. Physiol. 278, H2039-H2049.

Rigg, J. L., and Mooney, S. R. (2011). Concussions and the military: issues specific to service members. PM R 3(10 Suppl. 2), S380-S386. doi:10.1016/j.pmrj.2011. 08.005

Rippon, G., Brock, J., Brown, C., and Boucher, J. (2007). Disordered connectivity in the autistic brain: challenges for the "new psychophysiology". Int. J. Psychophysiol. 63, 164-172. doi:10.1016/j.ijpsycho.2006.03.012

Rizzo, P. A., Amabile, G., Caporali, M., Spadaro, M., Zanasi, M., and Morocutti, C. (1978). A CNV study in a group of patients with traumatic head injuries. Electroencephalogr. Clin. Neurophysiol. 45, 281-285. doi:10.1016/0013-4694(78) 90012-3

Roche, R. A. P., Dockree, P. M., Garavan, H., Foxe, J. J., Robertson, I. H., and O'Mara, S. M. (2004). EEG alpha power changes reflect response inhibition deficits after traumatic brain injury (TBI) in humans. Neurosci. Lett. 362, 1-5. doi:10.1016/j.neulet.2003.11.064
Rockstroh, B. S., Wienbruch, C., Ray, W. J., and Elbert, T. (2007). Abnormal oscillatory brain dynamics in schizophrenia: a sign of deviant communication in an neural network? BMC Psychiatry 7:44. doi:10.1186/1471-244X-7-44

Romano, M. C., Thiel, M., Kurths, J., and von Bloh, W. (2004). Multivariate recurrence plots. Phys. Lett. A 330, 214-223. doi:10.1016/j.physleta.2004.07.066

Roopun, A. K., Cunningham, M. O., Rucca, C., Alter, K., Traub, R. D., and Whittington, M. A. (2008). Region-specific changes in gamma and beta2 rhythms in NMDA receptor dysfunction models of schizophrenia. Schizophr. Bull. 34, 962-973. doi:10.1093/schbul/sbn059

Rosenbaum, R. S., Furey, M. L., Horwitz, B., and Grady, C. L. (2008). Altered connectivity among emotion-related brain regions during short-term memory in Alzheimer's disease. Neurobiol. Aging 31, 780-786. doi:10.1016/j.neurobiolaging. 2008.06.002

Rubinov, M., Sporns, O., Van Leeuwen, C., and Breakspear, M. (2009). Symbiotic relationship between brain structure and dynamics. BMC Neurosci. 10:55. doi:10.1186/1471-2202-10-55

Rugg, M. D., Cowan, C. P., Nagy, M. E., Milner, A. D., Jacobson, I., and Brooks, D. N. (1988). Event related potentials from closed head injury patients in an auditory "oddball" task: evidence of dysfunction in stimulus categorization. J. Neurol. Neurosurg. Psychiatry 51, 691-698. doi:10.1136/jnnp. 51.5.691

Rugg, M. D., Pickles, C. D., Potter, D. D., Doyle, M. C., Pentland, B., and Roberts, R. C. (1993). Cogntive brain potentials in a three stimulus auditory "oddball" task after closed head injury. Neuropsychologica 31, 373-393. doi:10.1016/0028-3932(93)90161-R

Rulkov, N. F., Sushchik, M. M., Tsimring, L. S., and Abarbanel, H. D. I. (1995). Generalized synchronization of chaos in directionally coupled chaotic systems. Phys. Rev. E Stat. Phys. Plasmas Fluids Relat. Interdiscip. Topics 51, 980-994. doi:10.1103/PhysRevE.51.980

Sabeti, M., Katebi, S., and Boostani, R. (2009). Entropy and complexity measures for EEG signal classification of schizophrenic and control participants. Artif. Intell. Med. 47, 263-274. doi:10.1016/j.artmed.2009.03.003

Salinsky, M. C., Oken, B. S., and Morehead, L. (1991). Test-retest reliability in EEG frequency analysis. Electroencephalogr. Clin. Neurophysiol. 79, 382-392. doi:10.1016/0013-4694(91)90203-G

Sangal, R. B., and Sangal, J. M. (1996). Closed head injury patients with mild cognitive complaints without neurological or psychiatric findings have abnormal visual P300 latencies. Biol. Psychiatry 39, 305-307. doi:10.1016/0006-3223(95) 00447-5

Sazonov, A. V., Ho, C. K., Bergmans, J. W. M., Arends, J. B. A. M., Griep, P. A. M., Verbitskiy, E. A., et al. (2009). An investigation of phase locking index for measuring interdependency of cortical source signals recorded in the EEG. Biol. Cyben. 100, 129-146. doi:10.1007/s00422-008-0283-4

Schiff, S. J. (2005). Dangerous phase. Neuroinformatics 3, 315-318. doi:10.1385/NI: 3:4:315

Schnitzler, A., and Gross, J. (2005). Normal and pathological oscillatory communication in the brain. Nat. Rev. Neurosci. 6, 285-296. doi:10.1038/nrn 1650

Schreiber, T. (2000). Measuring information transfer. Phys. Rev. Lett. 85, 461-464. doi:10.1103/PhysRevLett.85.461

Segalowitz, S. J., Bernstein, D. M., and Lawson, S. (2001). P300 event-related potential decrements in well-functioning university students with mild head injury 6 years post-injury. Brain Cogn. 45, 342-356. doi:10.1006/brcg.2000.1263

Segalowitz, S. J., Dywan, J., and Unsal, A. (1997). Attentional factors in response time variability after traumatic brain injury: an ERP study. J. Int. Neuropsychol. Soc. 3, 95-107.

Segalowitz, S. J., Unsal, A., and Dywan, J. (1992). CNV evidence for the distinctiveness of frontal and posterior processes in traumatic brain injury. J. Clin. Exp. Neuropsychol. 14, 545-565. doi:10.1080/01688639208402844

Shannon, C. E. (1948). A mathematical theory of communication. Bell Syst. Tech. J. 27, 379-423. doi:10.1002/j.1538-7305.1948.tb01338.x

Shaw, M. (2002). Abnormal functional connectivity in posttraumatic stress disorder. Neuroimage 15, 661-674. doi:10.1006/nimg.2001.1024

Shrout, P. E., and Fleiss, J. L. (1979). Intraclass correlations: uses in assessing rater reliability. Psychol. Bull. 86, 420-428. doi:10.1037/0033-2909.86.2.420

Siegel, S. J., Ehrlichman, R. S., Phillips, J. M., Liang, Y., Turetsky, B. I., Aillon, D. D., et al. (2006). Ketamine causes persistent oscillations similar to schizophrenia and reduced hippocampal glutamate concentrations in mice. Biol. Psychiatry 59, 245 S. 
Sims, C. (1972). Money, income and causality. Am. Econ. Rev. 62, 540-552.

Sinai, Y. A. G. (1959). On the concept of entropy of a dynamical system. Dokl. Acad. Nauk USSR 124, 768-781.

Slewa-Younan, S., Green, A. M., Baguley, I. J., Felminham, K. L., Haig, A. R., and Gordon, E. (2002). Is 'gamma' ( $40 \mathrm{~Hz}$ ) synchronous activity disturbed in patients with traumatic brain injury? Clin. Neurophysiol. 113, 1640-1646. doi:10.1016/S1388-2457(02)00239-0

Sloan, E. P., and Fenton, G. W. (1993). EEG power spectra and cognitive change in geriatric psychiatry: a longitudinal study. Electroencephalogr. Clin. Neurophysiol. 86, 361-367. doi:10.1016/0013-4694(93)90131-E

Slobounov, S., Sebastianelli, W., and Hallett, M. (2012). Residual brain dysfunction observed one year post mild traumatic brain injury combined EEG and balance study. Clin. Neurophysiol. 123, 1755-1756. doi:10.1016/j.clinph.2011.12.022

Smit, D. J., Stam, C. J., Posthuma, D., Boomsma, D. I., and de Geus, E. J. (2008). Heritability of "small-world" networks in the brain: a graph theoretical analysis of resting-state EEG functional connectivity. Hum. Brain Mapp. 29, 1368-1378. doi: $10.1002 / \mathrm{hbm} .20468$

Solbakk, A.-K., Reinvang, I., and Andersson, S. (2002). Assessment of P3a and P3b after moderate to severe brain injury. Clin. Electroencephalogr. 33, 102-110. doi:10.1177/155005940203300306

Solbakk, A.-K., Reinvang, I., Nielsen, C., and Sundet, K. (1999). ERP indicators of disturbed attention in mild closed head injury: a frontal lobe syndrome? Psychophysiology 36, 802-817. doi:10.1111/1469-8986.3660802

Solbakk, A.-K., Reinvang, I., and Nielsen, C. S. (2000). ERP indices of resource allocation difficulties in mild head injury. J. Clin. Exp. Neuropsychol. 22, 743-760. doi:10.1076/jcen.22.6.743.953

Solbakk, A.-K., Reinvang, I., Svebak, S., Nielsen, C. S., and Sundet, K. (2005). Attention to affective pictures in closed head injury: event-related brain potentials and cardiac responses. J. Clin. Exp. Neurospychol. 27, 205-223. doi:10.1080/ 13803390490515739

Spencer, K. M. (2005). “Averaging, detection and classification of single-trial ERPs," in Event Related Potentials: A Methods Handbook, ed. T. C. Handy (Cambridge, MA: MIT Press), 209-227.

Spencer, K. M., Nestor, P. G., Niznikiewicz, M. A., Salisbury, D. F., Shenton, M. E., and Mccarley, R. W. (2003). Abnormal neural synchrony in schizophrenia. J. Neurosci. 23, 7407-7411.

Spencer, K. M., and McCarley, R. W. (2006). Neuropsychiatric abnormalities: a new vista from studies on fundamental properties of neural communication. Psychiatr. Times 25. Available at: http://www.psychiatrictimes.com/display/article/ $10168 / 46711$

Spencer, K. M., Nestor, P. G., Perlmutter, R., Niznuikiewicz, M. A., Klump, M. C., Frumin, M., et al. (2004). Neural synchrony indexes, disordered perception and cognition in schizophrenia. Proc. Natl. Acad. Sci. U.S.A. 101, 17288-17293. doi:10.1073/pnas.0406074101

Spencer, K. M., Niznikiewicz, M. A., Shenton, M. E., and McCarley, R. W. (2008a). Sensory-evoked gamma oscillations in chronic schizophrenia. Biol. Psychiatry 63, 744-747. doi:10.1016/j.biopsych.2007.10.017

Spencer, K. M., Salisbury, D. F., Shenton, M. E., and McCarley, R. W. (2008b). Gamma-band auditory steady-state responses are impaired in first episode patients. Biol. Psychiatry 64, 369-375. doi:10.1016/j.biopsych.2008.02.021

Spikman, J. M., van der Naalt, J., van Weerden, T. W., and van Zomeren, A. H. (2004). Indices of slowness of information processing in head injury patients: tests for selective attention related to ERP latencies. J. Int. Neuropsychol. Soc. 10, 851-861. doi:10.1017/S1355617704106061

Sponheim, S. R., McGuire, K. A., Kang, S. S., Davenport, N. D., Aviyente, S., Bernat, E. M., et al. (2011). Evidence of disrupted functional connectivity in the brain after combat-related blast injury. Neuorimage 54, S21-S29. doi:10.1016/j.neuroimage. 2010.09.007

Stam, C. J. (2005). Nonlinear dynamical analysis of EEG and MEG: review of an emerging field. Clin. Neurophysiol 116, 2266-2301. doi:10.1016/j.clinph.2005.06. 011

Stam, C. J., de Haan, W., Daffertshofer, A., Jones, B. F., Manshanden, I., van Cappellen van Walsum, A. M., et al. (2009). Graph theoretical analysis of magentoencephalographic functional connectivity in Alzheimer's disease. Brain 132, 213-224. doi:10.1093/brain/awn262

Stam, C. J., Jones, B. F., Manshanden, I., Van Cappellen Van Walsum, A. M., Montez, T., Verbunt, J. P., et al. (2006). Magnetoencephalographic evaluation of restingstate functional connectivity in Alzheimer's disease. Neuroimage 32, 1335-1344. doi:10.1016/j.neuroimage.2006.05.033
Stam, C. J., Jones, B. F., Nolte, G., Breakspear, M., and Scheltens, P. H. (2007). Smallworld networks and functional connectivity in Alzheimer's disease. Cereb. Cortex 17, 92-99. doi:10.1093/cercor/bhj127

Stam, C. J., Van Der Made, Y., Pijnenburg, Y. A., and Scheltens, P. (2003). EEG synchronization in mild cognitive impairment and Alzheimer's disease. Acta Neurol. Scand. 108, 90-96.

Stam, C. J., and van Dijk, B. W. (2002). Synchronizaiton likelihood: an unbiased measure of generalized synchronization in multivariate data sets. Physica D 163, 236-251. doi:10.1016/S0167-2789(01)00386-4

Steuer, R., Molgedey, L., Ebeling, W., and Jiménez-Montaño, M.-A. (2001). Entropy and optimal partition for data analysis. Eur. Phys. J. B 19, 265-269. doi:10.1007/ s100510170335

Stoffers, D., Bosboom, J. L. W., Deijen, J. B., Walters, E. C., Berendse, H. W., and Stam, C. J. (2007). Slowing of oscillatory brain activity is a stable characteristic of Parkinson's disease without dementia. Brain 130, 1847-1860. doi:10.1093/brain/awm034

Stratford, P. W. (1989). Confidence limits for your ICC. Phys. Ther. 69, 237-238.

Symond, M. B., Harris, A. W. F., Gordon, E., and Williams, L. M. (2005). "Gamma synchrony" in first-episode schizophrenia: a disorder of temporal connectivity? Am. J. Psychiatry 162, 459-465. doi:10.1176/appi.ajp.162.3.459

Takahashi, T., Cho, R. Y., Mizuno, T., Kikuchi, M., Murata, T., Takahashi, K., et al. (2010). Antipsychotics reverse abnormal EEG complexity in drug-naive schizophrenia: a multiscale entropy analysis. Neuroimage 51, 173-182. doi:10.1016/j. neuroimage.2010.02.009

Takens, F. (1981). "Detecting strange attractors in turbulence," in Lecture Notes in Mathematics, Vol. 898, eds D. A. Rand and L. S. Young (New York, NY: SpringerVerlag), 365-381.

Tebano, M. T., Cameroni, M., Gallozzi, G., Loizzo, A., Palazzino, G., Pezzini, G., et al. (1988). EEG spectral analysis after minor head injury in man. Electroencephalogr. Clin. Neurophysiol. 70, 185-189. doi:10.1016/0013-4694(88)90118-6

Thatcher, R. W. (2000). EEG operant conditioning (biofeedback) and traumatic brain injury. Clin. Electroencephalogr. 31, 38-44. doi:10.1177/ 155005940003100110

Thatcher, R. W. (2006). "Electroencephalography and mild traumatic brain injury," in Foundations of Sports Related Brain Injuries, eds S. M. Slobounov and W. J. Sebastianelli (New York, NY: Springer-Verlag), 241-266.

Thatcher, R. W., Biver, C., Gomez, J. F., North, D., Curtin, R., Walker, R. A., et al. (2001). Estimation of the EEG power spectrum using MRI T2 relaxation time in traumatic brain injury. Clin. Neurophysiol. 112, 1729-1745. doi:10.1016/S1388-2457(01)00609-5

Thatcher, R. W., Biver, C. J., and North, D. M. (2003). Quantitative EEG and the Frye and Daubert standards of admissibility. Clin. Electroencephalogr. 34, 39-53.

Thatcher, R. W., Cantor, D. S., McAlaster, R., Geisler, F., and Krause, P. (1991). Comprehensive predictions of outcome in closed head injury: the development of prognostic equations. Ann. N. Y. Acad. Sci. 620, 82-104. doi:10.1111/j.17496632.1991.tb51576.x

Thatcher, R. W., Moore, N., John, E. R., Duffy, F., Hughes, J. R., and Krieger, M. (1999). QEEG and traumatic brain injury: rebuttal of the American Academy of Neurology 1997 report by the EEG and Clinical Neuroscience Society. Clin. Electroencephalogr. 30, 94-98. doi:10.1177/155005949903000304

Thatcher, R. W., Walker, R. A., Gerson, I., and Geisler, F. (1989). EEG discriminant analyses of mild head trauma. Electroencephalogr. Clin. Neurophysiol. 73, 93-106. doi:10.1016/0013-4694(89)90188-0

Theiler, J., Eubank, S., Longtin, A., Galdrikian, B., and Farmer, J. D. (1992). Testing for nonlinearity in time series: the method of surrogate data. Physica 58D, 77-94.

Thornton, K. (2003). The electrophysiological effects of a bain injury on auditory memory functioning: qEEG correlates of impaired memory. Arch. Clin. Neuropsychol. 18, 363-378. doi:10.1093/arclin/18.4.363

Thornton, K. E. (1999). Exploratory investigation into mild brain injury and discriminant analysis with high frequency bands (32-64 Hz). Brain Inj. 13, 477-488. doi:10.1080/026990599121395

Tomarken, A., Davidson, R. J., Wheeler, R. E., and Kinney, L. (1992). Psychometric properties of resting anterior EEG asymmetry: temporal stability and internal consistency. Psychophysiology 29, 576-592. doi:10.1111/j.1469-8986.1992. tb02034.x

Tomkins, O., Feintuch, A., Benifla, M., Cohen, A., Friedman, A., and Shelef, I. (2011). Blood-brain barrier breakdown following traumatic brain injury: a possible role in posttraumatic epilepsy. Cardiovasc. Psychiatry Neurol. 2011:765923. doi:10.1155/2011/765923 
Tononi, G., and Edelman, G. M. (2000). Schizophrenia and the mechanisms of conscious integration. Brain Res. Rev. 31, 391-400. doi:10.1016/S0165-0173(99) 00056-9

Tononi, G., Sporns, O., and Edelman, G. M. (1994). A measure for brain complexity: relating functional segregation and integration in the nervous system. Proc. Natl. Acad. Sci. U.S.A. 91, 5033-5037. doi:10.1073/pnas.91.11.5033

Trudeau, D. L., Anderson, J., Hansen, L. M., Shagalov, D. N., Schmoller, J., Nugent, S., et al. (1998). Findings of mild traumatic brain injury in combat veterans with PTSD and a history of concussion. J. Neuropsychiatry Clin. Neurosci. 10, 308-313. doi:10.1176/jnp.10.3.308

Tsirka, V., Simos, P. G., Vakis, A., Kanatsouli, K., Vourkas, M., Erimaki, S., et al. (2011). Mild traumatic brain injury: graph-model characterization of brain networks for episodic memory. Int. J Psychophysiol. 79, 89-96. doi:10.1016/j.ijpsycho.2010. 09.006

Uhlhaas, P. J., Haenschel, C., Nikolic, D., and Singer, W. (2008). The role of oscillations and synchrony in cortical networks and their putative relevance for the pathophysiology of schizophrenia. Schizophr. Bull. 34, 927-943. doi:10.1093/ schbul/sbn062

Uhlhaas, P. J., and Singer, W. (2006). Neural synchrony in brain disorders: relevance for cognitive dysfunctions and pathophysiology. Neuron 52, 155-168. doi:10.1016/j.neuron.2006.09.020

Unsal, A., and Segalowitz, S. J. (1995). Sources of P300 attenuation after head injury: single trial amplitude, latency jitter and EEG power. Psychophysiology 32, 249-256. doi:10.1111/j.1469-8986.1995.tb02953.x

Van Albada, S. J., Rennie, C. J., and Robinson, P. A. (2007). Variability of model-free and model-based quantitative measures of EEG. J. Integr. Neurosci. 6, 279-307. doi:10.1142/S0219635207001520

Van Albada, S. J., and Robinson, P. A. (2007). Transformation of arbitrary distributions to the normal distribution with application to EEG test-retest reliability. J. Neurosci. Methods 161, 205-211. doi:10.1016/j.jneumeth.2006.11.004

van Dellen, E., Douw, L., Baayen, J. C., Heimans, J. J., Ponten, S. C., Vandertop, W. B., et al. (2009). Long-term effects of temporal lobe epilepsy on local neural networks: a graph theoretical analysis of corticography recordings. PLoS ONE 4:e8081. doi:10.1371/journal.pone.0008081

van der Stelt, O., and Belger, A. (2007). Applications of electroencephalography to the study of cognitive and brain functions in schizophrenia. Schizophr. Bull. 33, 955-970. doi:10.1093/schbul/sbm016

Vastano, J. A., and Swinney, H. L. (1988). Information transport in spatiotemporal systems. Phys. Rev. Lett. 60, 1773-1776. doi:10.1103/PhysRevLett.60.1773

Vidal, C., Nicolson, R., DeVito, T. J., Hayashi, K. M., Geaga, J. A., Drost, D. J., et al. (2006). Mapping corpus callosum deficits in autism: an index of aberrant cortical connectivity. Biol. Psychiatry 60, 218-225. doi:10.1016/j.biopsych.2005. 11.011

Vierling-Claassen, D., Siekmeier, P., Stufflebeam, S., and Kopell, N. (2008). Modeling GABA alterations in schizophrenia: a link between impaired inhibiton and altered gamma and beta range auditory entrainment. J. Neurophysiol. 99, 2656-2671. doi:10.1152/jn.00870.2007

Viggiano, M. P. (1996). Event-related potentials in brain-injured patients with neuropsychological disorders: a review. J. Clin. Exp. Neurospsychol. 18, 631-647. doi:10.1080/01688639608408288

von Bierbrauer, A., and Weissenborn, K. (1998). P300 after minor head injury (a follow-up examination). Acta Neurol. Belg. 98, 21-26.

von Bierbrauer, A., Weissenborn, K., Hinrichs, H., Scholz, M., and Künkel, H. (1992). Automatic (computer-assisted) EEG analysis in comparison with visual EEG analysis in patients following minor cranio-cerebral trauma (a follow-up study). EEG EMG Z. Elektroenzephalogr. Elektromyogr. Verwandte Geb. 23, 151-157.

Wang, J. T., Young, G. B., and Connolly, J. F. (2004). Prognostic value of evoked responses and event-related brain potentials in coma. Can. J. Neurol. Sci. 31, 438-450. doi:10.1017/S0317167100003619

Watanabe, T. A. A., Cellucci, C. J., Kohegyi, E., Bashore, T. R., Josiassen, R. C., Greenbaun, N. N., et al. (2003). The algorithmic complexity of multichannel EEGs is sensitive to changes in behavior. Psychophysiology 40, 77-97. doi:10.1111/1469-8986.00009

Watson, S. J. (ed.) (1995). Biology of Schizophrenia and Affective Disease. Washington, DC: Amer. Psychiatric Press.

Watts, D. J., and Strogatz, S. H. (1998). Collective dynamics of small-world networks. Nature 393, 440-442. doi:10.1038/30918
Welsh, J. P., Ahn, E. S., and Placantonakis, D. G. (2005). Is autism due to brain desynchronization? Int. J. Dev. Neurosci. 23, 253-263. doi:10.1016/j.ijdevneu. 2004.09.002

Wendling, F., Ansari-Asl, K., Bartolomei, F., and Senhadji, L. (2009). From EEG signals to brain connectivity: a model based evaluation of interdependence measures. J. Neurosci. Methods 183, 9-18. doi:10.1016/j.jneumeth.2009.04.021

Werner, R., and Vanderzant, C. (1991). Multimodality evoked potential testing in acute mild closed head injury. Arch. Phys. Med. Rehabil. 72, 31-34.

Whittington, M. A. (2008). Can brain rhythms inform on underlying pathology in schizophrenia? Biol. Psychiatry 63, 728-729. doi:10.1016/j.biopsych.2008.02.007

Wickelgren, I. (2005). Autistic brains out of synch? Science 308, 1856-1858. doi:10.1126/science.308.5730.1856

Wiener, N. (1956). “The theory of prediction," in Modern Mathematics for Engineers, ed. E. F. Beckenbach (New York, NY: McGraw Hill), 165-190.

Williams, B. R., Lazic, S. E., and Ogilvie, R. D. (2008). Polysomnographic and quantitative EEG analysis of subjects with long-term insomnia complaints associated with mild traumatic brain injury. Clin. Neurophysiol. 119, 429-438. doi:10.1016/j.clinph.2007.11.003

Winterer, G., Ziller, M., Dorn, H., Frick, K., Mulert, C., Wuebben, Y., et al. (2000). Schizophrenia: reduced signal-to-noise ratio and impaired phase-locking during information processing. Clin. Neurophysiol. 111, 837-849. doi:10.1016/S13882457(99)00322-3

Wu, H. T., Liu, C. C., Lo, M. T., Hsu, P. C., Liu, A. B., Chang, K. Y., et al. (2013). Multiscale cross-approximate entropy analysis as a measure of complexity among the aged and diabetic. Comput. Math. Methods Med. 2013, 324325 doi:10.1155/2013/324325

Xu, J., Liu, Z.-R., and Liu, R. (1994). The measure of sequence complexity for EEG studies. Chaos Solitons Fractals 4, 2111-2119. doi:10.1016/0960-0779(94) 90125-2

Yuan, Q., Zhou, W., Li, S., and Cai, D. (2011). Epileptic EEG classification based on extreme learning machine and nonlinear features. Epilepsy Res. 96, 29-38. doi:10.1016/j.eplepsyres.2011.04.013

Yun, K., Park, H. K., Kwon, D. H., Kim, Y. T., Cho, S. N., Cho, H. J., et al. (2012). Decreased cortical complexity in methamphetamine abusers. Psychiatry Res. 201, 226-232. doi:10.1016/j.pscychresns.2011.07.009

Zawski v. Giggs. Commonwealth of Massachusetts, Superior Court Department C.A. No 08-2280.

Zhou, Y. X., Dougherty, J. H., Hubner, K. F., Bai, B., Cannon, R. L., and Hutson, R. K. (2008). Abnormal connectivity in the posterior cingulate and hippocampus in early Alzheimer's disease and mild cognitive impairment. Alzheimers Dement. 4, 265-270. doi:10.1016/j.jalz.2008.04.006

Zou, G. Y. (2012). Sample size formulas for estimating intraclass correlation coefficients with precision and assurance. Stat. Med. 31, 3972-3981. doi:10.1002/sim. 5466

Zourdakis, G., Patidar, U., Pollonini, L., Situ, N., Rezaie, R., Castillo, E. M., et al. (2011). "Default brain connectivity network in mild traumatic brain injury preliminary MEG results,” in $20111^{\text {st }}$ Middle East Conference on Biomedical Engineering (MECBME). Sharjah.

Conflict of Interest Statement: The authors declare that the research was conducted in the absence of any commercial or financial relationships that could be construed as a potential conflict of interest.

Received: 04 August 2014; accepted: 07 January 2015; published online: 04 February 2015.

Citation: Rapp PE, Keyser DO, Albano A, Hernandez R, Gibson DB, Zambon RA, Hairston WD, Hughes JD, Krystal A and Nichols AS (2015) Traumatic brain injury detection using electrophysiological methods. Front. Hum. Neurosci. 9:11. doi: 10.3389/fnhum.2015.00011

This article was submitted to the journal Frontiers in Human Neuroscience.

Copyright (c) 2015 Rapp, Keyser, Albano, Hernandez, Gibson, Zambon, Hairston, Hughes, Krystal and Nichols. This is an open-access article distributed under the terms of the Creative Commons Attribution License (CC BY). The use, distribution or reproduction in other forums is permitted, provided the original author(s) or licensor are credited and that the original publication in this journal is cited, in accordance with accepted academic practice. No use, distribution or reproduction is permitted which does not comply with these terms. 